\title{
WINNERS-TAKE-SOME: \\ The Impact of Conversion Technologies on Network Effects in Digital Goods Markets
}

\author{
by \\ Zhechao Liu \\ B.A in Economics, Xiamen University, 1999 \\ M.A in Economics, Tulane University, 2002
}

\author{
Submitted to the Graduate Faculty of \\ Katz Graduate School of Business in partial fulfillment \\ of the requirements for the degree of \\ Doctor of Philosophy in Business Administration
}

University of Pittsburgh

June, 2008 


\title{
UNIVERSITY OF PITTSBURGH \\ KATZ GRADUATE SCHOOL OF BUSINESS
}

\author{
This dissertation was presented \\ by
}

Zhechao Liu

It was defended on

April $21^{\text {st }}, 2008$

and approved by

Esther Gal-Or, Professor, Katz Graduate School of Business

Brian S. Butler, Associate Professor, Katz Graduate School of Business

Michael D. Smith, Associate Professor, Carnegie Mellon University

Sandra A. Slaughter, Professor, Georgia Institute of Technology

Dissertation Advisor: Chris F. Kemerer, Professor, Katz Graduate School of Business 
Copyright $\mathbb{C}$ by Zhechao Liu

2008 


\title{
Winners-Take-Some: The Impact of Conversion Technologies on Network Effects in Digital Goods Markets
}

\author{
Zhechao Liu, $\mathrm{PhD}$ \\ University of Pittsburgh, 2008
}

Both theoretical and empirical evidence suggest that, in markets with standards competition, strong network effects can make the strong grow stronger and even "tip" the market towards a single, winner-take-all standard. We theorize that the presence of conversion technologies will reduce the tendency towards market dominance in markets for digital goods. We develop three essays to explore this phenomenon within both an analytic and empirical framework.

In essay 1 the results from a duopoly model confirm that the existence of a converter can mediate the network effects of a pre-existing installed base. A "winners-take-some" outcome that sustains competition after the entrant enters the market is more likely to arise with lower conversion costs. Surprisingly, higher quality conversion technology does not necessarily enhance the likelihood of the "winners-take-some" outcome.

In essay 2 we endogenize the decision to provide a converter and incorporate explicit negotiations between firms concerning the extent of conversion. We find that the Subgame Perfect Nash Equilibrium involves firms' agreeing on providing converters at a sufficiently low price to all consumers. At this equilibrium, not only the entrant, but also the incumbent are better off since the provision of converters alleviates price competition and leads to both higher product 
revenues and higher proceeds from the sale of converters. Moreover, under some circumstances the provision of converters is welfare enhancing.

In essay 3 we empirically test our hypotheses in the context of the flash memory market where both network effects and high quality digital converters are present. Our results show that the availability of digital converters reduces the price premium of the leading flash card formats more than that of the minority formats. In addition, market concentration decreases as converters become more widely available. Our findings imply that producers of non-dominant standards are better off with the provision of conversion technology, as this technology tends to neutralize the impact of network effects.

These findings have important implications for research and practice in IT standards competition and technology adoption as the introduction of conversion technologies provides an alternative mechanism to reduce the social costs of standardization without compromising the benefits of network effects.

Keywords: Network Effects, Network Externalities, Conversion Technologies, Digital Goods, Flash Memory, Compatibility, Standards Competition, Panel Data, Game Theory. 


\section{TABLE OF CONTENTS}

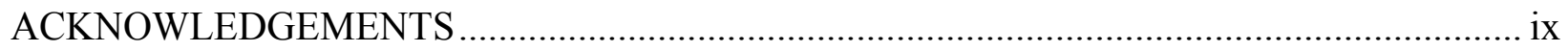

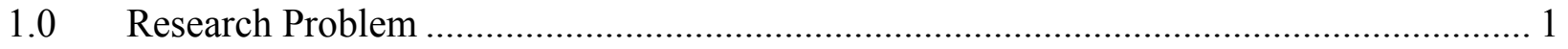

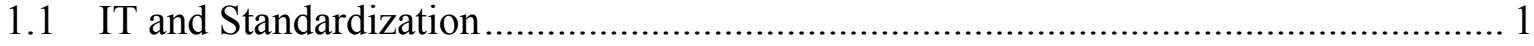

1.2 Prior Literature on the Economics of Standards and Conversion Technologies .......... 5

1.3 Previous Empirical Research on IT Standards..................................................... 8

1.4 Research Questions to be Addressed in this Dissertation...................................... 11

2.0 A Heterogeneous Consumer Preference Model.......................................................... 14

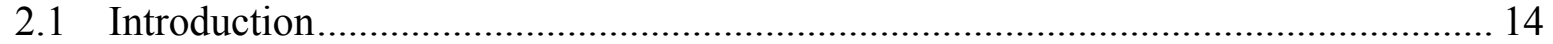

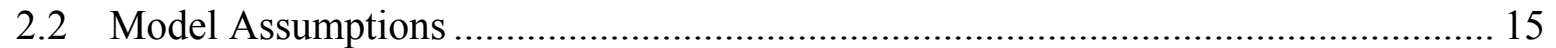

2.3 A Baseline Model Without a Converter.................................................................. 17

2.4 An Extended Model With a Converter ................................................................... 23

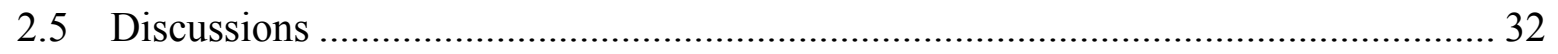

3.0 Negotiations on the Provision of Converters ......................................................... 35

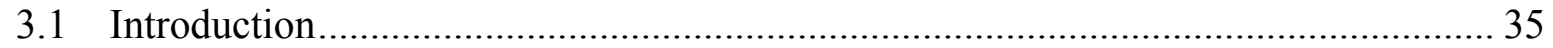

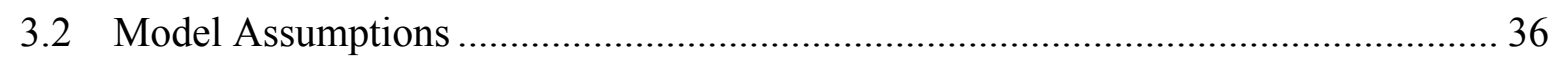

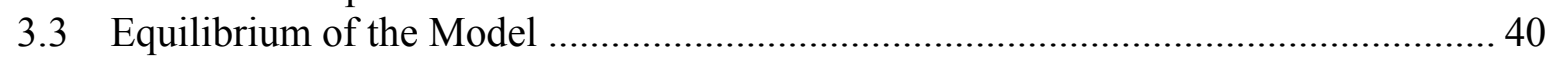

3.2.1 Second Stage Game ............................................................................ 40

3.2.2 The Maximization Problem of Firm A in the First Stage ............................... 47

3.4 Is It Ever Optimal to Commit to Less Than Full Conversion? ................................. 49

3.5 Comparison of Social Welfare .......................................................................... 52

3.6 Extensions of the Baseline Model......................................................................... 55

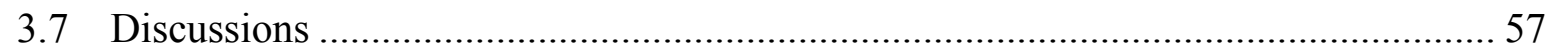

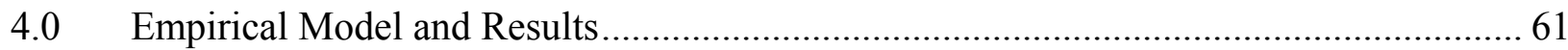

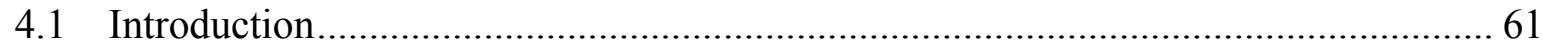

4.2 An Overview of the Flash Memory Market........................................................ 66

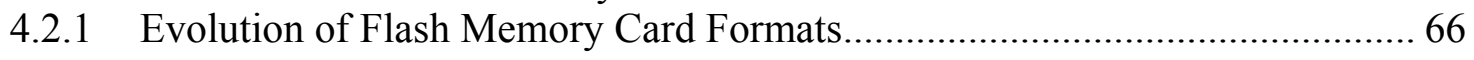

4.2.2 Conversion Technologies in the Flash Memory Market ................................ 74

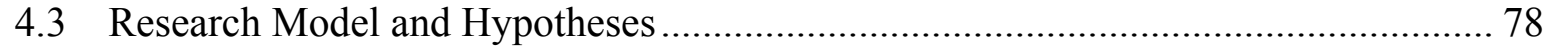

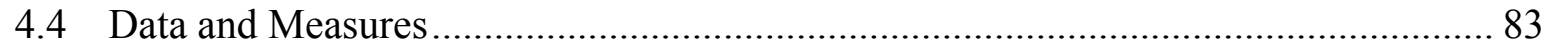

4.5 Empirical Models, Estimation and Results ........................................................ 86

4.5.1 Network effects, digital converters and price premia................................. 86

4.5.2 The effect of converters on market concentration ........................................ 92

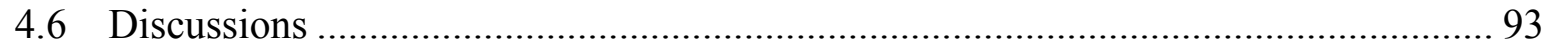

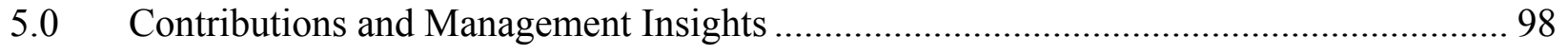

Extensions and Future Research .............................................................................. 104

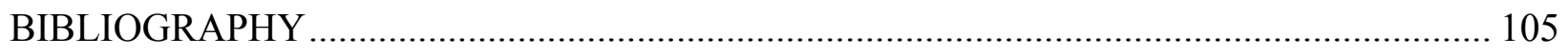

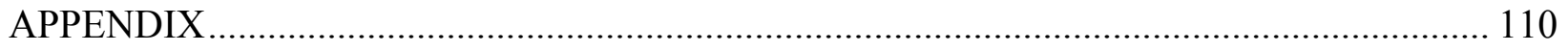




\section{LIST OF TABLES}

Table 1. Consumer's Utility Function in the Baseline Model (Without a Converter) ........... 17

Table 2. Market Segmentation Without a Converter: Pure Strategy Nash Equilibrium ......... 20

Table 3. Market Segmentation With a Converter: Pure Strategy Nash Equilibrium ............. 25

Table 4. Comparative Statics Analysis of the Market Segmentation Equilibrium................ 29

Table 5. Partial Conversion Equilibrium Second Stage Prices, Market Shares and Profits.... 42

Table 6. Full Conversion Equilibrium Second Stage Prices, Market Shares and Profits....... 45

Table 7. Full Conversion Equilibrium Prices, Market Shares and Profits ............................ 48

Table 8. The Equilibrium of the Entire Game under Commitment to No Conversion ........... 50

Table 9. The Equilibrium of the Entire Game under Commitment to Partial Conversion...... 50

Table 10. The Equilibrium of the Entire Game under Commitment to Partial Conversion...... 50

Table 11. Distribution of Flash Memory Card Observations by Card Type/Year .................. 84

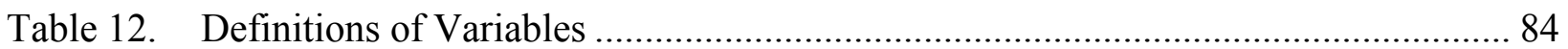

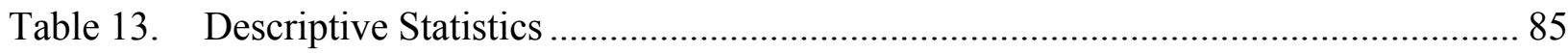

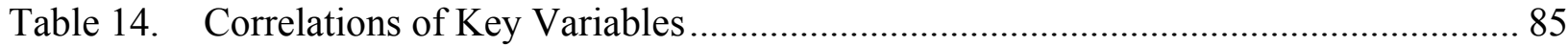

Table 15. Regression Results - Model 1 ...................................................................... 88

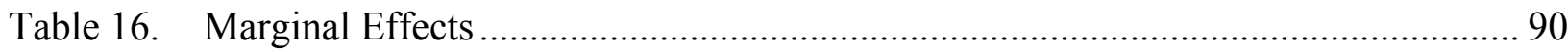

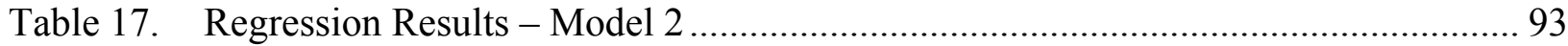




\section{LIST OF FIGURES}

Figure 1. Consumer's Preference Structure ............................................................... 16

Figure 2. Consumer's Choices and Market Division.......................................................... 17

Figure 3. Summary of Equilibria - a Baseline Model Without a Converter .......................... 22

Figure 4. Segmentation Market Division.......................................................................... 24

Figure 5. Summary of Equilibria With a Converter ....................................................... 27

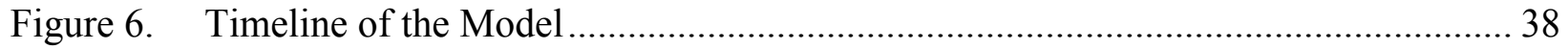

Figure 7. Flash Memory Card Monthly Market Share - January 2003 to August 2006 ......... 65

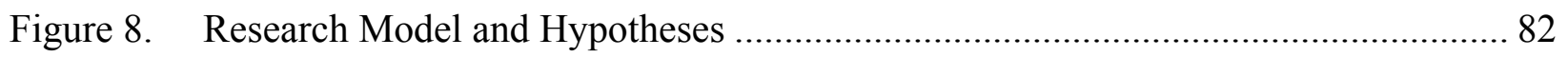

Figure 9. Price Premium of A Flash Memory Format at + or -2 Standard Deviations of the Mean Converter Adoption Level...................................................................... 96

Figure 10. Price Premium of A Flash Memory Format at + or -2 Standard Deviations of the Mean Flash Card Installed Base..... 


\section{ACKNOWLEDGEMENTS}

I would like to acknowledge many people for helping me during my doctoral work. This dissertation would not have been possible without their personal and practical support and I would like to take this opportunity to show my most sincere gratitude.

I would especially like to thank my advisor, Chris Kemerer, for his generous time and commitment. I am very fortunate to have an advisor who has unusual foresight and is always able to point out the right directions to pursue my goals. His helpful suggestions and insightful views on numerous things have been proven to be the most valuable resources in my dissertation and job search process. His words of encouragement, creative thinking and careful readings of all of my writing will never be forgotten.

I am also very grateful for having an exceptional dissertation committee. I wish to thank Esther Gal-Or for spending an enormous amount of time working with me on my analytic models. I am extremely indebted to Michael Smith for his valuable comments on numerous versions of my papers and his help in obtaining the data needed to complete the dissertation. I am very grateful to Sandy Slaughter who helps me tremendously with the empirical analysis and provides continual encouragement and support during my job search process. I also want to thank Brian Butler for his valuable input in developing my dissertation topic and his continual support and guidance since my enrollment into the Ph.D. program.

This dissertation research was partially funded by the NET Institute Research Grant and the Katz Graduate School of Business Dean's Dissertation Grant. The primary dataset used in this dissertation is generously provided by the NPD research group. Their financial support is also gratefully acknowledged.

I also owe a special note of gratitude to Carrie Woods and Gina Cecchetti at the doctoral office who have been providing exceptional administrative support to me and all doctoral students.

Finally, I'd like to thank my family. My parents have been very encouraging and supportive during the time I pursue my Ph.D. degree. I'm especially grateful to my wife, Yanyan, for her patience and for helping me keep my life in proper perspective and balance. She and my lovely daughter, Christina, who was born right before I started my dissertation, have always been the most important momentum for me to complete my dissertation. 


\subsection{RESEARCH PROBLEM}

Compatibility is a crucial aspect to most, if not all, information technology (IT) markets. Telecommunications systems would be unworkable without compatibility, as would computer hardware and software. The increasing reliance on networking and wireless communication standards further highlights the importance of compatibility in the IT industry. In an environment where technologies evolve rapidly, consumers often run the risk of being stranded with a technology if it becomes incompatible with the dominant technology in the future; this is especially true when switching costs are high. The widely observed presence of network effects ${ }^{1}$ in IT markets tends to exacerbate this consumer dilemma. How does a consumer choose between, for example, a widely compatible dominant technology and a new, more innovative, but incompatible, technology? How do both the incumbent and the entrants engage in competition in such a market? And what is the social optimal path of technology adoption? This dissertation seeks to address these questions in the context of IT standards competition.

\subsection{IT and Standardization}

Compatibility and network effects have been studied extensively by IT researchers (Katz and Shapiro, 1985, 1986a, Farrell and Saloner, 1985, Economides, 1996). Network effects refer to circumstances in which the net value of the action of consuming a good (e.g., subscribing to telephone service) is affected by the number of agents taking equivalent actions (Liebowitz and

\footnotetext{
${ }^{1}$ Network effects are often referred to as network externalities in the literature.
} 
Margolis, 1994). Network effects arise in compatible products where one user's adoption decision changes the utility of other users. Classic examples are the telephone and fax markets where the value created by an n-node two-way network is on the order of $n *(n-1)$, also known as Metcalfe's Law (Gilder, 2000).

The presence of network effects makes the choice of a technology standard or platform an important strategic decision for both consumers and firms (Katz and Shapiro, 1985, Economides, 1996). Both theoretical and empirical studies suggest that strong network effects can lead to "winner-take-all" outcomes (Shapiro and Varian, 1999). Once a standard establishes a leading position in the market, consumers are inclined to believe that the current technology will eventually become the de facto industry standard. Demand will increase for the current technology, further enhancing the possibility of such an expectation being realized. A classic example of this phenomenon is seen in the VHS and Betamax standards war, where hardware/software incompatibilities and high conversion costs led the market to a single standard (Park, 2004). Since then, the impact of network effects is revisited with each new generation of consumer electronics. For example, consider the recent battle between Blu-Ray and HD-DVD for dominance in the high definition DVD market (Marr and McBride, 2007). A similar type of competition can be seen in several other markets such as satellite radio (Sirius and XM), portable music players (Apple's iPod vs. Microsoft's Zune), Web service platforms (Sun's J2EE vs. Microsoft's .NET), videogame consoles and games (Microsoft's Xbox vs. Sony's Play Station), and cellular phones.

When network effects are strong, consumers generally benefit from compatibility since a large and standardized product network confers greater utility that would not be available in the absence of compatibility. From a societal standpoint, standardization across different product 
formats yields much larger social surplus than the sum of those obtained from several smaller product networks. However, standardization can be difficult to achieve. The dominant firms may prefer not to be compatible with other products so that they can enjoy a number of strategic advantages such as a higher price premium (Brynjolfsson and Kemerer, 1996, Gandal, 1994, Gallaugher and Wang, 2002), a faster rate of market penetration (Kauffman et al., 2000, Zhu et al., 2006), the ability to deter potential entrants (Lee et al., 2003) and the possibility to control the design interface (Conner, 1995). Such allegations have been directed, for instance, at Microsoft, who has faced antitrust charges from both the US Justice Department and the European Union (Bresnahan, 2001). Consumers may prefer product variety when they have heterogeneous preferences. New entrant firms may oppose standardization if they have to follow the standard established by the incumbent (Xie and Sirbu, 1995, Christensen et al., 1998) as doing often results in sacrificing their unique product features or giving up much of their prior investments in product development. In any case, significant private and social loss may occur before the market identifies the dominant technology (Farrell and Saloner, 1986).

Amid concerns over tradeoffs between the benefits and associated costs from standardization, an alternative way to achieve compatibility may emerge from the market for digital goods (i.e., software, digital media, etc) with the availability of converters. As the content carried by these products is in a digital format, communications between the incompatible products can be realized through a converter, frequently without significant loss in quality. For example, Microsoft Word users can open Word Perfect documents by using a file converter. Software can convert music and video files between different formats to play on different devices. In short, the digital nature of these products (or their outputs) opens up the possibility of achieving compatibility without incurring significant costs or seriously degrading performance. 
This property is not typically observed in most analog goods and other product categories. For example, in addition to the physical incompatibilities in their cassette formats, even video conversion between the VHS and Betamax standards was costly and resulted in signal degradation (Cusumano et al., 1992).

The presence of conversion technologies in IT markets has important implications for both consumers and manufacturers of digital devices. When standardization is attained through converters, significant development and adoption costs can be saved since existing firms can maintain their unique product features and spare the need to redesign their products. New entrant firms can take advantage of the network effects from the incumbent's installed base by offering partial (or full) compatibility with the existing standard. Consequently, new innovative technologies are more likely to survive and consumers have minimal risk of being stranded on a non-dominant standard. At the same time, if compatibility can be achieved through a lower cost converter, the choice of a standard may rely more heavily on other factors, including perhaps brand and quality-related attributes, rather than simply the size of its installed base, thus giving rise to sharper price competition. From a social planner's perspective, the provision of a converter spares the need to potentially compromise between product variety and standardization, especially for markets characterized with high consumer heterogeneity. Given that policy makers may be accused of market distortion due to sub-optimal levels of standardization, our analysis contributes to the debate on standardization in IT markets by enriching the set of options that are available for consideration.

Given the important impact of conversion technologies on the standards competition and technology adoption in IT markets, in this dissertation, I explore the market dynamics in the presence of network effects and conversion technologies using both an analytic and empirical 
approach. The analytic approach provides a framework to examine the effect of various characteristics of converters on market equilibrium, whereas the empirical approach enables us to validate the findings derived from the analytic analysis. The remainder of Chapter 1 reviews both the analytic and empirical literature on network effects and conversion technologies, and presents the research questions to be addressed in this dissertation.

\subsection{Prior Literature on the Economics of Standards and Conversion Technologies}

This thesis relates to a small but growing literature on network effects and conversion technologies. In the absence of a feasible market mechanism or a successful intervention to achieve standardization, the provision of a conversion (gateway) technology serves as bridge between otherwise incompatible technologies. The notion of a "gateway technology" was first presented in David and Bunn (1988). Drawing on the battle between AC and DC electrical systems, they argued that, given two incompatible rival technologies, the adoption process and formation of de facto standards may be decisively tipped by the development of a "one-way" converter that allows one party to appropriate some of the network effects accrued from the installed base of the other. However, this seminal idea has not received as much attention in the network effects literature as it may deserve.

The role of converters on technology adoption and standards competition has primarily been studied in the analytical literature. Incentives to provide converters have been found in complementary products markets when network effects are absent (Matutes and Regibeau, 1988, Economides, 1989). Farrell and Saloner (1992) were among the first to model converters in a market characterized with network effects. They found that contrary to the common beliefs that converters can internalize the network effects benefits in the market, the provision of converters 
is not welfare improving and under some circumstances the incumbent would prefer not to supply converters or make them costly. However, due to the symmetric nature of competition, they simplify consumers' adoption decision by assuming that converters are exogenously available and arbitrarily adopted by any of the two product networks. Extending this work, Choi $(1996,1997)$ develop an overlapping-generations model to analyze the role of converters in the transition process between incompatible technologies. The results from these studies suggest that the existence of converters does not necessarily facilitate the transition to a new technology as the availability of converters enhances not only the value of adopting the new technology, but also that of the existing technology, and allocation inefficiency may arise when consumers from the larger network have to bear the cost of converters.

Although the extant literature provides a general framework to study the impact of converters on technology adoption, several questions remain unanswered. First, the existing static framework of symmetric competition does not adequately capture a market characterized with sequential entry and dynamic price competition, characteristics common in digital goods markets. Moreover, in the rapidly evolving IT industry, the length of the initial monopoly period may be a lot shorter than that of the subsequent competitive period, and consumers' expectation may hinge critically on the length of the consumption period. These important features have not been adequately captured in the prior literature.

Second, in the prior literature consumers are assumed to have identical preferences for the use of converters (i.e. if a user buys a converter, all users of the same technology buy a converter). However, this assumption is unlikely to hold in reality as consumers may vary in their valuation for converters, and imposing ubiquitous adoption of converters overestimates the impact of conversion technologies, and can lead to inaccurate conclusions.

Third, most existing studies of conversion technology assume that converters are 
exogenously provided and the provision of converters does not require consent from firms who develop the incompatible technologies. Such assumptions neglect the importance of ownership embedded in many technology standards. Unlike traditional commodities, many technology standards are proprietary or protected by intellectual property laws. Consequently, production of conversion technologies typically requires joint agreement of the parties involved, and in most situations cannot be facilitated without coordination. Therefore, to ensure the validity of the results, it is important to explicitly examine firms' incentives to supply converters and the mechanism through which such an agreement can be reached.

Finally, given that converters are often assumed to be exogenously provided, the price of the converter is also assumed to be competitively determined and in most cases equals the marginal cost of production. Accordingly, proceeds from the sale of converters are absent from the decisions of the firms. However, in reality, firms can also profit from the sale of converters. Hence, they would take the proceeds of converters into account when negotiating with competitors on reaching an agreement on conversion. When the provision of converters is jointly determined, division of proceeds from the sale of converters constitutes an important part of the negotiations. Likewise, the price of the converter can be determined strategically to facilitate or block the adoption of converters.

In order to capture the environment firms are facing, I incorporate the above considerations in this dissertation and examine how the market equilibrium changes when we relax these assumptions. We discuss the specific research questions in $\S 1.4$. 


\subsection{Previous Empirical Research on IT Standards}

As summarized in $\S 1.2$, the role of conversion technologies on standards competition has primarily been studied in the analytic framework. Although there is a vast empirical literature on network effects, most studies focus on identifying the presence and magnitude of network effects and very little attention has been devoted to empirically validating the analytic findings on conversion technologies. In this section, we draw on the extant empirical studies on network effects and discuss how we can extend these studies to the context where both network effects and conversion technologies are present.

Both prior research and anecdotal evidence have suggested that, in product markets with network effects, early success in accumulating a large installed base of customers can give rise to a number of strategic advantages. In addition to the positive feedback loop generated by selffulfilling consumer and retailer expectations, empirical research has suggested that network effects help to create switching costs to lock-in existing customers (Chen and Hitt, 2002, Zhu et al., 2006) and to increase the speed at which market demand grows (Economides and Himmelberg, 1995, Kauffman et al., 2000). Other strategic advantages include the ability to deter potential entrants (Lee et al., 2003, Suárez and Utterback, 1995) and the possibility to control the design interface (Conner, 1995). Moreover, as network effects are often perceived to be the consumer's valuation for a standard (Farrell and Saloner, 1985), a stream of empirical research on network effects focuses on estimating the influence of the installed base on a consumer's willingness to pay for the dominant standard. Several empirical studies have found a price premium for dominant standards in markets for IBM compatible microcomputers (Hartman, 1989), mainframe computers (Greenstein, 1993), spreadsheet software (Gandal, 1994, 
Brynjolfsson and Kemerer, 1996), databases (Gandal, 1995) and communications equipment (Chen and Forman, 2006).

Although the above empirical studies differ in their highlighted antecedents of network effects, they all adopt the same notion of price premium in interpreting the estimated coefficients on the compatibility variables. Price premium refers to the price advantage a product enjoys over the other competing products due to one or more distinct product features such as brand, quality, or in the above studies, compatibility. A number of techniques have been used to identify the price premium resulted from network effects, of particular interest is the use of hedonic regressions in capturing this value.

Hedonic regressions were first applied to IT products by Chow (1967) in estimating the annual quality-adjusted price decline in mainframe computers from 1960-1965. As a useful method to disaggregate consumers' consumption utility into independent valuations of different aspects of a product, the hedonic regression has been widely employed in estimating the marginal benefit of products that include multiple attributes, and has been usefully employed in the empirical literature on network effects. By treating various antecedents of network effects, such as the size of the installed base or learning costs, as implicit features of a product, hedonic regressions allow researchers to obtain estimates of the parameters capturing a consumer's willingness to adopt a standard (or the opportunity costs to switch to a different network). Hence price premium can be computed as the portion of the listed price that is attributed to the size of the product installed base, controlling for other intrinsic values of a product. As the choice of a flash memory card also depends on a variety of considerations other than the size of the installed base (e.g. brand, capacity, speed), we follow the literature and adopt the hedonic framework in our study as an appropriate approach to distinguish the impact of network effects from other factors. 
A major challenge of any empirical study on this topic lies in distinguishing the counteracting effects of conversion technologies on product price. In the absence of a common interface, converters enable incompatible systems to communicate with each other and hence internalize the compatibility benefits that would have been lost without converters. Via the provision of converters, consumer benefits include both product variety and the size of the network to which the consumer belongs (Matutes and Regibeau, 1988, Economides, 1989). As a result, consumers are willing to pay a higher price for otherwise incompatible products. On the other hand, the presence of converters also reduces the expected price premium of the dominant standards as both the relative attractiveness of their products and product switching costs decrease due to a lower compatibility barrier (Farrell and Saloner, 1992). The installed base of the dominant standards may expand more slowly and competition may intensify as the intransient incompatibility period extends (Choi, 1996, 1997). At the same time, new entrants are more likely to enter the market and to survive the standards war.

Given these complicated interactions, the product price premium is not merely an indicator of the perceived value of the installed base, as is typically assumed in the network effects literature. A consumer's valuation of product compatibility, as measured by product price, should be further disaggregated into variation due to the product installed base, the adoption of conversion technologies, and the interaction of the two effects. Drawing on the findings from the above literature, in Chapter 4, I develop a conceptual framework with specific hypotheses to examine the dynamics between conversion technologies and the various antecedents and outcomes of network effects. 


\subsection{Research Questions to be Addressed in this Dissertation}

As discussed in $\S 1.2$ and $\S 1.3$, although the extant literature provides a general framework to study the impact of converters on technology adoption, several questions remain unanswered and, to the best of my knowledge, there is no empirical examination of the analytic findings. This dissertation seeks to extend the extant literature on conversion technologies and fill the gap between the analytic literature and empirical literature. To this end, I conduct three separate but related studies. The first two studies adopt the game theory approach and examine the questions that have not been adequately addressed in the analytic literature. The third study empirically tests some of the findings from the first two studies with panel data collected from the flash memory market.

The first study focuses on understanding how different characteristics of converters affect market equilibrium when technologies are introduced into the market sequentially and consumers have different valuations on the adoption of converters. Extending the work of Farrell and Saloner (1992), I develop a duopoly model with sequential entry and heterogeneous consumer preferences and examine how conversion quality and conversion costs affect the equilibrium prices, market shares and profits of the firms.

The second study analyzes firms' incentives to supply converters when technology standards are proprietary and provision of converters requires joint agreement of the firms. Specifically, we seek to understand that, in the absence of a feasible market mechanism or a successful intervention to achieve coordination, how do firms agree on the provision of converters and compete in the presence of conversion technology? How can the provision of converters be actually implemented? And how do such actions affect consumer's adoption decision and social welfare? To address these questions, we extend the two-stage duopoly model 
developed in study 1 by endogenizing the decision to supply converters. Moreover, by varying the symmetric setup of baseline model, we also explore how the length of competition in different stages of the game and firms' relative negotiation power affect market equilibrium and social welfare.

The third study seeks to test some of the findings from the first two studies in the context of the flash memory market. The flash memory card market offers an appropriate test case for this research. The characteristics of the early flash memory card market imply the presence of network externalities (Katz and Shapiro, 1985). In the absence of a highly compatible and affordable converter, an increase in the demand for one type of flash memory card would be expected to increase the variety of digital products that are compatible with it, which in turn would raise demand for that type of flash memory card. However, such a typical self-reinforcing "loop" of a popular format becoming more popular and leading to a winner-take-all market has not occurred in the flash memory market to date. There are currently more than six incompatible formats in the market, and a number of variants deriving from each format, with little evidence of a tendency towards format standardization. Further, early success has not necessarily translated into future success, as incumbent formats have been experiencing a decline in market share and as new formats continue to emerge. These market outcomes raise two important questions: (1) Why is there little evidence of standards convergence in a market that desires compatibility and would benefit from network effects, and (2) What distinguishes the flash memory card market from other markets with similar characteristics?

In contrast to other IT Markets studied in the network effects literature, a candidate explanation for the structure of the flash memory card market involves both the digital nature of flash memory products and the associated presence of conversion technologies. Flash memory 
cards can store any information in digital format, which means that, unlike many other technologies, their contents can be transferred without loss of quality. Additionally, there is a widespread availability of inexpensive PC- and USB-based converters, ${ }^{2}$ allowing for easy conversion of data between various card formats. The existence of these conversion technologies provides for compatibility across different formats without compromising product performance or features (Farrell et al., 1992). This aspect of the flash memory market has not typically been observed in other markets for analog products with network effects. For example, converting between the VHS and Betamax videotape standards was costly and resulted in signal loss (Cusumano et al., 1992).

To validate this explanation, in the third study we analyze the flash memory market and empirically examine the role of digital converters in shaping the competition in this market. Specifically, we examine how the adoption of converters affects the price premium of the competing products in the flash memory market and how the market concentration of different competing standards changes as the adoption of converters increases.

The rest of the dissertation is organized as follows: these three studies are presented in Chapters 2, 3 and 4, respectively. Chapter 5 summarizes the contribution of these studies and discusses the implications of our findings. Chapter 6 concludes the dissertation with directions for future research. The analytical derivations and proofs are included in an Appendix.

\footnotetext{
${ }^{2}$ These converters (also known as multi-format flash memory card readers) have multiple slots for different types of otherwise incompatible flash cards. Through a USB cable consumers can read from or write to multiple flash memory cards simultaneously from a PC. Currently more than 100 models of converters are available in the market (http://www.amazon.com/exec/obidos/tg/browse/-/1197398).
} 


\subsection{A HETEROGENEOUS CONSUMER PREFERENCE MODEL}

\section{$2.1 \quad$ Introduction}

As mentioned in $§ 1.2$, the existing static framework of symmetric competition does not adequately capture a market characterized with sequential entry and dynamic price competition, characteristics common in digital goods markets. Moreover, the prior literature assumes that consumers have identical preferences for the use of converters (i.e. if a user buys a converter, all users of the same technology buy a converter). However, this assumption is unlikely to hold in reality as consumers may vary in their valuation for converters, and imposing ubiquitous adoption of converters overestimates the impact of conversion technologies, and can lead to inaccurate conclusions.

In order to capture market dynamics we relax these assumptions and develop a two-stage duopoly model to analyze equilibrium outcomes in a market characterized with network effects, sequential entry, and consumer preference heterogeneity for both the technology and a converter. We develop a baseline model without a converter, and then extend this model to incorporate conversion. The base model serves as a benchmark to examine the consequences of introducing the conversion technology on market equilibrium and firms' incentives to supply the converter.

The results from this game theory model show that in the presence of low cost and high quality conversion technologies, the importance of network effects can be lessened to the point where co-existence of multiple incompatible standards is more pervasive. The entrant favors the

provision of converters as it facilitates its market expansion and increases profit. Moreover, the 
incumbent also has a strong incentive to provide a high quality converter as the conversion equilibrium yields higher profits for the incumbent even though its first mover advantage is weakened by the adoption of converters. These results from our analytical model are consistent with growing anecdotal evidence in several digital goods markets, such as digital media files and flash memory cards.

\subsection{Model Assumptions}

Consider a two-stage game in which two incompatible durable goods, A and B, offered by firm A and firm B, respectively, compete in a market that exhibits network effects. Firm A enters the market in stage 1 and firm B enters the market in stage 2. Consumers have unit demand and the market size is normalized to 1 . The price set by firm $j \in\{A, B\}$ at stage $k \in\{1,2\}$ is designated by $P_{j k}$. Without loss of generality, marginal costs are assumed to be zero for both products $\mathrm{A}$ and $\mathrm{B}$. Firm A can adjust the price of its product over time. Hence, $P_{A l}$ may differ from $P_{A 2}$. In the first stage firm A is a monopolist, and in the second stage it competes against firm B. The utility function of a consumer who buys product jin stage $k$ is specified as:

$$
U_{j k}=r+\sum_{k}^{2} x_{j k}+\beta \sum_{k}^{2} M S_{j k}-P_{j k} \quad(0 \leq \beta<1),
$$

where $r$ is a consumer's reservation price ${ }^{3}$ for the general product category and $x_{j k}$ refers to a consumer's preference for the specific brand offered by firm $j$, which is independent of network size (Liebowitz and Margolis, 1999). We also assume that consumers do not discount this network-size-independent utility, which implies that $x_{j 1}=x_{j 2}=x_{j}$. With the presence of network effects, a consumer is better off the larger installed base to which she belongs. This positive

\footnotetext{
${ }^{3}$ We assume $r$ is sufficiently large so that the market is always fully covered.
} 
consumption externality is captured by $\beta \sum_{k}^{2} M S_{j k}$ where $\beta$ measures the strength of the network effects $^{4}$ and $M S_{j k}$ is the market size ${ }^{5}$ of firm $j$ in stage $k$.

Given that the network independent utility $x_{j}$ may vary among consumers, we let $x_{j}$ be uniformly distributed on the interval $[0,1]$. The consumer's location on this interval can be interpreted as the characteristics of the product she prefers best. As is typical in such models, we assume that the consumer's distance from the left end point of the interval measures her network-size-independent additional ${ }^{6}$ utility from product $\mathrm{A}, x_{A}$. Her distance from the right end point measures her network-size-independent additional utility from product $\mathrm{B}, x_{B}$, where $x_{B}=1-$ $x_{A}$. Specifically, a consumer located at $x=s(s \in[0,1])$ enjoys a network-size-independent additional utility $s\left(x_{A}=s\right)$ if she purchases product A, and $1-s\left(x_{B}=1-s\right)$ if she purchases B. On the extremes, the consumer at $s=1$ has a network-size-independent added utility of 1 if she purchases product A and zero if she purchases product B, and similarly for $s=0$. One can think of the consumer at $s=0$ as a "B-lover" and the consumer at $s=1$ as an "A-lover" (Figure 1).

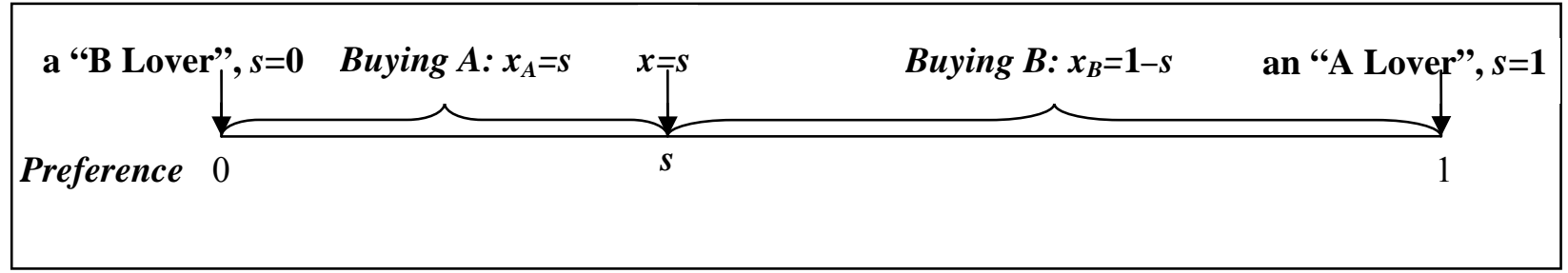

Figure 1. Consumer's Preference Structure

In this two-stage game, we first derive the Sub-game Perfect Nash Equilibrium (SPNE) from a baseline model in which a converter is not available and then compare the results to those derived from the extended model in which a converter is available.

\footnotetext{
${ }^{4}$ When $\beta>1$, the demand function may reverse direction and slope upward. In reality, we rarely observe network effects of such magnitude.

${ }^{5}$ As we normalize market size to $1, M S_{j k}$ also measures the market share of firm $j$ in stage $k$.

${ }^{6}$ Added utility above the reservation price $r$.
} 


\subsection{A Baseline Model Without a Converter}

In the absence of a converter, envisioning that firm B will compete with firm A in stage 2, consumers face three choices: 1) buy product $\mathrm{A}$ in stage 1 ; 2) buy product $\mathrm{A}$ in stage 2 ; 3) buy product B in stage 2 . Because the product is durable, those who buy product A in stage 1 enjoy twice the network independent added utility and twice the network effect benefits. ${ }^{7}$

In order to derive the equilibrium, we designate the location of the consumer who is indifferent between buying product $\mathrm{A}$ in stage 1 and buying it in stage 2 as $i^{*}$ and the location of the consumer who is indifferent between buying products $\mathrm{A}$ and $\mathrm{B}$ in stage 2 as $s^{*}$. Following this notation, and the assumption concerning the uniform distribution of the consumer's brand preference, we find that firm A's market size in stage $1\left(M S_{A 1}\right)$ and stage $2\left(M S_{A 2}\right)$ are: $1-i^{*}$ and $i^{*}-S^{*}$, respectively, and firm B's market size in stage $2\left(M S_{B}\right)$ is simply $s^{*}$ (Figure 2).

Preferences $\underbrace{M S_{B}=s^{*}}_{\text {Choices }} \underbrace{M S_{A 2}=i^{*}-s^{*}}_{s^{*} \text { Buying B in Stage 2 }} \underbrace{M S_{A 1}=1-i^{*}}_{i^{*}}$

Figure 2. Consumer's Choices and Market Division

Table 1 shows the total utility that a type $s$ consumer derives from buying product $j$ in stage $k$.

Table 1. Consumer's Utility Function in the Baseline Model (Without a Converter)

\begin{tabular}{|c|c|c|}
\hline Consumer's Choice & Stage 1 & Stage 2 \\
\hline Buy A & $U_{A 1}=r+2 s+\beta\left(1-i^{*}\right)+\beta\left(1-s^{*}\right)-P_{A 1}$ & $U_{A 2}=r+s+\beta\left(1-s^{*}\right)-P_{A 2}$ \\
\hline Buy B & n/a & $U_{B 2}=r+(1-s)+\beta \bullet s^{*}-P_{B}$ \\
\hline
\end{tabular}

The derivations in the remainder of $\$ 2.3$ imply the following proposition:

\footnotetext{
${ }^{7}$ For simplicity, we assume that $r$ is not doubled in this case. As mentioned earlier, the parameter $r$ is added to guarantee full market coverage. Specifically, $r$ is assumed to be large enough to ensure that the net payoff of each consumer is always positive.
} 
Proposition 1: In the baseline model, there are two types of equilibria ${ }^{8}$ :

(1) Market Segmentation Equilibrium: the incumbent, firm A, sells its product to some consumers in stage 1 and to others in stage 2. The entrant, firm B, serves the segment of the market that remains uncovered by firm $A,{ }^{9}$ in stage 2 .

(2) Market Dominance Equilibrium: the incumbent captures the entire market in stage 1.

\section{$\underline{\text { Market Segmentation Equilibrium }}^{10}$}

In this case, the entrant survives the competition with the incumbent and attracts some consumers after it enters the market. One can think of such an outcome as a "winners-take-some" scenario where the market is partitioned among several firms that enter the market sequentially. The Segmentation equilibrium is also characterized by the incumbent practicing inter-temporal price discrimination by adjusting its prices to cater to different groups of consumers. To better understand the dynamics of this setting, we use backward induction to examine firms' strategies retrospectively.

We start our analysis by locating the marginal consumer for each possible purchase decision listed in Table 1. In equilibrium, a consumer who is indifferent between buying product A in stage 1 and stage 2 satisfies the following equation:

$$
2 i^{*}+\beta\left(1-i^{*}\right)+\beta\left(1-s^{*}\right)-P_{A 1}=i^{*}+\beta\left(1-s^{*}\right)-P_{A 2} .
$$

Similarly, a consumer who is indifferent between buying product A or B in stage 2 satisfies:

$$
1-s^{*}+\beta s^{*}-P_{B}=s^{*}+\beta\left(1-s^{*}\right)-P_{A 2} \Rightarrow s^{*}=\frac{1+\mathrm{P}_{\mathrm{A} 2}-\mathrm{P}_{\mathrm{B}}-\beta}{2(1-\beta)} .
$$

\footnotetext{
${ }^{8}$ Another possible equilibrium is a sequential competition in which the incumbent covers a portion of the market in stage 1 and the entrant covers the remaining market in stage 2 . However, our analysis shows that such an equilibrium is not feasible as the incumbent does not have the incentive to withdraw himself from the competition in the second stage. In other words, in the absence of commitment power, given the market share covered by the incumbent in stage 1, our analysis shows that in stage 2 the entrant can not set a low price to preclude the incumbent from attracting some customers at a positive price. Hence, it reduces to the same type of competition as described in the "Market Segmentation Equilibrium".

${ }^{9} \mathrm{We}$ found that some consumers choose to withdraw from the market when $\beta<1 / 6$. Since we want to focus on the situation that the market is fully covered and each consumer participates in the market, we restrict our attention to the case that $1 / 6 \leq \beta<1$.

${ }^{10}$ Hereafter referred to as Segmentation Equilibrium.
} 
From (2) and (3), it follows that if a consumer prefers buying A in stage 1 to buying $\mathrm{A}$ in stage 2, she prefers buying A in stage 1 to buying B in stage 2 (since $U^{i *}{ }_{A l}=U^{i{ }^{*}}{ }_{A 2} \geq U^{s^{*}}{ }_{A 2}=U^{s^{*}}{ }_{B} \geq U^{i *}{ }_{B}$ ).

In the second stage, the firms take the market share established by firm A in the first stage as given. For a fixed $M S_{A I}=1-i^{*}$, their market shares in the second stage are $M S_{A 2}=i^{*}-S^{*}$ for A and $M S_{B}=s^{*}$ for B. Firms' maximization problems in stage 2 can therefore be written as:

$$
\left\{\begin{array}{l}
\operatorname{Max}_{P_{A 2}} \Pi_{A 2}=P_{A 2}\left(i^{*}-s^{*}\right)=P_{A 2}\left(i^{*}-\frac{1+P_{A 2}-P_{B}-\beta}{2(1-\beta)}\right) \\
\operatorname{Max}_{P_{B}} \Pi_{B}=P_{B} \bullet s^{*}=P_{B}\left(\frac{1+P_{A 2}-P_{B}-\beta}{2(1-\beta)}\right)
\end{array}\right.
$$

subject to the constraints that $0<s^{*}<i^{*} \leq 1$, and $P_{j k}>0$. Solving for the SPNE in terms of $i^{*}$ yields:

$$
\begin{aligned}
& P_{A 2}{ }^{*}\left(i^{*}\right)=\frac{1}{3}\left(4 i^{*}-4 i^{*} \beta-1+\beta\right) . \\
& P_{B}{ }^{*}\left(i^{*}\right)=\frac{1}{3}\left(2 i^{*}-2 i^{*} \beta-1+\beta\right) .
\end{aligned}
$$

Substituting (2-6) into (2-2), we can also obtain the expression for $P_{A l}$ in terms of $i^{*}$ as follows:

$$
P_{A 1}^{*}\left(i^{*}\right)=\beta+\frac{(1-\beta)\left(7 i^{*}-1\right)}{3} \text {. }
$$

In the first stage of the game, firm A's maximization problem can be written as:

$$
\underset{i^{*}}{\operatorname{Max}_{A 2}}=P_{A 1}\left(1-i^{*}\right)+P_{A 2}\left(i^{*}-\frac{1+P_{A 2}-P_{B}-\beta}{2(1-\beta)}\right),
$$

subject to the constraints that $0<i^{*} \leq s^{*} \leq 1, P_{A 1}>0$ and the expressions for $P_{A 2}, P_{B}$ and $P_{A 1}$ that are given by equations (6), (7) and (8), respectively. ${ }^{11}$ Firm A's maximization problem reduces to a choice of $i^{*}$ that maximizes the incumbent's profits over both periods. Solving the first order condition yields the characterization of the Segmentation equilibrium summarized in Table 2.

\footnotetext{
${ }^{11}$ Note that we solve the game using backward induction because firm A cannot commit in stage 1 to its stage 2 price. This captures the environment described in Stokey (1979) for inter-temporal price discrimination and is consistent with the Coase (1972) conjecture that rational buyers can foresee the possibility of second period discounting.
} 
Table 2. Market Segmentation Without a Converter: Pure Strategy Nash Equilibrium*

\begin{tabular}{|c|c|c|c|c|}
\hline & Firm A (Stage 1) & Firm A (Stage 2) & Firm A (Overall) & Firm B (Stage 2) \\
\hline Price & $P_{A 1}^{*}=\frac{38-33 \beta}{26} \downarrow$ & $P_{A 2}^{*}=\frac{9-15 \beta}{13} \downarrow$ & $\mathrm{n} / \mathrm{a}$ & $P_{B}^{*}=\frac{11-14 \beta}{13} \downarrow$ \\
\hline Market Share & $1-i^{*}=\frac{6+3 \beta}{26(1-\beta)} \uparrow$ & $i^{*}-s^{*}=\frac{9-15 \beta}{26(1-\beta)} \downarrow$ & $1-s^{*}=\frac{15-12 \beta}{26(1-\beta)}$ & $s^{*}=\frac{11-14 \beta}{26(1-\beta)} \downarrow$ \\
\hline Profit & $\Pi_{\mathrm{A} 1}=\frac{3\left(76-28 \beta-33 \beta^{2}\right)}{676(1-\beta)}$ & $\Pi_{\mathrm{A} 2}=\frac{9\left(9-30 \beta+25 \beta^{2}\right)}{338(1-\beta)}$ & $\Pi_{\mathrm{A}}=\frac{3\left(10-16 \beta+9 \beta^{2}\right)}{52(1-\beta)}$ & $\Pi_{\mathrm{B}}=\frac{121-308 \beta+196 \beta^{2}}{338(1-\beta)}$ \\
\hline
\end{tabular}

The arrows in the table correspond to the comparative statics results of prices, market shares and profits with respect to $\beta$ $(0<\beta<3 / 5)$.

$\Pi_{A}$ is decreasing in $\beta$ when $0<\beta<\frac{(3-\sqrt{3})}{3}$ and is increasing in $\beta$ when $\frac{(3-\sqrt{3})}{3}<\beta<\frac{3}{5}$.

In order for this equilibrium to hold, it requires that all prices, market shares and profits are positive. It can be shown that the most binding constraint is for firm A to set a positive price and attract some consumers in stage $2\left(i^{*} \geq s^{*}\right.$ or $\left.P_{A 2}{ }^{*} \geq 0\right)$ as the remaining market consists exclusively of consumers who strongly prefer product $\mathrm{B}$, and this constraint is violated when $3 / 5<\beta<1$. This implies that firm A will adopt the market segmentation strategy when network effects are not too large $(0<\beta<3 / 5)$. When network effects are sufficiently large (i.e. when $\beta>3 / 5)$, the incumbent's penetration induces fierce competition with the entrant. There is limited room for further price reduction in the second stage $\left(P_{A 2} \rightarrow 0\right)$, thus inducing the incumbent to give up competing with the entrant in stage 2.

\section{$\underline{\text { Market Dominance Equilibrium }}^{12}$}

When network effects are sufficiently large, the incumbent can capture the entire market in stage 1. This is analogous to the classic "winner-takes-all" outcome. To do so, the incumbent must ensure that the consumer located at $x=0$ (the "B-Lover") prefers buying product $\mathrm{A}$ in the first stage versus buying product B in the second stage, namely,

$$
1-P_{B} \leq 2 \beta-P_{A 1} \Rightarrow P_{A 1} \leq P_{B}+2 \beta-1 .
$$

\footnotetext{
${ }^{12}$ Hereafter referred to as Dominance Equilibrium.
} 
As the lowest price the entrant can charge is $\varepsilon(\lim \varepsilon \rightarrow 0)$, the maximum price that the incumbent can set in order to dominate the market is $2 \beta-1$. This requires that $\beta>1 / 2$ in order to support a positive price. The incumbent's profit in this case is equal to $2 \beta-1$. Note that even though the incumbent captures the entire market, it requires him to cut prices due to the threat of entry.

We also examine the feasibility of two other types of Dominance equilibria, namely, the incumbent may choose to serve some consumers in stage 1 and cover the remaining market in the second stage, or, he may cover the entire market in the second stage only. In either case, the incumbent must ensure that he is able to attract the "B-lover" who is located at $x=0$, which requires: $1-P_{B} \leq \beta-P_{A 2}$, or $P_{A 2} \leq P_{B}+\beta-1$. Since the entrant can always set a low price $\left(P_{B}<1-\beta\right)$ so that $P_{A}<0$, such Dominance equilibria are not feasible in our model.

Summarizing, the above discussion and the comparative statics reported in Table 2 imply the following:

Proposition 2: Stronger network effects favor the incumbent over the entrant.

a) The incumbent's overall market share increase with the strength of network effects $(\beta)$. Under the Segmentation equilibrium, though, the incumbent's second-stage market share shrinks as network effects intensify.

b) Under the Dominance equilibrium, the incumbent's profit increases with the strength of network effects $(\beta)$. Under the Segmentation equilibrium, the incumbent's initially decreases then increases as network effects intensify.

c) The entrant's market share and profit decline as network effects $(\beta)$ increase.

d) Price competition intensifies as network effects increase. At the Segmentation Equilibrium, an increase in the strength of network effects $(\beta)$ yields a more significant reduction in the prices of the incumbent than that of the entrant. 
Note that, the incumbent's second-stage market share and price both decline as network effects increase. This is because stronger network effects enhance early adoption benefits since early adopters can enjoy twice the network effects. On the other hand, this first mover advantage comes at the cost of sharper price reductions by the incumbent. This finding is consistent with the empirical evidence that in markets characterized with strong network effects firms must "compete for the market" before they "compete in the market" as the initial price reduction can always be compensated by gains from a larger installed base (note that $\left|\frac{\partial P A 1^{*}}{\partial \beta}\right| \frac{\partial P A 2^{*}}{\partial \beta} \mid$ in Table 2).

When $\beta>1 / 2$, the Dominance equilibrium can coexist with the Segmentation (when $1 / 2<\beta<3 / 5$ ). However, because firm A sets a low price to attract the marginal consumer in a "winner-takes-all" market, profit comparison shows that when $1 / 2<\beta<3 / 5$, firm A will prefer market segmentation to market dominance. ${ }^{13}$ Figure 3 illustrates the range of $\beta$ supporting each type of equilibrium. It follows that:

Proposition 3: A unique pure-strategy Nash Equilibrium always exists in the baseline model when a converter is unavailable.

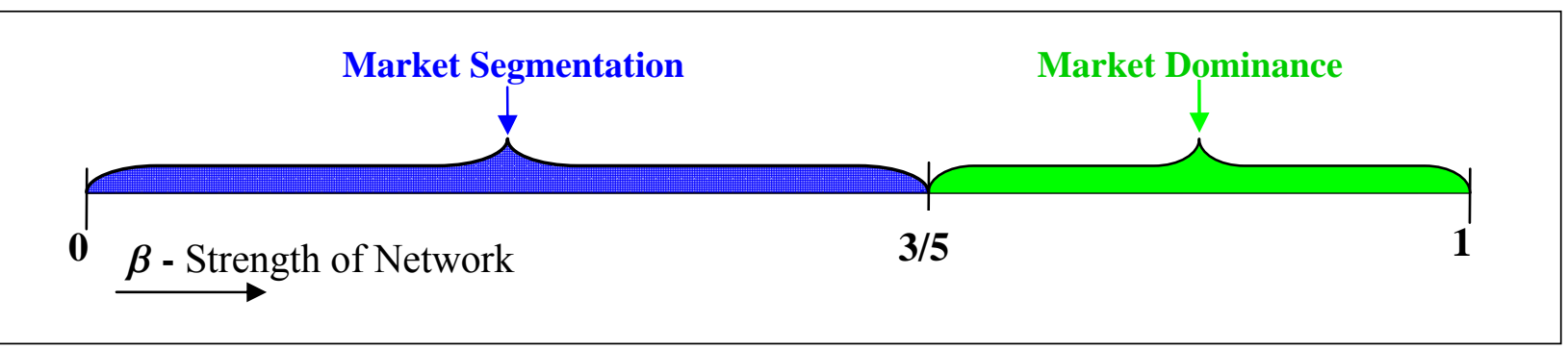

Figure 3. Summary of Equilibria - a Baseline Model Without a Converter

\footnotetext{
${ }^{13}$ Profit comparison shows that: $\Pi_{\mathrm{A}}{ }^{\text {Segmentation }}=\frac{3\left(10-16 \beta+9 \beta^{2}\right)}{52(1-\beta)}>\Pi_{\mathrm{A}}{ }^{\text {Dominance }}=2 \beta-1$ when $\frac{1}{2}<\beta<\frac{3}{5}$
} 


\subsection{An Extended Model With a Converter}

Thus far we have assumed that there are no converters and that products $\mathrm{A}$ and $\mathrm{B}$ are incompatible. We now extend this model to incorporate the possibility of conversion as follows:

(1) A one-way converter for each product is available for purchase ${ }^{14}$ in stage 2 . A consumer who buys product A (or B) can also buy a converter from a third party vendor and exploits partial (or full) externalities from the network of product B (or A), but not vice versa ${ }^{15}$.

(2) The market for converters is perfectly competitive and hence the price of the converter equals marginal cost, which we assume to be zero ${ }^{16}$.

(3) Following the conversion technology literature, we assume that converters are imperfect and some quality loss is possible in the conversion process. The quality of conversion is captured by $\theta(0<\theta \leq 1)$. When $\theta=0$, our model degenerates to the baseline model. When $\theta=1$, the converter offers perfect conversion and consumers who own the converter take full advantage of the positive network effects that accrue from the rival technology's installed base. (Again note that, unlike analog goods, digital goods offer the possibility of perfect conversion.)

(4) Consumers incur costs in the process of conversion due to the required effort or technical difficulty. As different consumers value conversion differently, the perception of the conversion cost, measured by $c$, is likely to vary among consumers. We assume conversion cost

\footnotetext{
${ }^{14}$ Here we assume that both one-way converters are simultaneously present, which can be achieved through a cross-licensing agreement between the two firms. It can be shown that if one firm does not provide a converter to consumers, the other firm would not have an incentive to do so either. We later examine the incentive to sign such an agreement in Chapter 3.

${ }^{15}$ Prior studies often assume that converters are two-way, which means that users of incompatible products can communicate with each other without requiring both consumers to own converters. In other words, as long as a consumer owns a two-way converter, any consumer of the rival incompatible product can free-ride on this consumer's converter to communicate with this consumer. However, in reality, possession of converters is often required in order to take advantage of the conversion benefits, and the assumption of two-way converters tends to overestimate the impact of converters and simplify the adoption decision of converters. Therefore, to model the adoption of converters as an independent decision, we assume that these converters are oneway converters and a consumer has to purchase a converter in order to take advantage of the conversion benefits.

${ }^{16}$ We also examined the case where the marginal cost of the converter is non-zero, and found that our results still hold. Thus, this assumption is without loss of generality.
} 
is uniformly distributed on the interval $[0, \bar{C}],{ }^{17}$ where $0<\bar{C}<1$.

Given this framework, if a consumer chooses not to buy a converter, her utility function remains the same as in (1). But if she chooses to buy a converter, her utility function becomes:

$$
U_{j k}=r+\sum_{k}^{2} x_{j}+\beta \sum_{k}^{2} M S_{j k}-P_{j k}+\beta M S_{-j}-c,
$$

where $\theta \beta M S_{-j}$ captures the partial (or full when $\theta=1$ ) network benefits from the rival product's installed base. Obviously, this happens only if conversion benefits outweigh costs $\left(\theta \beta M S_{-j}>c\right)$.

As in the baseline model, there are three types of equilibria when a converter is available.

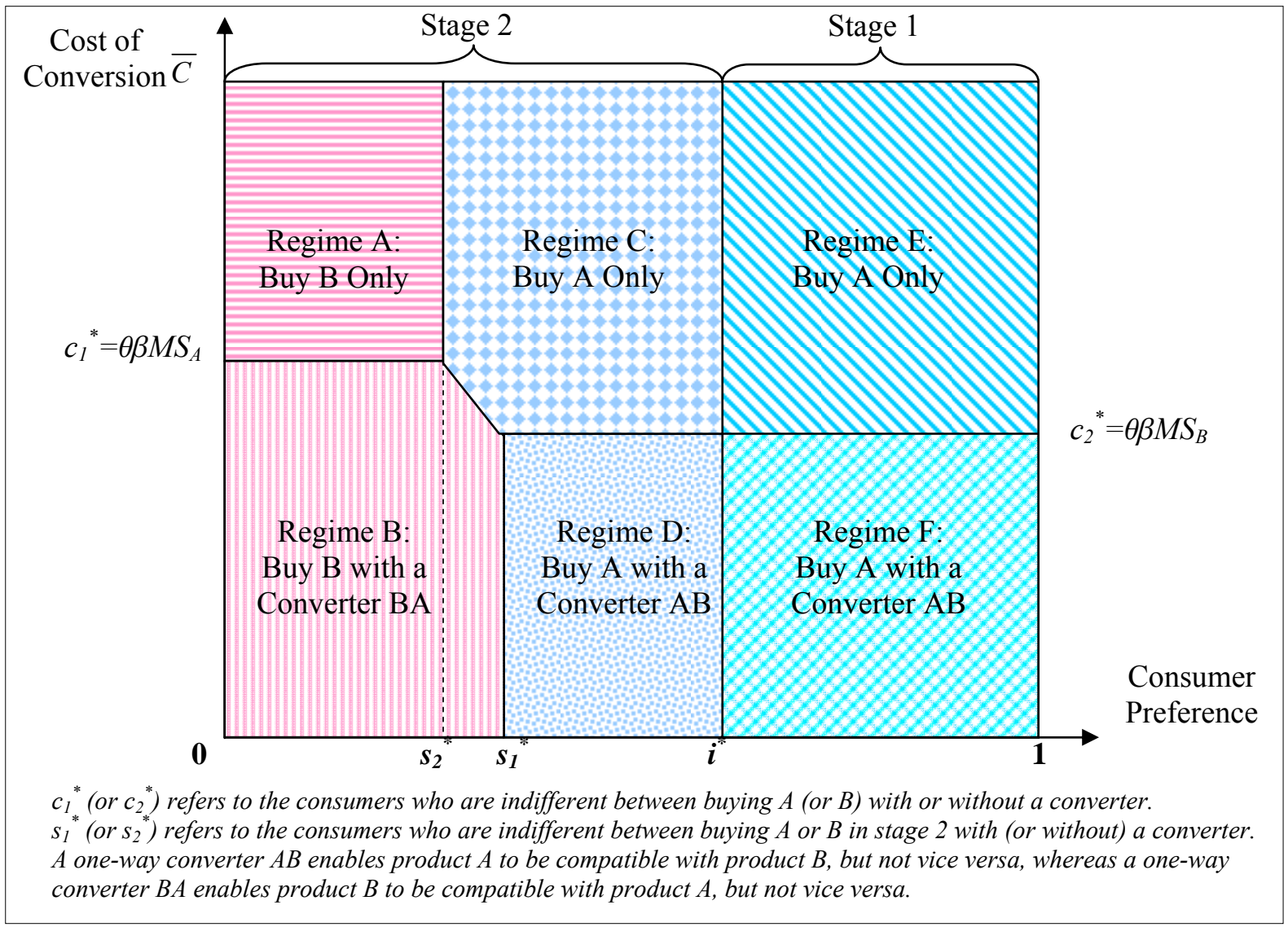

Figure 4. Segmentation Market Division

\footnotetext{
${ }^{17}$ If the minimum conversion cost is nonzero, consumers' conversion costs will be uniformly distributed on the interval $[\underline{\mathrm{C}}, \bar{C}]$, This does not change our results qualitatively. Therefore, for simplicity, we normalize $\underline{\mathrm{C}}$ to be equal to zero.
} 


\section{Segmentation Equilibrium in the presence of a converter}

Figure 4 shows the market division under the Segmentation equilibrium. ${ }^{18}$ To be consistent with the baseline model, the market size remains at 1 in the extended model. Therefore, as $\bar{C}$ changes, the density function $(1 / \bar{C})$ changes as well so that the overall market size stays unchanged. Similar to the baseline model, $M S_{j k}$ measures both the market size and market share of firm $j$ at stage $k$.

In Figure 4, we express the size of each regime in terms of $s_{1}{ }^{*}, s_{2}{ }^{*}, c_{1}{ }^{*}$ and $c_{2}{ }^{*}$. Moreover, since the consumers located at these values represent indifferent consumers, we can express $s_{l}{ }^{*}$, $s_{2}{ }^{*}, c_{1}{ }^{*}$ and $c_{2}{ }^{*}$ as functions of $P_{j k}, \theta, \beta$, and $\bar{C}$ to derive $M S_{j k}$. Following the same backward induction approach as above, we solve the PSNE and present the equilibrium results in Table 3.

Table 3. Market Segmentation With a Converter: Pure Strategy Nash Equilibrium*

\begin{tabular}{|c|c|c|c|}
\hline \multirow{2}{*}{ Price } & Firm A (Stage 1) & Firm A (Stage 2) & Firm A (Overall) \\
\hline \multirow{2}{*}{ Market Share } & $P_{A 1}^{*}=1+P_{A 2}^{*}+\beta M S_{A 1}^{*}-M S_{A 1}^{*}$ & $P_{A 2}^{*}=\left(2-2 \beta+\frac{\theta^{2} \beta^{2}}{\bar{C}}\right) M S_{A 2}^{*}$ & $P_{B}^{*}=\left(2-2 \beta+\frac{\theta^{2} \beta^{2}}{\bar{C}}\right) M S_{B}^{*}$ \\
\cline { 2 - 4 } & $M S_{A 1}^{*}=\frac{3\left(4 \bar{C}+2 \bar{C} \beta-\theta^{2} \beta^{2}\right)}{4\left(13 \bar{C}-13 \bar{C} \beta+2 \theta^{2} \beta^{2}\right)}$ & $M S_{A 2}^{*}=\left(\frac{1}{2}-\frac{2 M S_{A 1}}{3}\right)$ & \multirow{2}{*}{$M S_{B}^{*}=\left(\frac{1}{2}-\frac{M S_{A 1}}{3}\right)$} \\
\hline Profit & $M S_{A}^{*}=M S_{A 1}^{*}+M S_{A 2}^{*}=\left(\frac{1}{2}+\frac{M S_{A 1}}{3}\right)$ & \\
\hline & $\Pi_{A}^{*}=M S_{A 1}^{*}+(\beta-1)\left(M S_{A 1}^{*}\right)^{2}+\left(2-2 \beta+\frac{\theta^{2} \beta^{2}}{\bar{C}}\right)\left(M S_{A 2}^{*}\right)\left(M S_{A}^{*}\right)$ & $\Pi_{B}^{*}=\left(2-2 \beta+\frac{\theta^{2} \beta^{2}}{\bar{C}}\right)\left(M S_{B}^{*}\right)^{2}$ \\
\hline
\end{tabular}

${ }^{*}$ For simplicity, prices and profits are expressed in terms of market shares. The expressions for market shares are also provided in the table. Please refer to the Appendix for detailed derivation of the above results.

As in the baseline model, we find that the binding constraint to support the Segmentation equilibrium with conversion is the requirement that firm $\mathrm{A}$ is not able to charge a positive price and attract some consumers at stage 2, namely:

$$
i^{*} \geq s_{1}^{*} \Leftrightarrow 4 \bar{C}\left(13 \bar{C}-13 \bar{C} \beta+2 \theta^{2} \beta^{2}\right)-\left(4 \bar{C}+2 \bar{C} \beta-\theta^{2} \beta^{2}\right)\left(4 \bar{C}+2 \bar{C} \theta \beta-\theta^{2} \beta^{2}\right) \geq 0 .
$$

\footnotetext{
${ }^{18}$ There could be other types of market configurations under the Segmentation equilibrium. i.e., when $\bar{C}$ is very small, it is likely that all consumers adopt the converter. Since the results derived from the Market Segmentation equilibrium in the extended model still hold with different variations of market division, we omit the derivation of the equilibrium outcome under those cases.
} 


\section{Dominance Equilibrium in the presence of a converter}

If the incumbent is able to capture the entire market, there is no need for a converter to exist. Nonetheless, since the conversion benefit for a B adopter is larger than that in the Segmentation equilibrium where the market share gap is relatively smaller, the presence of the converter increases the marginal consumer's willingness to switch and reduces the incumbent's power to take over the entire market. Specifically, if the consumer located at the origin (a "B-lover") can obtain a converter and take advantage of product A's user base, the necessary condition to avoid this from happening is to set a price such that

$$
2 \beta-\mathrm{P}_{\mathrm{A}} \geq 1+\theta \beta-c \Rightarrow P_{A} \leq 2 \beta-1+c-\theta \beta
$$

The consumer most likely to switch is the one located in the lower left corner as she values product $\mathrm{B}$ most and has the smallest conversion cost $\left(\boldsymbol{x}_{\boldsymbol{B}}=1\right.$ and $\left.\boldsymbol{c}=0\right)$. To retain this marginal consumer, the incumbent must set its price at $P_{A 1} \leq(2-\theta) \beta-1$ (which requires that $\beta>\frac{1}{2-\theta}$ to guarantee a positive price), yielding profits equal to $(2-\not) \beta-1$. As in the baseline model, other types of Dominance equilibria are not feasible.

In summary, as in the baseline model, in the extended model the Dominance equilibrium may coexist with the Segmentation equilibrium. However, through a profit comparison we are able to eliminate multiple equilibria in the extended model. It follows that:

Proposition 4: A unique pure-strategy Nash Equilibrium always exists in the extended model in which a converter is available. (Please see the appendix for proof) 


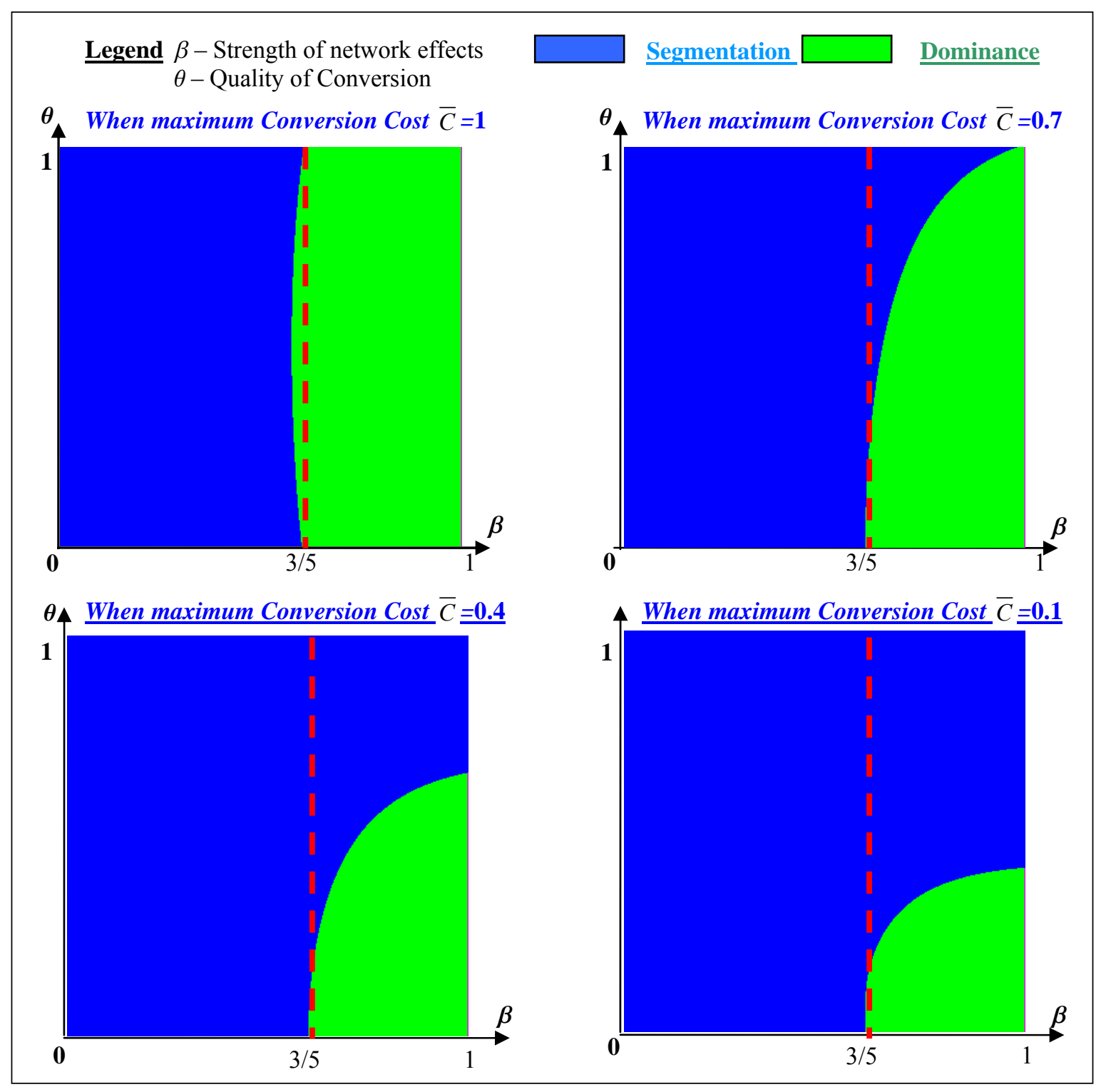

Figure 5. Summary of Equilibria With a Converter

In Figure 5, we illustrate the respective parameter regions for the two different types of equilibria in the extended model. Specifically, we depict the regions in a two dimensional space of the parameters $\theta$ and $\beta$ and repeat this depiction for various values of the maximum conversion cost $\bar{C}$. When $\theta=0$, our model reduces to the baseline model in which the conversion technology is unavailable. Hence the cut off points derived on the horizontal axis of each figure coincide with those in the baseline model. In general, when $\theta>0$, the "winners-take-some" 
outcome is more likely to emerge as an equilibrium than in the absence of a converter. Numeric calculation of the constraints that determine the boundaries of the three types of equilibria reveals that:

a) As the value of the maximum conversion $\operatorname{cost} \bar{C}$ increases, the likelihood of market segmentation declines and the likelihood of market dominance increases.

b) When the value of the conversion quality parameter $\theta$ is small, the likelihood of market dominance increases as $\theta$ increases. On the contrary, when $\theta$ is large, the likelihood of market segmentation increases as $\theta$ increases.

As shown in Figure 5, the lower the maximum conversion cost, the more likely that a Segmentation equilibrium arises, since lower maximum conversion costs increase the benefits of adopting a converter. However, the size of the region that supports market segmentation is not necessarily a monotonic function of the conversion quality parameter $\theta$. For example, Figure 5 shows that for smaller values of $\theta$, an increase in $\theta$ reduces the likelihood of the market segmentation outcome, and for bigger values of $\theta$, an increase in $\theta$ increases the likelihood of such an outcome. The ambiguous implications of the conversion quality parameter on the equilibrium stem from two counteracting effects. On one hand, as $\theta$ increases, the first mover advantage of the incumbent is eroded. As a result, the incumbent can expect to cover a smaller segment of the market. Since the extent of heterogeneity among consumers in a smaller market is more moderate, the incumbent has reduced incentives to segment his customers between those who purchase his products early and those who postpone their purchases to the second stage. However, as $\theta$ increases further, more consumers may postpone their purchases to the second stage since they expect intensified price competition at this stage, as the advantage of the incumbent over the entrant is reduced. This inclination on the part of consumers may force the 
incumbent to segment the market between early and late adopters, as the incumbent cannot afford to simply give up the larger segment of consumers who choose to wait until stage 2 .

\section{Comparative Statics}

In this section, we conduct comparative statics analyses to examine the impact of conversion cost and conversion quality on prices, market shares, and firms' profits.

Table 4. Comparative Statics Analysis of the Market Segmentation Equilibrium*

\begin{tabular}{|c|c|c|c|c|c|c|c|c|c|}
\hline & $\partial \mathrm{P}_{\mathrm{A} 1}{ }^{*}$ & $\partial \mathrm{P}_{\mathrm{A} 2}{ }^{*}$ & $\partial \mathrm{P}_{\mathrm{B}}{ }^{*}$ & $\partial M S_{\mathrm{A} 1}{ }^{*}$ & $\partial M S_{\mathrm{A} 2}{ }^{*}$ & $\partial M S_{\mathrm{A}}{ }^{*}$ & $\partial M S_{\mathrm{B}}{ }^{*}$ & $\partial \Pi_{\mathrm{A}}{ }^{*}$ & $\partial \Pi_{\mathrm{B}}{ }^{*}$ \\
\hline$\partial \theta$ & $>0$ & $>0$ & $>0$ & $<0$ & $>0$ & $<0$ & $>0$ & $>0$ & $>0$ \\
\hline$\partial \bar{C}$ & $<0$ & $<0$ & $<0$ & $>0$ & $<0$ & $>0$ & $<0$ & $<0$ & $<0$ \\
\hline
\end{tabular}

Proposition 5: It follows from Table 4 that, when a converter is available, changes in the values of the maximum conversion cost parameter $(\bar{C})$ and the conversion quality parameter $(\theta)$ have opposite effects on prices, market shares and firms' profits.

a) Improved conversion quality $(\theta)$ is positively associated with prices and firms' profits. Increased conversion cost $(\bar{C})$ is negatively associated with prices and firms' profits.

b) A higher conversion quality $(\theta)$ and a lower conversion cost $(\bar{C})$ reduce the incumbent's market share in stage 1 and its overall market share. However, the market shares of both the incumbent and entrant in the second stage increase.

It can be seen that a low cost and high quality converter favors the entrant's market expansion and are associated with higher prices and profits (for both firms). This indicates that whenever both firms supply converters, they will seek to improve the quality of their converters and reduce the cost of adoption. According to Table 4, higher conversion quality and lower conversion cost offered by both firms are also associated with higher profits for the incumbent, despite the loss of market share experienced as a result of reduced first mover advantage. This is attributed to the extra network effects derived from conversion, and consequently the upward- 
shift in the demand curve facing the incumbent.

\section{Incentive to Provide Converters}

The above results are obtained on the premise that both firms agree to provide converters. However, the incentive to do so depends on whether the provision of a converter can increase firms' profits. In this section we investigate if such an incentive is compatible with both firms' interests. As can be seen from Figure 5, for some ranges of the parameters, our models support both a non-conversion equilibrium from the baseline model and a conversion equilibrium from the extended model. For this reason we compare firms' profits from different equilibria to examine if firms are willing to supply converters.

Proposition 6: When Dominance is the only feasible outcome both in the presence and absence of a converter, the incumbent has no incentive to make the converter available.

Recall that when the incumbent dominates the market, even though there is no consumer demand to buy a converter AB to communicate with product B users, the incumbent's installed base induces a desire among "B-lovers" to purchase product B with a converter BA. This potential demand is stronger the higher the conversion quality and the lower the conversion cost. The availability of a high quality converter forces the incumbent to cut prices. Hence the incumbent has no incentive to make the converter available when it dominates the market.

Proposition 7: When the Segmentation equilibrium is the only feasible outcome both in the presence and absence of a converter (i.e., when $0<\beta<3 / 5$, and inequality (11) holds), the following are true:

a) Both the incumbent and the entrant enjoy higher profits when a converter is available than when it is absent. 
b) The equilibrium prices for both firms are higher in a conversion equilibrium than in a non-conversion equilibrium.

c) The gap between the two firms' market shares is smaller when a converter is available.

(A detailed proof is provided in the Appendix.)

When the entrant is able to compete in the market, the existence of the conversion technology may benefit both firms. Unlike a market with homogeneous products where the existence of a converter does not generate any benefit (since it isn't adopted), in a "winners-take-some" environment, firms' profits can unambiguously increase with the introduction of converters, as converters increase the consumers' willingness to pay for the product, and consequently firms can increase their profits by charging higher prices.

Significantly, both the entrant and the incumbent are better off in the conversion equilibrium, though for different reasons. The entrant benefits from both market expansion and increased product attractiveness leveraged by the incumbent's large existing installed base. The incumbent, despite a shrinking user base in the early stage of the competition, also benefits because of his consumers' higher willingness to pay. This higher willingness to pay more than compensates for the loss of market share to the incumbent.

Proposition 8: When the Dominance equilibrium arises in the baseline model (i.e., when $3 / 5<\beta \leq 1$ ), making the conversion technology available to consumers so that Market Segmentation is facilitated (i.e., inequality (11) holds) always benefits the entrant. It also benefits the incumbent if network effects are moderate (i.e. when $3 / 5<\beta \leq 7 / 8$ ). With relatively high network effects, however (i.e. when $7 / 8<\beta \leq 1$ ), the incumbent may be worse off when the conversion technology is made available. (A detailed proof is provided in the Appendix.)

When $3 / 5<\beta \leq 1$ and constraint (11) holds, both Dominance without a converter and 
Segmentation with a converter may arise as equilibria (see Figures 3 and 5). Profit comparison reveals that when both $3 / 5<\beta \leq 7 / 8$ and constraint (11) hold, profit from the Segmentation equilibrium in the extended model is higher than profit from the Dominance equilibrium in the baseline model.

However, when $7 / 8<\beta \leq 1$, it is unclear which type of equilibrium dominates. Recall that when $\beta>3 / 5$, the Segmentation strategy is not feasible due to the fierce competition induced by network effects and the Dominance equilibrium emerges as a result. When the strength of network effects is not very large (i.e. when $3 / 5<\beta \leq 7 / 8$ ), the incumbent has to charge very low prices in order to prevent further entry. Dominance, therefore, yields relatively low profits and induces the incumbent to switch to a conversion equilibrium if it becomes available. On the other hand, when network effects are very strong (i.e. when $7 / 8<\beta \leq 1$ ), the benefits from covering the entire market are large due to consumers' overall high willingness to pay. In this case, firm A may not be willing to share the market with the entrant, implying that it will not necessarily offer converters in the market. In contrast, the entrant always prefers a Segmentation Conversion equilibrium to a Dominance equilibrium, since he makes no profit when firm A dominates the market. Hence, whenever the incumbent offers to supply a converter simultaneously and engage in competition, the entrant will cooperate.

\subsection{Discussions}

The classic theory of network effects predicts that once critical mass has been achieved, a positive feedback loop will make the strong grow stronger and the weak grow weaker. However, in digital goods markets, there are also growing examples of "winners-take-some" outcomes,

e.g., flash memory cards. In our analytical model we have shown that in markets characterized 
with network effects and sequential entry, by promoting an extensive adoption of a conversion technology, the tendency towards a monopoly can be weakened in a way that is revenue enhancing for both the incumbent and the entrant. Such a conversion equilibrium is more sustainable the higher the conversion quality and the lower the conversion costs.

The findings derived from this study have implications both for markets with network effects and for technology standards competition. In the presence of network effects, being first to market creates not only a timing advantage in accumulating a customer base, but also a strategic advantage in controlling the deployment of the conversion technology in the market. When network effects are relatively small, an incumbent who envisions the advent of duopoly or oligopoly competition as inevitable could always lead the market into a "compatibility through conversion" equilibrium in which the extra utility created by a converter can be appropriated among the incumbent, the entrant and consumers.

In contrast to the above mutually beneficial "winners-take-some" conversion equilibrium, firms' motivation to supply the converter will differ substantially when the incumbent is able to dominate the market. While the entrant always responds positively to the presence of a converter as it increases his prospects for successful entry, the incumbent may not benefit from the presence of a converter in this case. However, contrary to the common wisdom that market dominance is a profit-maximizing strategy for a powerful market player, our analysis suggests that in a market with network effects and heterogeneous preferences, market dominance yields higher payoffs only when network effects are very large (i.e. $\beta \rightarrow 1$ in our model). When network effects are moderate (i.e. $3 / 5<\beta \leq 7 / 8$ in our model), the incumbent seeks market dominance only to avoid a fierce price war when the entrant enters the market. This indicates that the existence of a converter gives the incumbent more flexibility in determining the nature of competition. As 
shown in Proposition 8, when network effects are not large enough to warrant high profits, the incumbent can tactically lower entry barriers or even encourage market participation to create a demand for converters, so that the outcome switches from a dominance equilibrium without a converter to a competitive equilibrium with a converter. Nevertheless, when network effects are very strong, the incumbent has to offer a steep discount to all his consumers in order to sustain a conversion equilibrium. Hence, in this situation the incumbent finds it optimal to drive the entrant completely out of the market. And, since the existence of the conversion technology creates no value, but increases the entrant's ability to attract marginal consumers, the incumbent will not seek to provide the conversion technology and thereby reduce the prospects of entry and enhance his profits.

It is worth noting that in markets where technologies are adequately protected by intellectual property law, a firm cannot unilaterally supply a converter without cooperation from the other competitor. Therefore, a conversion equilibrium is not a traditional spontaneous non-cooperative result and proactive cooperation maybe needed in pursuit of such an outcome. But, as shown in Proposition 7, both the incumbent and the entrant are better off by jointly offering converters to their customers. In our context, we expect that whenever one firm supplies the converter, it is to the advantage of the other firms to supply a converter as well, since the provision of a converter makes their own product more attractive by allowing their customers to communicate with people outside of their own network. In the next study, we explicitly examine this prediction by endogenizing the decision to provide a converter and incorporate explicit negotiations between firms concerning the extent of conversion. 


\subsection{NEGOTIATIONS ON THE PROVISION OF CONVERTERS}

\subsection{Introduction}

Despite the benefits of conversion, provision of conversion technologies in the presence of network effects can be difficult. In many IT markets, different technology standards are often introduced to the market sequentially. Without explicit agreement on how to appropriate the profits from the provision of converters, the incumbent firm may not have an incentive to supply converters to consumers who purchase the incompatible formats. This is especially true when technology standards are proprietary and dominant firms can impose intellectual property rights to block the provision of converters. In the absence of a feasible market mechanism or a successful intervention to achieve coordination, how do firms agree on the provision of converters and compete in the presence of conversion technology? And how do converters affect consumer's adoption decision and social welfare? In this analysis, we address these questions in the context of proprietary technology competition. We extend the two-stage duopoly model developed in $\$ 2.2$ to analyze the impact of converters on technology adoption and social welfare in a market characterized with network effects, sequential entry, and heterogeneous consumer preferences. More importantly, we examine the firms' incentives to provide converters when such provision requires joint agreement from both parties, and when the price of converters can be strategically chosen by firms. We also introduce a mechanism through which firms can determine the extent of conversion and the allocation of proceeds from the sale of converters.

The main results of the analytic analysis can be summarized as follows: supplying 
converters to all consumers is the unique subgame perfect equilibrium except when network effects are very large. At this equilibrium, firms agree to charge a sufficiently low price for converters in order to encourage extensive adoption of converters. As the extent of converter adoption increases, price competition among competing products is alleviated, thus leading to higher product revenues. The entrant favors the provision of converters as it facilitates its market expansion and profit increase. However, even the incumbent has a strong incentive to supply converters despite the fact that its first mover advantage is weakened by the adoption of converters. Finally, the provision of converters can be welfare enhancing when the period of competition among multiple technologies is sufficiently long in comparison to the initial monopoly period when a single technology dominates the market.

\subsection{Model Assumptions}

In this study, we adopt the same baseline model setup as described in $\S 2.2$, with the following new assumptions regarding the provision of converters in the second stage of the game:

When product $\mathrm{B}$ enters the market in stage 2 , the firms can jointly decide to offer converters that enable users of one of the products to communicate with users of the other incompatible technology, and exploit some network externalities from the rival network. We assume that the decision to supply converters is obtained via negotiation. ${ }^{19}$ Moreover, as a result of such negotiations, firms also jointly set the price for converters, which we designate by $C$. When converters are available, if a consumer chooses not to buy a converter, her utility function

\footnotetext{
${ }^{19}$ When any of the two technologies is proprietary or involves intellectual property rights, provision of converters requires joint agreement from both firms.
} 
remains the same as in (1). But if she chooses to buy a converter, her utility function becomes (10) as shown in $\S 2.3$.

$$
U_{j k}=r+\sum_{k}^{2} x_{j}+\beta \sum_{k}^{2} M S_{j k}-P_{j k}+\beta M S_{-j}-C,
$$

where $\beta M S_{-j}$ captures the network benefits from the rival product's installed base. ${ }^{20}$ Obviously, a consumer will choose to buy a converter only if the conversion benefits outweigh the price of the converter $\left(\beta M S_{-j}>C\right)$.

The outcome of the negotiations between the firms in the second stage can take one of three forms: (1) No Conversion arises if firms fail to reach an agreement. In this case, both products remain incompatible with each other. (2) Partial Conversion arises if firms choose to offer converters at a high enough price so that only consumers from one of the two product networks find it optimal to buy a converter. Given firm A's first mover advantage, we will show that firm A's overall market share is always larger than that of firm B. Therefore, when the negotiated converter price satisfies $\beta M S_{B}<C \leq \beta M S_{A}$, only product B customers are willing to buy a converter. (3) Full Conversion arises when the firms make converters affordable to all consumers in the market. Specifically, when the negotiated converter price satisfies the inequality $C \leq \beta M S_{B}$, all customers find it optimal to buy a converter.

Following the negotiations, we assume that firms cannot collude on product prices. Instead, each firm chooses its product price to maximize its product revenue. Prices are chosen, though, after firms can observe the extent of conversion that the negotiations between them generate.

In Figure 6, we describe the timeline of the model.

\footnotetext{
${ }^{20}$ As explained in footnote 15 , we assume that these converters are one-way converters and a consumer has to purchase a converter in order to take advantage of the conversion benefits.
} 


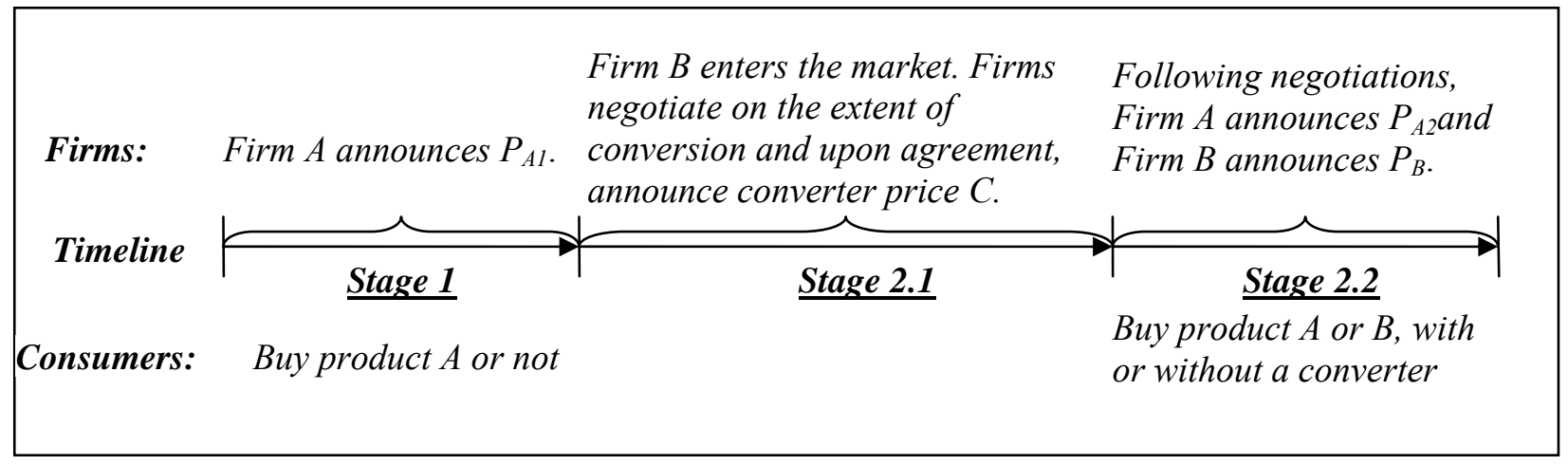

Figure 6. Timeline of the Model

To model the negotiations, we use the Nash Bargaining Solution (Nash, 1950). This solution concept implies that the payoff of each party consists of its "outside option" and half of the "gains from trade," if such gains are positive. The "outside option" coincides with the negotiating party's profits in case agreement cannot be reached. The "gains from trade" are calculated as the added joint benefit to the parties from reaching an agreement. ${ }^{21}$ In addition, as part of the negotiations, the price of the converter is chosen to maximize the joint payoff of the negotiating parties upon reaching an agreement. It is important to note, that an agreement can be reached only if there are positive "gains from trade." Specifically, if $J^{N}, J^{P}$, and $J^{F}$ designate the firms' second stage joint payoff with No, Partial, and Full Conversion, then for Partial Conversion to arise it is necessary that: $J^{P}>J^{N} \Leftrightarrow \Pi_{A 2}^{P}+\Pi_{B}^{P}+C^{P^{*}} M S_{B}^{P^{*}}>\Pi_{A 2}^{N}+\Pi_{B}^{N}$, and for Full Conversion it is necessary that: $J^{F}>J^{N} \Leftrightarrow \Pi_{A 2}^{F}+\Pi_{B}^{F}+C^{F^{*}}\left(M S_{A}^{F^{*}}+M S_{B}^{F^{*}}\right)>\Pi_{A 2}^{N}+\Pi_{B}^{N}$, where the firms' joint payoff $J$ consists of profits from selling products in stage 2 as well as proceeds from the sale of converters (i.e., $C^{P^{*}} M S_{B}^{P^{*}}$ for Partial Conversion and $C^{F^{*}}\left(M S_{A}^{F^{*}}+M S_{B}^{F^{*}}\right)$ for Full

\section{Conversion).}

\footnotetext{
${ }^{21}$ If agreement between the parties generates a joint payoff of $J^{A g}$, then at the Nash Bargaining Solution, the payoff allocated to the negotiator $j, W_{j}^{A g}$, solves the maximization of the product $\left(W_{j}^{A g}-W_{j}^{D i s}\right)^{1 / 2}\left(J^{A g}-W_{j}^{D i s}-W_{g}^{D i s}\right)^{1 / 2}$, where $W_{j}^{D i s}$ and $W_{g}^{D i s}$ designate the "outside options", or disagreement payoffs of the two parties. This maximization yields the solution that $W_{j}^{A g}=W_{j}^{D i s}+1 / 2\left(J^{A g}\right.$ $\left.W_{j}^{D i s}-W_{g}^{\text {Dis }}\right)$, as stated in the main text. The above maximization assumes that both parities have symmetric negotiating powers. To address asymmetric negotiating positions of the parties, the generalized Nash Bargaining Solution allows for an unequal division of the gains from trade $\left(J^{A g}-W_{j}^{D i s}-W_{g}{ }^{D i s}\right)$. We consider this asymmetry in a later section.
} 
Designating by $W_{j}^{A g}$ the second stage payoff of firm $j$ upon reaching an agreement on conversion, the above discussion implies that:

$$
W_{j}^{A G}=\left\{\begin{array}{l}
\Pi_{j}^{N}+\frac{1}{2}\left(\Pi_{j}^{P}+\Pi_{g}^{P}-\Pi_{j}^{N}-\Pi_{g}^{N}\right)+\frac{1}{2} C^{P^{*}} M S_{B}^{P^{*}} \text { with agreement on Partial Conversion, and } \\
\Pi_{j}^{N}+\frac{1}{2}\left(\Pi_{j}^{F}+\Pi_{g}^{F}-\Pi_{j}^{N}-\Pi_{g}^{N}\right)+\frac{1}{2} C^{F^{*}}\left(M S_{A}^{F^{*}}+M S_{B}^{F^{*}}\right) \text { with agreement on Full Conversion }
\end{array}\right.
$$

It may be interesting to consider how the above outcome is actually implemented. Following the agreement on conversion, the parties sell their products in the market, expecting profits of $\Pi_{j}^{P(F)}$ from such a sale. To obtain the agreement payoff described in (13), therefore, firm $j$ can expect some additional compensation as follows:

$$
T_{j}^{A G}=\left\{\begin{array}{l}
\frac{1}{2} C^{P^{*}} M S_{B}^{P^{*}}+\left[\frac{1}{2}\left(\Pi_{g}^{P}-\Pi_{g}^{N}\right)-\frac{1}{2}\left(\Pi_{j}^{P}-\Pi_{j}^{N}\right)\right] \quad \text { for Partial Conversion, and } \\
\frac{1}{2} C^{F^{*}}\left(M S_{A}^{F^{*}}+M S_{B}^{F^{*}}\right)+\left[\frac{1}{2}\left(\Pi_{g}^{F}-\Pi_{g}^{N}\right)-\frac{1}{2}\left(\Pi_{j}^{F}-\Pi_{j}^{N}\right)\right] \quad \text { for Full Conversion. }
\end{array}\right.
$$

Hence, at the conclusion of the negotiations each party receives half of the proceeds from the sale of converters adjusted by an amount that depends on which party benefits more from reaching an agreement. If $\left(\Pi_{A 2}^{P(F)}-\Pi_{A 2}^{N}\right)<\left(\Pi_{B}^{P(F)}-\Pi_{B}^{N}\right)$, firm B benefits more from reaching an agreement than firm A. As a result, firm B will have to offer a "side payment" to firm A as measured by the second term of $T_{j}^{A G}$ in (14). This second term reflects how much more reaching an agreement is valued by firm B than by firm A. 


\subsection{Equilibrium of the Model}

\subsubsection{Second Stage Game}

As we stated earlier, following the negotiations in the second stage, firms behave noncooperatively when choosing prices for their products. Since we wish to focus on sub-game perfect equilibrium $(S P N E)$, we start by considering the equilibrium prices selected by the firms in the second stage. The derivation of the equilibria varies based on the extent of conversion agreed upon by the firms at the beginning of the second stage. We start by considering the equilibrium in the absence of agreement, namely, the "outside option" for firms. This analysis is the same as the derivations in $§ 2.3$ except that we add a superscript $N$ to denote No Conversion.

\section{No Conversion}

In stage 2, a consumer who is indifferent between buying product A without a converter or buying product $\mathrm{B}$ without a converter satisfies:

$$
r+s^{*}+\beta\left(1-s^{*}\right)-P_{A 2}^{N}=r+1-s^{*}+\beta s^{*}-P_{B}^{N} \Rightarrow s^{*}=\frac{1+P_{A 2}^{N}-P_{B}^{N}-\beta}{2(1-\beta)}
$$

In the second stage, firms take the market share established by the incumbent in the first stage as given. For a fixed $M S_{A l}=1-i^{*}$, their market shares in the second stage are $M S_{A 2}=i^{*}-S^{*}$ for A and $M S_{B}={ }^{*}$ for B. The firms' maximization problems in stage 2 can therefore be written as:

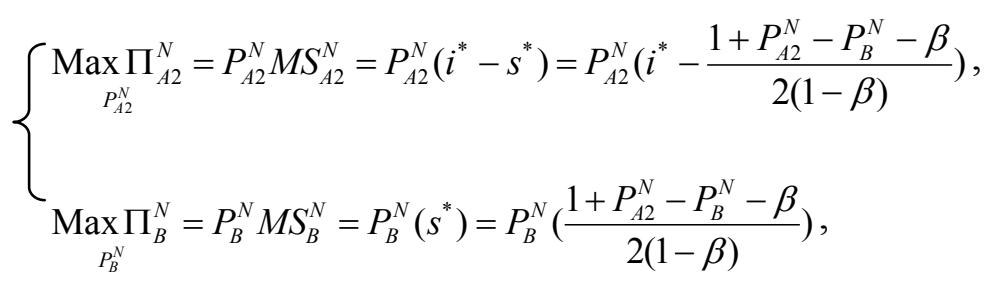

subject to the constraints that $0<S^{*} \leq i^{*}$, and $P^{*}{ }_{j k}>0$. Solving for the prices in terms of $i^{*}$ yields:

$$
\left.P_{A 2}^{N}\left(i^{*}\right)=\frac{\left(4 i^{*}-1\right)(1-\beta)}{3}\right)
$$




$$
\left.P_{B}^{N}\left(i^{*}\right)=\frac{\left(2 i^{*}+1\right)(1-\beta)}{3}\right)
$$

Since $M S_{B}^{N}\left(i^{*}\right)=s^{*}$ and $M S_{A 2}^{N}\left(i^{*}\right)=i^{*}-s^{*}$, we use (15) to obtain:

$$
\begin{aligned}
& M S_{A 2}^{N}\left(i^{*}\right)=\frac{4 i^{*}-1}{6}, \\
& M S_{B}^{N}\left(i^{*}\right)=\frac{2 i^{*}+1}{6} .
\end{aligned}
$$

Substituting (18), (19), (20), and (21) into (16) and (17) yields the firms' profits as a function of $i^{*}:$

$$
\begin{aligned}
& \Pi_{A 2}^{N}\left(i^{*}\right)=\frac{\left(4 i^{*}-1\right)^{2}(1-\beta)}{18}, \\
& \Pi_{B}^{N}\left(i^{*}\right)=\frac{\left(2 i^{*}+1\right)^{2}(1-\beta)}{18} .
\end{aligned}
$$

And the firms' joint profits in the absence of converters are therefore given by:

$$
J^{N}\left(i^{*}\right)=\Pi_{A 2}^{N}\left(i^{*}\right)+\Pi_{B}^{N}\left(i^{*}\right)=\frac{(1-\beta)\left(10 i^{* 2}-2 i^{*}+1\right)}{9} .
$$

Note that in order for the incumbent to charge a positive price and cover a portion of the remaining market in stage 2 , it must be true that $P_{A 2}^{N}\left(i^{*}\right)>0$ and $M S_{A 2}^{N}\left(i^{*}\right)>0$, hence $i^{*}>1 / 4$. If $i^{*}<1 / 4$, the incumbent covered a large portion of the market in stage $1\left(M S_{A 1}{ }^{*}=1-i^{*}>3 / 4\right)$ and the remaining market consists entirely of consumers who have such a strong preference for product $\mathrm{B}$ that the incumbent cannot attract any of them at a positive price.

Next we examine what happens if firms reach an agreement on conversion.

\section{Partial Conversion:}

If, at the conclusion of the negotiations, the firms agree on charging a price for the converter that satisfies the inequality $\beta M S_{B}^{P}<C^{P} \leq \beta M S_{A}^{P}$, only product B customers are willing to buy a converter, as they are the only consumers whose conversion benefits outweigh the cost (due to 
firm A's relatively larger network size). In stage 2, a consumer who is indifferent between buying product $\mathrm{A}$ without a converter and buying product $\mathrm{B}$ with a converter satisfies:

$$
r+s^{*}+\beta\left(1-s^{*}\right)-P_{A 2}^{P}=r+1-s^{*}+\beta s^{*}+\beta\left(1-s^{*}\right)-P_{B}^{P}-C^{P} \Rightarrow s^{*}=\frac{1+P_{A 2}^{P}-P_{B}^{P}-C^{P}}{(2-\beta)} .
$$

Similar to the No Conversion equilibrium, solving firms' stage 2 maximization problems yields firms' second stage prices, market shares and profits as a function of $i^{*}$ (summarized in Table 5).

Table 5. Partial Conversion Equilibrium Second Stage Prices, Market Shares and Profits

\begin{tabular}{|c|c|c|}
\hline & Firm A & Firm B \\
\hline Price & $P_{A 2}^{P}=\frac{2 i^{*}(2-\beta)-\left(1-C^{P}\right)}{3}$ & $P_{B}^{P}=\frac{i^{*}(2-\beta)+\left(1-C^{P}\right)}{3}$ \\
\hline $\begin{array}{c}\text { Market } \\
\text { Share }\end{array}$ & $M S_{A 2}^{P}=\frac{2 i^{*}(2-\beta)-\left(1-C^{P}\right)}{3(2-\beta)}$ & $M S_{B}^{P}=\frac{i^{*}(2-\beta)+\left(1-C^{P}\right)}{3(2-\beta)}$ \\
\hline Profit & $\Pi_{A 2}^{P}=\frac{\left[2 i^{*}(2-\beta)-\left(1-C^{P}\right)\right]^{2}}{9(2-\beta)}$ & $\Pi_{B}^{P}=\frac{\left[i^{*}(2-\beta)+\left(1-C^{P}\right)\right]^{2}}{9(2-\beta)}$ \\
\hline $\begin{array}{c}\text { Joint } \\
\text { Profits }\end{array}$ & $J^{P}\left(i^{*}, C^{P}\right)=\Pi_{A 2}^{P}+\Pi_{B}^{P}+C^{P} \cdot M S_{B}^{P}=\frac{5 i^{* 2}(2-\beta)^{2}-2 i^{*}(2-\beta)\left(1-C^{P}\right)+2\left(1-C^{P}\right)^{2}}{9(2-\beta)}+\frac{C^{P}\left[i^{*}(2-\beta)+\left(1-C^{P}\right)\right]}{3(2-\beta)}$ \\
\hline
\end{tabular}

* In order for the Partial Conversion equilibrium to exist, firm A must be able to charge a positive price and have a positive market share in stage 2 , which requires: $i^{*}>\left(1-C^{\mathrm{P}}\right) /(4-2 \beta)$.

Note that the firms' second stage joint payoff is a function of the remaining market size $i^{*}$ that firm A didn't cover in the first stage and the converter price $C^{P}$. When firms decide to supply a converter (i.e. when $J^{P}>J^{N}$ ), they choose an optimal converter price to maximize their second stage joint payoff, regardless of how the firms eventually divide the proceeds from converters. The Nash Bargaining solution described in (13) and (14) yields a higher payoff to each negotiator if actions are selected to maximize the joint payoff function. Observing the entries of Table 5 implies the comparative statics reported in Lemma 1:

Lemma 1: In a Partial Conversion equilibrium, as the price of the converter increases, the incumbent's second stage product price and market share increase $\left(\partial P_{A 2}^{P} / \partial C^{P}>0, \frac{\partial M S_{A 2}^{P}}{\partial C^{P}}>0\right)$, but the entrant's product price and market share both decline $\left(\frac{\partial P_{B}^{P}}{\partial C^{P}}<0, \frac{\partial M S_{B}^{P}}{\partial C^{P}}<0\right)$. 
Lemma 1 implies that the strategic position of firm B is weakened in comparison to that of firm A if the price of the converter increases. Note that this might have counteracting effects on the proceeds from the sale of converters, since a decline in the market share of firm B implies that fewer consumer buy converters at the Partial Conversion equilibrium. To obtain the optimal price of the converters that maximizes the joint payoff function, we differentiate $J^{P}\left(i^{*}, C^{P}\right)$ from Table 5 to obtain the solution reported in Lemma 2.

Lemma 2: Agreement on Partial Conversion is feasible when $i^{*}>\operatorname{Max}\left\{\frac{1}{4}, \operatorname{Min}\left\{\frac{1}{3(2-\beta)}, \frac{1+\beta-\beta^{2}}{(2-\beta)(5-3 \beta)}\right\}\right.$. The price of the converter is then chosen as follows:

(i) When $\frac{15-\sqrt{57}}{14} \leq \beta \leq 1$ and $\operatorname{Min}\left\{\frac{1}{4}, \frac{1}{3(2-\beta)}\right\}<i^{*}<\frac{1+\beta-\beta^{2}}{(2-\beta)(5-3 \beta)}$,

$$
C^{P^{*}}=C_{\mathrm{int}}^{P}=\frac{5 i^{*}(2-\beta)-1}{2} .
$$

(ii) When $\beta<\frac{15-\sqrt{57}}{14}$ and $i^{*}>1 / 4$, or when $\frac{15-\sqrt{57}}{14} \leq \beta \leq 1$ and $i^{*}>\frac{1+\beta-\beta^{2}}{(2-\beta)(5-3 \beta)}$,

$$
C^{P^{*}}=C_{\max }^{P}=\beta M S_{B}^{P}=\frac{\beta\left[(5-3 \beta)-i^{*}(2-\beta)\right]}{2(3-2 \beta)} .
$$

According to Lemma 2, when the strategic position of firm A relative to that of firm B is very strong, either because the strength of network effects is strong (large $\beta$ values) or because firm A has established a significant market share in the first stage (small $i^{*}$ values), the firms' joint payoff is maximized when the price of the converter is chosen so that $\partial J^{P}\left(i^{*}, C^{P}\right) / \partial C^{P}=0$, thus obtaining the interior solution denoted by $C_{\text {int }}^{P}$.

In contrast, when the strength of the network effects is moderate (small $\beta$ values) or if firm A's first stage market share is relatively small (large $i^{*}$ values), the price of the converter that maximizes the firms' second stage joint payoff is determined by the maximum willingness to pay on the part of consumers $\left(\beta M S_{A}^{P}\right)$. Smaller values of $\beta$ and/or bigger values of $i^{*}$ imply that the 
market share of firm $\mathrm{A}$ in stage 1 declines, thus reducing the network benefits that accrue to consumers who purchase converters. As a result, the value of $C^{P}$ that satisfies the condition $\partial J^{P}\left(i^{*}, C^{P}\right) / \partial C^{P}=0$ exceeds the maximum willingness to pay on the part of consumers.

It is interesting to note from the expressions obtained for $C^{P^{*}}$ in (26) and (27), that the optimal price of the converter chosen in the negotiations is initially an increasing function of $i^{*}$ for sufficiently small values of $i^{*}$. However, for larger values of $i^{*}$, the optimal converter price declines with $i^{*}$. Since larger $i^{*}$ values reduce the overall market share of the incumbent, consumers of product B derive less benefit from conversion, thus leading to lower willingness to pay on their part and a lower converter price when $i^{*}$ is sufficiently large $\left(i^{*}>\frac{1+\beta-\beta^{2}}{(2-\beta)(5-3 \beta)}\right)$.

However, for smaller values of $i^{*}$, firm B's market share as reported in Table 5 is relatively small, implying that the overall demand of converters is small (since with Partial Conversion, only product B's consumers buy converters). Hence, increasing $i^{*}$ in this case increases the extent of demand for converters, allowing the firms to charge higher prices.

Substituting the optimal price of from (26) and (27) back into the joint payoff expression in Table 5 yields the following joint payoff of the firms as a function of the market share established by firm $\mathrm{A}$ in the first stage: ${ }^{22}$

$$
J^{P}\left(i^{*}\right)=\left\{\begin{array}{l}
\frac{5(2-\beta)^{2} i^{* 2}-2(2-\beta) i^{*}+1}{4(2-\beta)}, \quad \text { if } C^{P^{*}}=C_{\max }^{P} \\
\frac{\left(40-80 \beta+52 \beta^{2}-11 \beta^{3}\right) i^{* 2}-\left(8-28 \beta+24 \beta^{2}-6 \beta^{3}\right) i^{*}+4-5 \beta+\beta^{3}}{4(3-2 \beta)^{2}}
\end{array} \quad \text { if } C^{P^{*}}=C_{\mathrm{int}}^{P} .\right.
$$

\section{$\underline{\text { Full Conversion }}$}

If the firms choose a price for the converter so that $C^{F} \leq \beta M S_{B}^{F^{*}}$, the users of both products A and B are willing to buy a converter as conversion benefits outweigh the cost of conversion

\footnotetext{
${ }^{22}$ There is some abuse of notation in defining $J^{P}\left(i^{*}\right)$ since we dropped the second argument of $J^{P}(\cdot)$ from Table 5, after substituting the optimal value of $C^{P}$.
} 
even for product A customers who benefit less from conversion. In stage 2, a consumer who is indifferent between buying product $\mathrm{A}$ with a converter and buying product $\mathrm{B}$ with a converter satisfies:

$r+s^{*}+\beta\left(1-s^{*}\right)+\beta s^{*}-P_{A 2}^{F}-C^{F}=r+1-s^{*}+\beta s^{*}+\beta\left(1-s^{*}\right)-P_{B}^{F}-C^{F} \Rightarrow s^{*}=\frac{1+P_{A 2}^{P}-P_{B}^{P}}{2}$.

As in the previous cases, following the negotiations product prices are determined noncooperatively in the second stage. In Table 6, we derive the Nash equilibrium prices, market shares and profits of the second stage game (as a function of the market share established by firm A in the first stage).

Table 6. Full Conversion Equilibrium Second Stage Prices, Market Shares and Profits*

\begin{tabular}{|c|c|c|}
\hline & Firm A & Firm B \\
\hline Price & $P_{A 2}^{F}=\frac{4 i^{*}-1}{3}$ & $P_{B}^{F}=\frac{2 i^{*}+1}{3}$ \\
\hline Market Share & $M S_{A 2}^{F}=\frac{4 i^{*}-1}{6}$ & $M S_{B}^{F}=\frac{2 i^{*}+1}{6}$ \\
\hline Profit & $\Pi_{A 2}^{F}=\frac{\left(4 i^{*}-1\right)^{2}}{18}$ & $\Pi_{B}^{F}=\frac{\left(2 i^{*}+1\right)^{2}}{18}$ \\
\hline Joint Profits & $J^{F}\left(i^{*}, C^{F}\right)=\Pi_{A 2}^{F}\left(i^{*}\right)+\Pi_{B}^{F}\left(i^{*}\right)+C^{F}=\frac{1-2 i^{*}+10 i^{* 2}}{9}+C^{F}$ \\
\hline
\end{tabular}

*The condition necessary to support positive prices in the second stage is $i^{*}>1 / 4$.

Lemma 3: Under Full Conversion, neither the firms' prices nor their market shares depend on the price of the converter. However, the firms' second stage joint payoff is an increasing function of the price of the converter. As a result, in the negotiations, firms will find it optimal to charge the highest possible price that is consistent with Full Conversion, namely $C^{F^{*}}=\beta M S_{B}^{F^{*}}$.

Substituting $C^{F^{*}}$ into $J^{F}\left(i^{*}, C^{F}\right)$ yields the firms' second stage Full Conversion joint payoff: ${ }^{23}$

$$
J^{F}\left(i^{*}\right)=\frac{1-2 i^{*}+10 i^{* 2}}{9}+\frac{\beta\left(2 i^{*}+1\right)}{6} .
$$

Comparing the joint payoff derived under the three levels of conversion in (24), (28), and

\footnotetext{
${ }^{23}$ As explained in footnote 22, here as well we dropped the second argument of $J^{P}(\cdot)$ from Table 6 in $\operatorname{defining} J^{P}\left(i^{*}\right)$.
} 
(30) implies that Full Conversion is preferred by the firms, irrespective of the size of the market share obtained by firm A in the first stage of the game. We report this result in Proposition 9.

Proposition 9: For values of $i^{*}$ that can support all three different levels of conversion, namely, $i^{*}>\operatorname{Max}\left\{\frac{1}{4}, \operatorname{Min}\left\{\frac{1}{3(2-\beta)}, \frac{1+\beta-\beta^{2}}{(2-\beta)(5-3 \beta)}\right\}\right.$, the following is true: $J^{F}\left(i^{*}\right)>J^{P}\left(i^{*}\right)>J^{N}\left(i^{*}\right)$.

As a result, at the beginning of the second stage the firms have an incentive to reach an agreement on Full Conversion.

To understand why conversion leads to higher joint payoff in the second stage, in Observation 1 we demonstrate that product B's price is higher the greater the extent of conversion agreed upon by the firms. The alleviated competition on prices in the second stage leads, therefore, to higher joint profits from product sale. Moreover, in Observation 2, we establish that the proceeds from the sale of converters are higher with Full Conversion than with Partial Conversion. Specifically, even though Full Conversion entails a lower converter price (i.e. $C^{p^{*}}>C^{F^{*}}=\beta M S_{B}^{* *}$ ), the increased number of consumers buying converters more than compensates for the lower price, thus generating higher proceeds from the sale of converters. This is consistent with proposition 1 in that both product revenue and proceeds from converters increase with the extent of conversion.

Observation 1: (i) As the extent of conversion increases, firm B charges higher prices for its product. (ii) The firms' joint revenues from product sales in the second stage increase as the extent of conversion increases. ${ }^{24}$

Observation 2: Even though $C^{F^{*}}<C^{P^{*}}$, the proceeds from the sale of converters under Full Conversion is higher than under Partial Conversion. Specifically, $C^{F^{*}}>C^{P^{*}} \cdot M S_{B}^{P^{*}}$.

\footnotetext{
${ }^{24}$ The effect of conversion on firm A's prices in the second stage is ambiguous. It depends on the specific value of $i^{*}$ established in the first stage. However, joint product revenues increase with the extent of conversion irrespective of the value of $i^{*}$.
} 


\subsubsection{The Maximization Problem of Firm A in the First Stage}

Given that Full Conversion is anticipated in stage 2, in stage 1, the consumer located at $i^{*}$ is indifferent between buying product $\mathrm{A}$ in stage 1 and stage 2 and satisfies the following equation:

$$
r+2 i^{*}+\beta\left(1-i^{*}\right)+\beta-P_{A 1}^{F}-C^{F}=r+i^{*}+\beta-P_{A 2}^{F}-C^{F} \Rightarrow P_{A 1}^{F}=i^{*}+P_{A 2}^{F}+\beta-i^{*} \beta .
$$

Firm A's expected payoff of both stages can be rewritten as:

$$
\underset{i^{*}}{\operatorname{Max}} \Pi_{A}^{F}=P_{A 1}^{F}\left(i^{*}\right) M S_{A 1}^{F}\left(i^{*}\right)+\left[\Pi_{A 2}^{N}\left(i^{*}\right)+\frac{1}{2}\left(J^{F}\left(i^{*}\right)-J^{N}\left(i^{*}\right)\right]\right.
$$

subject to the constraints that $0<i^{*} \leq s^{*} \leq 1, P_{j k}^{*}>0$, and the expressions for $P_{A 2}^{F}, M S_{A 2}^{F}$ and $P_{A 1}^{F}$ are given in Table 6 and by equation (31), respectively. ${ }^{25}$

The payoff in (32) is the sum of revenues from the sale of the product in the first stage and the payoff from Full Conversion in the second stage. The second stage payoff includes revenues from the sale of the product in the second stage, half of the proceeds from the sale of converters, and a possible side payment ${ }^{26}$ from firm B to firm A. Combining these three sources of profit yields the Nash Bargaining outcome reported in the second term of (32). In the first stage, firm A chooses $P_{A 1}^{F}$ to maximize its payoff. It is simpler however to obtain the solution by maximizing over $i^{*}$ instead, given that the second stage prices and profits are all expressed in terms of $i^{*}$.

Optimizing (32) with respect to $i^{*}$ yields the equilibrium reported in Table 7. In Proposition 10 we report the comparative statics implied by the entries in Table 7.

\footnotetext{
${ }^{25}$ Note that similar to what we did in the baseline model, we solve the game using backward induction because firm A cannot commit in stage 1 to its stage 2 price.

${ }^{26}$ The side payment is equal to $\beta i(1-i) / 3$ which correspond to half of the additional benefit that firm B derives from reaching an agreement on full conversion relative to $\mathrm{A}$.
} 
Table 7. Full Conversion Equilibrium Prices, Market Shares and Profits

\begin{tabular}{|c|c|c|c|c|}
\hline & Firm A (Stage 1) & Firm A (Stage 2) & Firm B (Stage 2) & Converter \\
\hline \multirow{2}{*}{ Price } & $P_{A 1}^{F^{*}}=\frac{\left(76-43 \beta+3 \beta^{2}\right)}{4(13-6 \beta)}$ & $P_{A 2}^{F^{*}}=\frac{(9-7 \beta)}{(13-6 \beta)}$ & $P_{B}^{F^{*}}=\frac{(22-13 \beta)}{2(13-6 \beta)}$ & $C^{F^{*}}=\frac{\beta(22-13 \beta)}{4(13-6 \beta)}$ \\
\hline \multirow{3}{*}{$\begin{array}{c}\text { Market } \\
\text { Share }\end{array}$} & $M S_{A 1}^{F^{*}}=1-i^{*}=\frac{3(4+\beta)}{4(13-6 \beta)}$ & $M S_{A 2}^{F^{*}}=\frac{(9-7 \beta)}{2(13-6 \beta)}$ & \multirow{2}{*}{$M S_{B}^{F^{*}}=s^{*}=\frac{(22-13 \beta)}{4(13-6 \beta)}$} & \\
\cline { 2 - 5 } & $M S_{A}^{F C^{*}}=M S_{A 1}^{F C^{*}}+M S_{A 2}^{F C^{*}}=\frac{30-11 \beta}{4(13-6 \beta)}$ & & \\
\hline \multirow{3}{*}{$\begin{array}{c}\text { Profit } \\
\end{array}$} & $\Pi_{A}^{F C^{*}}=\Pi_{A 1}^{F C^{*}}+\Pi_{A 2}^{N C^{*}}+\frac{J^{F C^{*}}-J^{N C^{*}}}{2}=\frac{120+12 \beta-23 \beta^{2}}{16(13-6 \beta)}$ & $\Pi_{B}^{F *^{*}}=\Pi_{B}^{N C^{*}}+\frac{J^{F C^{*}}-J^{N C^{*}}}{2}=\frac{968-732 \beta-196 \beta^{2}+183 \beta^{3}}{16(13-6 \beta)^{2}}$ \\
\hline
\end{tabular}

Proposition 10: As the strength of network effects increases (higher values of $\beta$ ), the firms charge lower prices in both stages, the overall market share and profits of firm A increase, and those of firm B decrease. In addition, the price charged for the converter rises.

Substituting the equilibrium prices and market shares into the constraint necessary to support the Full Conversion equilibrium (i.e. $i^{*}>1 / 4$ ) implies that the Full Conversion equilibrium can be supported for all values of $\beta(0 \leq \beta<1)$. Nevertheless, one should note that other than being engaged in a two-stage competition, the incumbent also has the ability to capture the entire market in stage 1 . We now explicitly examine this possibility and compare it with the Full Conversion equilibrium.

Specifically, when network effects are sufficiently large, the incumbent can capture the entire market in stage 1. This is analogous to the classic "winner-takes-all" outcome. To do so, the incumbent must ensure that the consumer located at $x=0$ (the "B-Lover") prefers buying product $\mathrm{A}$ in the first stage versus buying product $\mathrm{B}$ in the second stage, namely, $1-P_{B}^{D} \leq 2 \beta-P_{A 1}^{D} \Rightarrow P_{A 1}^{D} \leq P_{B}^{D}+2 \beta-1$, where superscript $D$ refers to market dominance.

As the lowest price the entrant can charge is $\varepsilon(\lim \varepsilon \rightarrow 0)$, the maximum price that the incumbent can set in order to dominate the market is $2 \beta-1$. This requires that $\beta>1 / 2$ in order to 
support a positive price. The incumbent's profit in this case equals $2 \beta-1$. Note that even though the incumbent captures the entire market, he must cut prices due to the threat of entry.

Comparison between the profits from Market Dominance and the profits from Full Conversion reveals that Dominance profits are higher than Full Conversion profits only when network effects are very large (i.e. $\beta>0.982$ ). When network effects are not as strong (i.e. $\beta<0.982$ ), the incumbent has no incentive to take over the market as the overall profits from the Full Conversion equilibrium are higher than Dominance profits. This implies that:

Proposition 11: When $\beta<0.982$, Full Conversion emerges as the subgame perfect equilibrium. Otherwise, when network effects are sufficiently large (i.e. $\beta>0.982$ ), the incumbent prefers to dominate the entire market in the first stage.

\subsection{Is It Ever Optimal to Commit to Less Than Full Conversion?}

The analysis so far assumes that the incumbent cannot commit in the first stage to the level of conversion he will agree to in the second stage. In the absence of such a commitment, we have shown that Full Conversion is the only equilibrium that can arise as long as $\beta<0.982$. Next, we consider the possibility that the incumbent does have commitment power, and we examine whether in this case it will find it optimal to commit to partial or no conversion. In Tables 8,9 , 10 we characterize the equilibrium outcomes when the incumbent commits to No Conversion (Table 8) and Partial Conversion (Tables 9 and 10), respectively. 
Table 8. The Equilibrium of the Entire Game under Commitment to No Conversion ${ }^{\dagger \ddagger}(0<\beta<3 / 5)$

\begin{tabular}{|c|c|c|c|c|}
\hline & Firm A (Stage 1) & Firm A (Stage 2) & Firm A (Overall) & Firm B (Stage 2) \\
\hline Price & $P_{A 1}^{N^{*}}=\frac{38-33 \beta}{26} \downarrow$ & $P_{A 1}^{N^{*}}=\frac{38-33 \beta}{26} \downarrow$ & $\mathrm{n} / \mathrm{a}$ & $P_{B}^{N^{*}}=\frac{11-14 \beta}{13} \downarrow$ \\
\hline $\begin{array}{c}\text { Market } \\
\text { Share }\end{array}$ & $M S_{A 1}^{N^{*}}=\frac{6+3 \beta}{26(1-\beta)} \uparrow$ & $M S_{A 2}^{N^{*}}=\frac{9-15 \beta}{26(1-\beta)} \downarrow$ & $M S_{A}^{N^{*}}=\frac{15-12 \beta}{26(1-\beta)}$ & $M S_{B}^{N^{*}}=\frac{9-15 \beta}{26(1-\beta)} \downarrow$ \\
\hline Profit & $\Pi_{A 1}^{N^{*}}=\frac{3\left(76-28 \beta-33 \beta^{2}\right)}{676(1-\beta)} \uparrow$ & $\Pi_{A 2}^{N^{*}}=\frac{9\left(9-30 \beta+25 \beta^{2}\right)}{338(1-\beta)} \downarrow$ & $\Pi_{A}^{N^{*}}=\frac{3\left(10-16 \beta+9 \beta^{2}\right)}{52(1-\beta)}$ & $\Pi_{B}^{N^{*}}=\frac{\left.121-308 \beta+196 \beta^{2}\right)}{338(1-\beta)} \downarrow$ \\
\hline
\end{tabular}

${ }^{\dagger}$ The arrows in the table correspond to the comparative statics results of prices, market shares and profits with respect to $\beta$.

$\Pi_{A}$ is decreasing in $\beta$ when $0<\beta<\frac{(3-\sqrt{3)}}{3}$ and is increasing in $\beta$ when $\frac{(3-\sqrt{3})}{3}<\beta<\frac{3}{5}$.

Table 9. The Equilibrium of the Entire Game under Commitment to Partial Conversion ${ }^{\dagger}\left(C^{*}=C_{\max }\right)$

\begin{tabular}{|c|c|c|c|}
\hline & Firm A (Stage 1) & Firm A (Stage 2) & Firm B (Stage 2) \\
\hline Price & $P_{A 1}^{P^{*}}=\frac{912-2368 \beta+2304 \beta^{2}-992 \beta^{3}+159 \beta^{4}}{2\left(312-648 \beta+448 \beta^{2}-103 \beta^{3}\right)}$ & $P_{A 2}^{P *}=\frac{432-1336 \beta+1496 \beta^{2}-772 \beta^{3}+127 \beta^{4}}{2\left(312-648 \beta+448 \beta^{2}-103 \beta^{3}\right)}$ & $P_{B}^{P^{*}}=\frac{528-1496 \beta+1536 \beta^{2}-682 \beta^{3}+111 \beta^{4}}{2\left(312-648 \beta+448 \beta^{2}-103 \beta^{3}\right)}$ \\
\hline \multirow[t]{2}{*}{$\begin{array}{l}\text { Market } \\
\text { Share }\end{array}$} & $M S_{A 1}^{P^{*}}=\frac{4\left(18-15 \beta-4 \beta^{2}+4 \beta^{3}\right)}{\left(312-648 \beta+448 \beta^{2}-103 \beta^{3}\right)}$ & $M S_{A 2}^{P^{*}}=\frac{216-560 \beta+4684 \beta^{2}-127 \beta^{3}}{2\left(312-648 \beta+448 \beta^{2}-103 \beta^{3}\right)}$ & \multirow{2}{*}{$M S_{B}^{P^{*}}=\frac{264-616 \beta+460 \beta^{2}-111 \beta^{3}}{2\left(312-648 \beta+448 \beta^{2}-103 \beta^{3}\right)}$} \\
\hline & \multicolumn{2}{|c|}{$M S_{A}^{P^{*}}=\frac{360-732 \beta-196 \beta^{2}+183 \beta^{3}}{2\left(312-648 \beta+448 \beta^{2}-103 \beta^{3}\right)}$} & \\
\hline Profit & $\Pi_{A}^{P^{*}}=\Pi_{A 1}^{P^{*}}+\Pi_{A 2}^{N^{*}}+\frac{J^{P^{*}}-J^{N^{*}}}{2}=\frac{43}{2}$ & $\frac{0-8904 \beta+6952 \beta^{2}-2516 \beta^{3}+373 \beta^{4}}{24\left(312-648 \beta+448 \beta^{2}-103 \beta^{3}\right)}$ & \\
\hline
\end{tabular}

$\dagger$ when $\beta<0.717, C_{\text {int }}^{P}>C_{\max }^{P}$ and $C^{p *}=C_{\max }^{p}=\frac{360 \beta-680 \beta^{2}+436 \beta^{3}-95 \beta^{4}}{2\left(312-648 \beta+448 \beta^{2}-103 \beta^{3}\right)}$.

Table 10. The Equilibrium of the Entire Game under Commitment to Partial Conversion ${ }^{\dagger}\left(C^{*}=C_{\text {int }}\right)$

\begin{tabular}{|c|c|c|c|}
\hline & Firm A (Stage 1) & Firm A (Stage 2) & Firm B (Stage 2) \\
\hline Price & $P_{A 1}^{P^{*}}=\frac{159-193 \beta+58 \beta^{2}}{58-37 \beta}$ & $P_{A 2}^{P^{*}}=\frac{112-166 \beta+57 \beta^{2}}{58-37 \beta}$ & $P_{B}^{P^{*}}=\frac{-18+43 \beta-19 \beta^{2}}{58-37 \beta}$ \\
\hline $\begin{array}{c}\text { Market } \\
\text { Share }\end{array}$ & $M S_{A 1}^{P^{*}}=\frac{11-\beta}{58-37 \beta}$ & $M S_{A 2}^{P^{*}}=\frac{112-166 \beta+57 \beta^{2}}{116-132 \beta+37 \beta^{2}}$ & \\
\cline { 2 - 4 } & $M S_{A}^{P^{*}}=\frac{134-175 \beta-56 \beta^{2}}{(2-\beta)(58-37 \beta)}$ & $M S_{B}^{P^{*}}=\frac{18-43 \beta+19 \beta^{2}}{116-132 \beta+37 \beta^{2}}$ \\
\hline Profit & $\Pi_{A}^{P^{*}}=\Pi_{A 1}^{P^{*}}+\Pi_{A 2}^{P^{*}}+\frac{J^{P^{*}}-J^{N^{*}}}{2}=\frac{-800+12744 \beta-712 \beta^{2}+139 \beta^{3}}{6(2-\beta)(58-37 \beta)}$ & $\Pi_{B}^{P^{*}}=\frac{29548-78602 \beta+77526 \beta^{2}-33460 \beta^{3}+5339 \beta^{4}}{6(2-\beta)(58-37 \beta)^{2}}$ \\
\hline
\end{tabular}

$\dagger$ when $0.958<\beta<1, C_{\text {int }}^{P}<C_{\max }^{P}$ and $C^{p *}=C_{\text {int }}^{P}=\frac{206-289 \beta+95 \beta^{2}}{58-37 \beta}$.

We find that the comparative statics of the solution are similar to those reported in

Proposition 10. Specifically, as network effects become more important ( $\beta$ increases), firms price

more aggressively, the market share and profits of firm A increase and those of firm B decrease. 
However, as reported in the following Lemma, the range of $\beta$ values that support less than full conversion shrinks with the lower the committed extent of conversion chosen by the incumbent.

Lemma 3: (i) A commitment to No Conversion can be supported only if $0<\beta<0.6$. (ii) A commitment to Partial Conversion can be supported if $0<\beta<0.717$, in which case $C^{P^{*}}=C_{\max }^{P}$, or if $0.958<\beta<1$, in which case $C^{P^{*}}=C_{\text {int }}^{P}$.

The reason that a reduced level of conversion leads to a smaller range of values supporting it can be explained by observing the entries of Tables 8,9 and 10. A lower level of conversion results in more aggressiveness on the part of the incumbent in the first stage. Specifically, firm A prices more aggressively in order to obtain market share in the first stage. As a result, price competition between the firms in the second stage may lead to negative prices over a wider range of $\beta$ values. In essence, a higher degree of conversion alleviates price competition in the second stage. We summarize this finding in Observation 3.

Observation 3: A commitment to a higher level of conversion results in a smaller market share obtained by firm A in stage 1 and higher product prices charged by both firms in stage 2 .

In the next observation we compare the revenues from the sale of converters under Partial and Full Conversion.

Observation 4: The price of the converter is lower, but the overall profits from the sale of converters are higher, under a commitment to Full rather than Partial Conversion.

The above observations explain the comparison of the overall profits of the incumbent under the four regimes we have considered with commitment. We designate the profits that accrue in each case by $\Pi_{A}^{F}, \Pi_{A}^{P}, \Pi_{A}^{N}$ and $\Pi_{A}^{D}$ (corresponding to Full, Partial, and No Conversion, and to Dominance, respectively), and conduct this comparison in Proposition 12. 
Proposition 12: When $0<\beta<0.717, \Pi_{A}^{F}>\Pi_{A}^{P}>\Pi_{A}^{N}>\Pi_{A}^{D}$, when $0.717<\beta<0.982, \Pi_{A}^{F}>\Pi_{A}^{D}>\Pi_{A}^{P}$, and when $0.982<\beta<1, \Pi_{A}^{D}>\Pi_{A}^{F}>\Pi_{A}^{P}$, where the ranking is valid when the corresponding commitment regimes are feasible.

From Proposition 12, it follows, therefore, that the incumbent will have no incentive to commit to less than Full Conversion even if it has the commitment power to do so.

Even though Full Conversion is the preferred outcome (as long as $\beta<0.982$ ), it may sometimes not be feasible, for technical reasons, to provide converters to consumers. In this case, Proposition 12 leads to the following Corollary.

Corollary 1: In the absence of a conversion technology, the incumbent prefers sharing the market with the entrant over market dominance, for all values that support both types of outcomes.

Corollary 1 stems from the fact that market dominance requires the incumbent to cut its price sharply, thus rendering this choice less appealing than sharing the market with the entrant.

\subsection{Comparison of Social Welfare}

In this section we investigate the properties of the solution that maximizes social welfare (designated by $T S$ ), where welfare is calculated as the sum of consumer and producer surplus. Given the absence of any production costs in our model, social welfare is calculated as the average gross benefit derived by consumers before subtracting any expenditure on products and converters. Since the expenditure of the consumers comprises the revenues of the producers, all such expenses cancel out in the calculation of social welfare. We obtain, therefore: 


$$
T S= \begin{cases}r+\left[\beta+\beta\left(1-i^{*}\right)^{2}\right]+P D\left(s^{*}, i^{*}\right) & \text { under Full Conversion, } \\ r+\left[\beta s^{*}+\beta\left(1-s^{*}\right)^{2}+\beta\left(1-i^{*}\right)^{2}\right]+P D\left(s^{*}, i^{*}\right) & \text { under Partial Conversion, } \\ r+\left[\beta\left(s^{*}\right)^{2}+\beta\left(1-s^{*}\right)^{2}+\beta\left(1-i^{*}\right)^{2}\right]+P D\left(s^{*}, i^{*}\right) & \text { under No Conversion. }\end{cases}
$$

where $P D\left(s^{*}, i^{*}\right)=s^{*}\left(1-\frac{s^{*}}{2}\right)+\frac{i^{* 2}-s^{* 2}}{2}+\left(1-i^{* 2}\right)$.

Social welfare consists of the sum of three components: product reservation price $r$, the average network benefits derived by consumers, and the average brand specific benefits derived by consumers (designated by $P D$ to capture the benefits from product differentiation). In Proposition 13 we characterize the solution that maximizes social welfare in our setting.

\section{Proposition 13:}

(i) Social welfare is maximized with Full Conversion, when all consumers have access to converters. The optimal segmentation of the market at the maximum is given as:

$$
i_{T S}^{*}=s_{T S}^{*}= \begin{cases}\frac{1-2 \beta}{3-2 \beta}, & \text { if } \beta \leq \frac{1}{2} \\ 0 & \text { if } \beta>\frac{1}{2} .\end{cases}
$$

(ii) The maximum total surplus can be expressed, therefore as:

$$
T S^{*}= \begin{cases}r+\beta+\frac{\left(21-20 \beta+4 \beta^{2}\right)}{2(3-2 \beta)^{2}} & \text { if } \beta \leq \frac{1}{2} \\ r+\beta+1+\beta & \text { if } \beta>\frac{1}{2}\end{cases}
$$

It is noteworthy that the extent of segmentation that is welfare maximizing is far more limited than that obtained at the market equilibrium. In particular, all the consumers who wish to buy product A should do so in the first stage in order to maximize welfare. Moreover, when $\beta>1 / 2$, no consumer should purchase product B. Essentially, the extent of heterogeneity in preferences that we introduce in our model is relatively small in comparison to the network benefits. Since consumers who purchase the product early derive those benefits over a longer period of time, the welfare maximizing outcome sometimes dictates (when $\beta>1 / 2$ ) that firm A 
should dominate the market. The added benefit from prolonged use of the product more than outweighs the disutility of consumers who strongly prefer product B (those located close to zero on the line).

Comparing the solution described in Proposition 13 with the entries of Table 8 implies that even if firm A can commit never to agree on conversion, the market share of firm B at the market equilibrium is in excess of the optimal social welfare outcome. Since increasing the extent of conversion raises the market share of firm B even further, it follows that increased conversion may not always be welfare enhancing $\left(M S_{B}^{F^{*}}>M S_{B}^{N^{*}}>\frac{1-2 \beta}{3-2 \beta}\right)$. On the positive side, a higher extent of conversion enhances the network benefits of consumers. On the negative side, it reduces the market share of the dominant firm, thus distorting market segmentation further away from welfare maximization.

In fact, comparing the commitment regimes included in Tables 7 (Full), 8 (No), 9 and 10 (Partial) as well as the Dominance option considered earlier, it can be shown that when $0<\beta<0.289$, a commitment to Full Conversion yields the highest social welfare. However, when $0.289<\beta<0.5$, No Conversion is actually the most preferred regime in terms of social welfare. Moreover, when Dominance is feasible (i.e., when $\beta>0.5$ ), the Dominance equilibrium yields the highest level of social welfare, since when network effects are significant, early adoption by all customers is more important than any benefits from segmentation.

It should be pointed out that our welfare analysis relies heavily on the assumption that the two stages are of equal length. In the next section we show that if the "competitive" phase (second stage) is much longer than the "monopoly" phase (first stage), the welfare maximizing outcome awards a much larger market share to firm B, implying that market equilibrium with conversion is likely to be welfare enhancing over a longer range of $\beta$ values. 


\subsection{Extensions of the Baseline Model}

In the previous analysis, we assumed that the two stages of competition are of equal length. However, in the rapidly evolving IT industry, due to fast technology improvement, the initial monopoly period is likely to be much shorter than the subsequent competitive phase in which consumers realize utility over a longer period time. To capture this characteristic of the IT market and to examine how the length of the different phases of the game affect the results obtained earlier, we multiply consumer's second stage utility by a scaling parameter $k(k>1)$.

In this extended model, all the results obtained from the second stage game remain unchanged as $k$ has the same multiplicative impact on all second stage prices and profits. Hence, Full Conversion in stage 2 remains the only subgame perfect equilibrium outcome. In the first stage, firm A chooses $i^{*}$ (or alternatively $P_{A 1}^{F}$ ) to maximize the following objective function:

$$
\underset{i^{*}}{\operatorname{Max} \Pi_{A}^{F}}=\left[i^{*}+k P_{A 2}^{F}\left(i^{*}\right)+\beta\left(1-i^{*}\right)\right]\left(1-i^{*}\right)+k\left\{\Pi_{A 2}^{N}\left(i^{*}\right)+\frac{1}{2}\left[J^{F}\left(i^{*}\right)-J^{N}\left(i^{*}\right)\right]\right\}
$$

The first term of (34) captures the revenues that accrue from product sale in the first stage. Note, however, that because of the longer duration of the second stage, second stage prices are multiplied by $k$. As a result, the expression for the first stage price in terms of $i^{*}$ becomes $P_{A 1}^{F}\left(i^{*}\right)=i^{*}+k P_{A 2}^{F}\left(i^{*}\right)+\beta\left(1-i^{*}\right)$, where $P_{A 2}^{F}\left(i^{*}\right)$ is expressed in Table 6 for the case of $k=1$. The second term of (37) is the second stage payoff firm A can expect, given the anticipation for a Full Conversion agreement. The expressions for $\Pi_{A 2}^{N}\left(i^{*}\right), J^{N}\left(i^{*}\right)$, and $J^{F}\left(i^{*}\right)$ are obtained from equations (22), (24) and (30), respectively. Once again, the second stage payoff is multiplied by

$k$ due to the longer duration of consumption. Optimizing (34) with respect to $i^{*}$ yields the following solution: 


$$
i^{F^{*}}=\frac{k(22+9 \beta)+18(1-2 \beta)}{2[k(8+6 \beta)+18(1-\beta)]} .
$$

From (35) it follows that as the length of the competitive phase increases relative to the length of the monopoly phase, the incumbent is willing to restrict himself to a smaller market share in stage $1\left(\partial i^{F^{*}} / \partial k>0\right)$ in return for greater dividend in the second stage. As a result, equilibrium prices in the competitive phase rise.

Note also that as the length of the competitive period increases, the segmentation that maximizes social welfare awards an increasingly larger market share to firm B. Specifically, to maximize welfare:

$$
i_{T S}^{*}=s_{T S}^{*}= \begin{cases}\frac{k-2 \beta}{1+2 k-2 \beta}, & \text { if } \beta \leq \frac{\mathrm{k}}{2} \\ 0 & \text { if } \beta>\frac{\mathrm{k}}{2} .\end{cases}
$$

From Table 8 , in the absence of conversion, $M S_{B}^{N^{*}}=\frac{9-15 \beta}{26(1-\beta)}$. This market share is smaller than $s_{T S}^{*}$ for sufficiently large values of $k$. Hence increasing the extent of conversion, in this case, may imply not only improved network benefits but also an allocation of market shares that is closer to the welfare maximizing outcome. The last observation follows since increasing the extent of conversion leads to a larger market share for firm B. This is an opposite outcome to the conclusion reached in Farrell and Saloner (1992) in which they found that converters always lead to excessive adoption of the new technology.

Next we consider another possible extension of our model that is related to the sharing rule utilized by firms in allocating the "gains from trade" in the negotiations. So far we assumed that the firms agree to share those gains equally. However, the generalized Nash Bargaining 
Solution ${ }^{27}$ facilitates capturing asymmetry in the bargaining positions of the negotiators. In particular, if $\alpha$ is the share of the "gains from trade" allocated to firm A and $\alpha>1 / 2$, then firm A has a stronger negotiating position than firm B. It is very easy to show that as $\alpha$ increases, firm A behaves less aggressively in the first stage. Specifically $\partial i^{F^{*}} / \partial \alpha>0$, implying that the incumbent firm establishes a smaller market share in the first stage, thus leading to alleviated price competition in the second stage. Since the incumbent anticipates obtaining a larger share of the surplus when reaching an agreement on conversion, it has the incentive to foster a more cooperative environment in the second stage, which is feasible by cutting back on its extent of market coverage in the first stage.

\subsection{Discussions}

In this study, we analyze the role of converters in shaping the dynamic competition between two incompatible technologies when network effects are present. While incorporating explicit negotiations between the firms, we show that when firms can jointly determine the price of the converter, the subgame perfect equilibrium of the resulting competition involves firms setting the converter price low enough so that all consumers in the market find it optimal to purchase a converter. Moreover, such a conversion equilibrium can be achieved in a way that is revenue enhancing for both the incumbent and the entrant. This finding is consistent with the growing anecdotal evidence from some digital goods markets, e.g., Apple's adoption of its "boot camp" software for running the Windows operating system on Apple's computers (Wall Street Journal, April 6 2006) and the prevalence of digital converters in the flash memory market.

\footnotetext{
${ }^{27}$ Using the notation of footnote 21 , the payoff allocated to negotiator $j$ in this case, $W_{j}^{A g}$, is a maximizer of $\left(W_{j}^{A g}-W_{j}^{D i s}\right)^{\alpha}\left(J^{A g}-W_{j}^{D i s}-W_{g}^{D i s}\right)^{1-\alpha}$, where $\alpha$ is the bargaining power of negotiator $j$.
} 
In contrast to the prior literature, we endogenize the firm's decision to provide converters. We believe endogenizing the decision to provide a converter is essential to model converters in IT environments where firms frequently can impose intellectual property or technological control over the development of converters. Our different modeling approach yields several important findings that contradict those obtained in the prior literature.

First, we find that instead of making the converters costly as shown in Farrell and Saloner (1992), in our model firms will provide converters at a sufficiently low price to encourage extensive adoption of converters. Since the provision of converters alleviates price competition, firms have an incentive to do so even if they don't receive any proceeds from the sale of converters. Second, prior studies suggest that, due to significant development costs and the time it takes for firms to reach an agreement, converters are rarely available in the nascent stage of a new technology (David and Bunn 1988, Choi 1996). As a result, new technology adoption can be hindered which further delays the adoption of converters (Choi 1997). However, we find that the incumbent will choose to support Full Conversion even when it has the ability to commit to less than Full Conversion. Hence our study predicts that successful negotiations on conversion can be anticipated, thus allowing both firms and consumers to be well prepared for the provision of converters. Such a prediction has been supported by observations from several IT markets. For example, when Adobe introduced the Digital Negative (DNG) format in an effort to promote it as the standard for the raw files generated by various digital cameras, it also provided a free DNG converter, which easily translates raw files from many of today's popular cameras. Following this move, many software and digital camera manufacturers have developed support for the DNG format, which provides a strong signal to the industry that DNG may emerge as a de facto standard for the digital photo raw formats. As a result, the market penetration of the 
DNG format has risen significantly in the three years after launch. ${ }^{28}$

With regard to the impact of converters on social welfare, contrary to the finding in the literature that in markets with heterogeneous consumer preferences the provision of converters can lead to an inefficient social outcome (Farrell and Saloner, 1992), we show that the welfare implication of the availability of converters depends critically on the relative length of the competitive versus the monopoly periods. When the competitive period is sufficiently long, the availability of converters can be welfare enhancing. We believe this modeling decision better captures the reality of IT-based markets where different technologies emerge rapidly and new products have a longer product lifecycle than that of the old ones. Hence the provision of converters can be more critical as the conversion benefits are realized over a longer period of time.

Finally, we find that the adoption of converters can increase the likelihood of survival of the entrant, since the higher profits that can be anticipated with conversion lead the incumbent to compete less aggressively and create an environment that is conducive for the adoption of converters. With alleviated price competition, the possibility of blockading the transition to a new technology, which is identified in Choi (1996), is less likely to emerge in our model. This finding is best illustrated in the flash memory card market where in the presence of the conversion technologies, new entrant formats were able to survive the competition and in some cases outperform the incumbent formats.

In addition to these findings, we also explore several issues of great practical value that have not been examined in the prior literature, and that result in practical guidance for firms participating in such markets. For example, the proposed Nash Bargaining Solution to describe the process of negotiations offers a feasible mechanism for firms to implement an outcome ${ }^{28} \mathrm{http}: / /$ www.adobe.com/products/dng/supporters.html 
whenever joint agreement of all parties is essential in achieving this outcome. Furthermore, the findings we derive for the equilibrium with Partial Conversion are particularly salient when technical feasibility permits only conversion from one technology to the other, but not vice versa (i.e. when the new technology can be made backward compatible through a converter but the old technology cannot be made forward compatible through a converter). This is because in this setting, partial conversion will emerge as the equilibrium as it generates higher profits for firms than no conversion. Moreover, firms developing new products are often confronted with tradeoffs between design improvement and backward compatibility. When backward compatibility can be achieved through a converter, our results enable managers to optimally price the converter and better predict the anticipated payoffs prior to making a design decision. 


\subsection{EMPIRICAL MODEL AND RESULTS}

\subsection{Introduction}

In many IT markets, a widely adopted product may give rise to a longer product lifecycle, better product support and services, and a greater variety of complementary goods. In most traditional contexts, when quality and performance are similar across competing standards and consumers are increasingly aware of these compatibility benefits, they are more likely to opt for a product that adopts a more popular standard, which, in turn, creates a virtuous cycle for the leading formats and helps the strong grow stronger (Shapiro and Varian, 1999). Consequently, when multiple incompatible technologies coexist, firms often have to compete ex ante for ex post market power, as once the market falls into this positive feedback loop, the growth of the leading format often becomes irreversible until it achieves market dominance. This type of market evolution has been documented in the VHS and Betamax "standards wars" (Cusumano et al., 1992, Park, 2004), the adoption of the DVD format (Dranove and Gandal, 2003), and the markets for U.S. desktop operating systems and office productivity software (Bresnahan, 2001).

However, as we enter a "digital era", a new and different pattern of competition seems to be emerging from several digital goods markets. Despite strong demand for compatibility, these markets have not tipped towards a single standard, nor do we see a significant advantage for the incumbent over the new entrants. Witness, for example, the lack of standardization seen in markets for digital media files (e.g., Real Media, Windows Media, QuickTime, AVI, and MPEG), digital photography (e.g., JPEG, GIF, TIFF, and PNG), and flash memory cards (e.g., Compact 
Flash, SmartMedia, Secure Digital, Memory Stick, XD Picture, and Multimedia).

In this Chapter we focus on the flash memory market. Flash memory is a class of nonvolatile, electrically rewritable memory that was introduced into the consumer electronic market in $1994^{29}$. With the capability to store large amounts of data in digital format, fast read/write speeds, and compact size, it has emerged as the primary storage media of various digital electronic devices such as digital cameras, digital camcorders, mobile phones, PDAs, audio players, etc. Over the past decade the flash memory market has become one of the fastest growing sectors in the IT industry. According to the market research firm IDC, flash memory revenue is expected to reach $\$ 18.7$ billion in 2010 , up from a record $\$ 10.6$ billion in $2005 .^{30}$ This growth may not be surprising given the rapid expansion of the digital consumer electronics market and the heavy reliance of these digital devices on memory cards for data storage and transfer.

However, what is surprising is the variety of incompatible card formats that exist in the market in spite of an apparent demand side economy of scale. If network effects were present, consumers who purchased a particular flash card memory format would be more likely, all else equal, to take this format into consideration when purchasing their next digital device in order to be able to reuse the flash memory cards and to easily transfer digital outputs from one device to another. And, of course to the degree that one format became widely adopted, more manufacturers would find it desirable to make their device compatible with the emerging standard, which would generate the classic increasing returns to adoption found in network effects.

The presence of demand side economies of scale for flash memory card formats is

\footnotetext{
${ }^{29} \mathrm{http}: / /$ www.sandisk.com/Oem/DocumentInfo.aspx?DocumentID=1340

${ }^{30} \mathrm{http} / / / \mathrm{www}$.usatoday.com/tech/products/2006-06-04-storage-drive_x.htm
} 
suggested in the Wall Street Journal and elsewhere in the business press. For example, Sony

describes use of its Memory Stick product as follows:

In addition to navigation data, Memory Stick can be used to store a variety of data for reproduction on an extensive range of compliant products. For example, photos taken during a trip can be viewed immediately on your navigation system's large-screen monitor. To print the pictures you like, stop at a store with a kiosk terminal. You can get highquality prints quickly and easily. ... With a Memory Stick compatible car audio system, you can enjoy music while you drive. ${ }^{31}$

Sony has also highlighted compatibility in its strategic partnerships, e.g., with Samsung:

This agreement strengthens the cooperative relationship existing between the two companies beyond the basic agreement reached in August of 2001. Under the 2001 agreement, Sony worked with Samsung to add Memory Stick compatibility to a range of Samsung products including DVD players, mobile phones, PCs and televisions. ${ }^{32}$

SanDisk, another major manufacturer of flash memory, similarly promotes the universality of its products:

Another benefit of SanDisk's 256 MB mini SD card is that it will allow you to move the information from your phone to another phone or to your computer. Instead of keeping all of those cute pictures of the kids on your cell phone you can move them to your computer and ensure that you can keep them forever. This mini card will also come in handy if you decide to get a new cell phone but you don't want to lose all of the information you have on your current phone. Simply save all of the information on this mini SD card and move the information to your new phone!

...SanDisk Launches V-Mate, a Video Flash Memory Card Recorder; Device Lets Consumers Record Video to Flash Cards From TV, Cable And Satellite Set-Top Boxes, DVD or VCR Players to Play Back on Mobile Phones, PDAs, Game Consoles, and Video/Music Players. ${ }^{33}$

The business press has also alluded to demand side economies of scale for flash memory

cards. For example, the Wall Street Journal reported:

Memory-card selection has increasingly important ramifications for gadget owners.

Having a card that you can pop in and out of different devices lets you do things you couldn't otherwise. You can, for instance, take a picture on a digital camera, transfer the

\footnotetext{
${ }^{31} \mathrm{http} / / / \mathrm{www} . \mathrm{memorystick.com/en/lifestyle/incar/index.html}$

$32 \mathrm{http}: / /$ www.sony.net/SonyInfo/News/Press Archive/200308/03-0806E/

${ }_{33}$ Business Wire, September 2, 2006. http://findarticles.com/p/articles/mi_m0EIN/is_2006_Sept_2/ai_n16702773
} 
memory card to your personal organizer, and then bring up the picture on its screen. It also provides a much faster way to make digital prints than stringing a cord between your digital camera and computer, which is the most common method ${ }^{34}$.

The Wall Street Journal goes on to say:

But for consumers, these small cards are causing some big headaches. In an effort to lock in customers, the biggest names in consumer electronics, companies like Fuji Photo Film Co., Olympus Optical Co. and Sony Corp., are making gadgets that work only with their own memory cards. It is akin to what the razor makers do with their razor-and-blade combinations. This strategy forces consumers to pay a heavy price: The cards are as much as $50 \%$ more expensive than others on the market.

It seems clear that the vendors of these formats see a strategic advantage in promoting their format as the leading standard. For example, consider this comment by Sony President Kunitake Ando in reference to the Sony-Samsung deal:

"Memory Stick is a network media allowing seamless connection of content and services between PCs and various digital consumer electronics. Samsung Electronics is a major semiconductor manufacturer and its manufacture and sale of Memory Stick media will accelerate the growth of Memory Stick throughout the world. Together with media, the expansion of Samsung's lines of digital cameras, mobile phones and other Memory Stick compatible products will enable Memory Stick's 'Connected World' to expand allowing customers to enjoy a broad range of content and services through a diverse array of devices. ... I am convinced that it will strengthen the Memory Stick format's position as the global standard within the memory card market."

However, despite vendors' strategic efforts and the acknowledgement by the business press of demand side economies of scale for flash memory devices, the typical self-reinforcing "loop" of a popular format becoming more popular and leading to a winner-take-all market has not occurred in the flash memory market to date. There are currently more than six incompatible formats in the market, and a number of variants deriving from each format. Further, early success has not necessarily translated into future success, as incumbent formats have been experiencing a decline in market share and as new formats continue to emerge. As depicted in Figure 7, the SmartMedia and Compact Flash formats, despite their first mover advantage (more than a $70 \%$

\footnotetext{
${ }^{34} \mathrm{http} / / /$ online.wsj.com/article email/article print/SB104873133354332300-IFheoZinKJ6xJupZoCpeqaAdZ.html
} 
combined share in 2002), have both lost their once leading positions to the Secure Digital format, the current leader with a market share of $37 \%$. The rest of the market is split by a variety of standards including: Memory Stick and Memory Stick Pro (combined 22\% share), xD Picture (12\% share) and Multimedia cards ( $5 \%$ share) with little evidence of market consolidation.

These market outcomes raise two important questions: (1) Why is there little evidence of standards convergence in a market that desires compatibility and would benefit from network effects, and (2) What distinguishes the flash memory card market from other markets with similar characteristics?

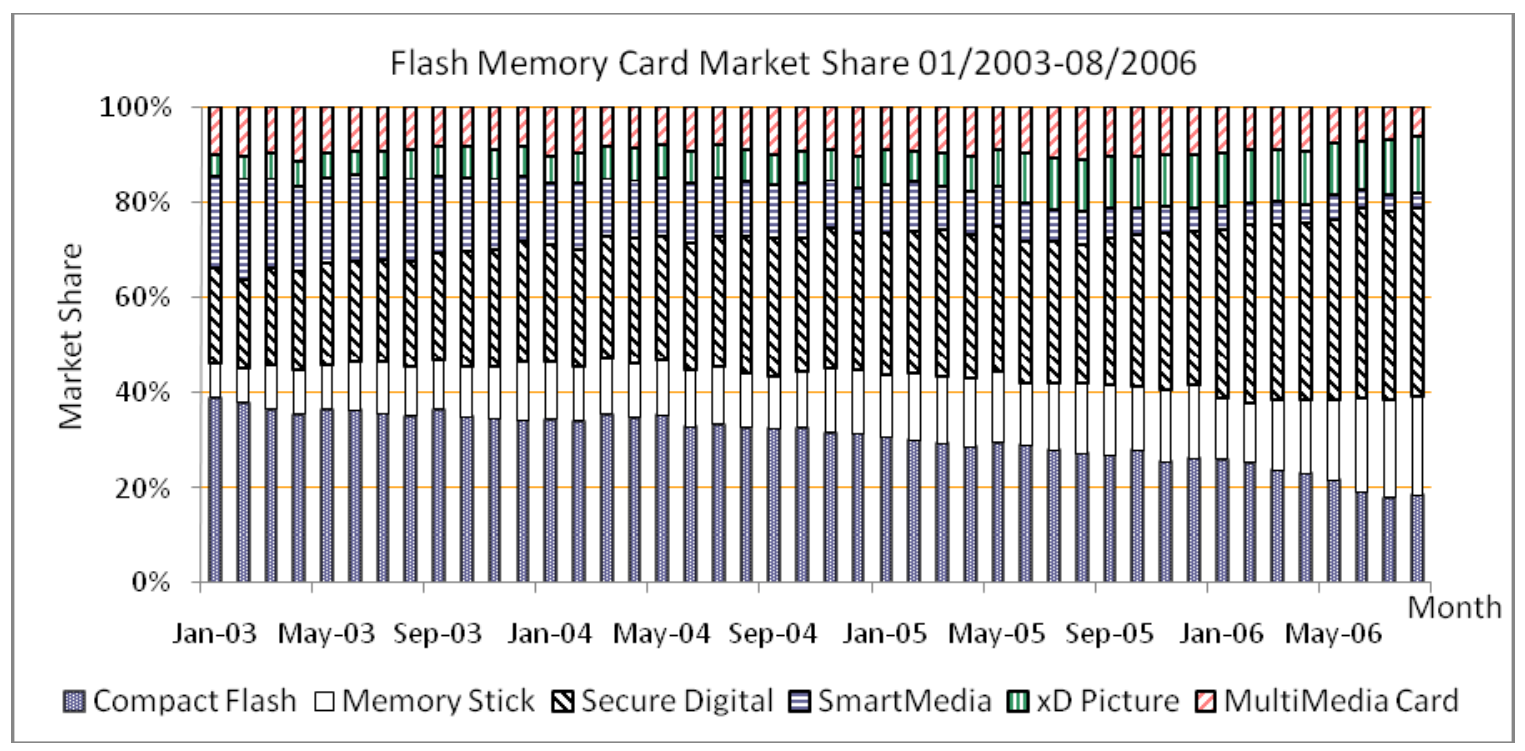

Figure 7. Flash Memory Card Monthly Market Share - January 2003 to August 2006

In contrast to other IT Markets studied in the network effects literature, a candidate explanation for the structure of the flash memory card market involves both the digital nature of flash memory products and the associated presence of conversion technologies. Flash memory cards can store any information in digital format, which means that, unlike many other technologies, their contents can be transferred without loss of quality. Additionally, there is a widespread availability of inexpensive PC- and USB-based converters, allowing for easy 
conversion of data between various card formats. The existence of these conversion technologies provides for compatibility across different formats without compromising product performance or features (Farrell et al., 1992). This aspect of the flash memory market has not typically been observed in other markets for analog products with network effects. For example, converting between the VHS and Betamax videotape standards was costly and resulted in signal loss (Cusumano et al., 1992).

Given the rich dynamics going on in the flash memory card market, in this Chapter we empirically examine the role of digital converters in shaping the competition in this market. Our results suggest that, in the presence of low cost conversion technologies and digital content, the probability of market dominance driven by network effects can be lessened to the point where multiple incompatible standards are viable. We find that in the flash memory market the increasing adoption of digital converters reduces the impact of the installed base on the product price premium, despite evidence of network effects. In particular, digital converters reduce the price premium of the leading formats more than they do that of the minority formats. Not only is the impact of network effects less significant when there is greater adoption of digital converters, but market concentration also decreases as digital converters are widely available, suggesting increasing competitiveness with converter adoption.

\subsection{An Overview of the Flash Memory Market}

\subsubsection{Evolution of Flash Memory Card Formats}

Flash memory is a form of non-volatile, electrically rewritable memory. Unlike PC memory, Flash memory can store data for an indefinite period without any power supply. In addition, flash 
memory offers almost as fast read access times as volatile RAM and better shock resistance than a hard disk. Therefore, it has become the most popular storage media format in digital consumer electronics such as digital cameras, digital camcorders, MP3 players, cell phones and PDAs, and continuous growth is expected to be sustained by increasing demand from the expanding digital application market.

Flash memory was invented by Dr. Fujio Masuoka while working for Toshiba in 1984. In 1988, Intel saw the market potential for flash memory and began to commercialize its production. The first flash memory produced was a NOR-based flash memory chip. NOR flash memory has long erase and write time with a relatively short lifespan of 10,000 to 100,000 rewriting operations. These features make it suitable to be used in computer BIOS and firmware that are less frequently accessed and modified. Most of the early flash-based storage media used NOR flash chips until the NAND-based flash memory appeared in the market and outperformed NORbased flash memory in both speed and cost.

NAND-based Flash was developed by Toshiba in 1989. It has shorter erase and write time, higher density, lower cost per bit than NOR-based flash, and ten times the endurance (up to 1,000,000 rewriting operations). These advantages over NOR flash memory rapidly made it into the market of PC cards and various removable storage devices. Foreseeing the brighter prospect of NAND flash over NOR flash, in July, 1992, IBM and Toshiba formed an alliance to develop NAND-based flash memory cards.

At the same time, SanDisk, a California-based company specializing in flash memory data storage products also entered the flash memory card market with a cross-licensing agreement with Intel. In November, 1994, SanDisk Corporation's introduction of CompactFlash (CF) was a watershed event for the users of computers, cameras and consumer electronics products. 
SanDisk's first CF cards were originally based on 4MB Intel NOR flash chips built with SanDisk's proprietary 0.5 micron technology. The capacities ranged from $1 \mathrm{MB}$ to $4 \mathrm{MB}$. These cards weighed about half an ounce, are approximately the size of a matchbook, and are available in Type I and Type II forms ${ }^{35}$, like the PC Card format.

The emergence of CompactFlash technology resulted in the introduction of a new class of advanced, small, lightweight and low-power mobile digital products that significantly increase the productivity of people who use these digital devices intensively, which, in return, greatly stimulated the demand for flash memory cards.

One year after CompactFlash debuted in the market, Toshiba introduced the first NANDbased flash application - a unique data storage device called "Solid State Floppy Disk Card" (SSFDC) at the Las Vegas COMDEX'95. At that time the SSFDC was a small, floppy diskshaped memory card that incorporated a 2MB NAND flash memory. Unlike standard NAND type flash memory, the SSFDC was housed in a package which can be easily interchanged between systems. The interface circuitry is external to the actual storage media and resides either in the host system or in an adapter card.

To enable SSFDC to be used with PC expansion slots, Toshiba also announced a Solid State Floppy Disk Adapter (SSFD). The SSFD was designed with the same size and specifications as the PC Card standard. Users can insert the small SSFDC into the adapter as an alternative to the conventional flash memory PC Card. The advantage to this "card-in-card concept" is that data can be stored on one SSFDC until each reaches capacity, and can then be replaced with a new SSFDC using the same adapter card. The unprecedented flexibility of this solution enabled an infinite number of storage cards based on SSFDC chips to be used with one SSFD, providing a

\footnotetext{
${ }^{35}$ The only difference between Type I and II is that Type II cards are thicker
} 
cost-effective alternative to buying the same number of flash memory PC Cards. For example, the price for the 4MB SSFDC was $\$ 40$ and for the SSFD was $\$ 75$, while a single 4MB flash memory PC card cost about $\$ 80$ at that time.

In July 1996, to better promote SSFDC in the growing small form factor storage market, Toshiba registered its SSFDC products under SmartMedia (SM) trademark. As the thinnest $(0.76 \mathrm{~mm})$ and the lightest $(2 \mathrm{~g})$ memory card of the time, SmartMedia cards quickly became the dominant storage media in the digital electronics. Its compatibility (through the use of the adapter) with floppy drive and PC card also allowed it to reap the benefits of the large install base of these two devices, leading to a unparalleled competitive advantage over other memory card formats.

In response to SmartMedia's technological improvement, SanDisk invested heavily in improving the capacity of the CompactFlash card. CompactFlash began to use NAND flash chips as it offers much higher density and lower cost. As the density of flash memory increases, considerably higher capacities can be achieved in the same size form factor. With continuous efforts, SanDisk expanded CompactFlash with 8MB technology in 1996, 16MB in 1998, and 32MB in 1999. At the same time, consumer prices declined as higher capacities can be obtained from the same number of silicon wafers. Demand for more storage increased over time.

Meanwhile, in consideration of integrating a series of computer and electronic products and extracting extra profits from its large user base, Sony began to enter the flash memory market with a unique flash memory device, Memory Stick (MS). Launched in 1998, Sony's memory stick was designed to store still images, digital video, music, computer data, voice recordings, and other content. Memory Sticks are about the size of an AA battery and have a transfer rate of around 1.5 MBit per second as opposed to $1.0 \mathrm{MBit} / \mathrm{s}$ for SmartMedia and $1.2 \mathrm{Mbit} / \mathrm{s}$ for 
CompactFlash at that time. By October, 1999, Memory Stick was available in 4MB, 8MB and 16MB capacities. Unlike CompactFlash and SmartMedia cards, Memory Sticks are accepted primarily by Sony products such as camcorders, digital cameras, MP3 players, selected CLIÉ Handhelds, and VAIO notebooks. The large user base for Sony electronic products soon brought Memory Stick increasing popularity in the flash memory market. In the first quarter of 1999 , Sony had shipped a total of 3 million Memory Sticks in the global market ${ }^{36}$.

As the demand for flash memory increased in the market of digital image, other consumer electronics markets such as cell phones, MP3 players and PDAs also emerged to take advantage of the small-size, solid-state data storage solution. As a result, several other flash memory formats were developed, further intensifying the competition already existed in the market.

The Multimedia card (MMC), a joint development between SanDisk and Siemens AG, was introduced on Nov 5, 1997. The Multimedia card weighs less than two grams and is the size of a postage stamp. It is a removable device about one-fifth the size of the CompactFlash memory card. The packaging is a simple molded package with a seven pin serial interface. The simple serial interface offers easy integration into various devices regardless of the microprocessor being used. Aside from providing additional storage for digital communications devices, Multimedia Card also provides storage for Global Positioning Systems (GPS), Digital camcorders and MP3 players. In March, 1998, Nokia introduced world's first mobile communications product to use SanDisk's Multimedia card and Pontis GmbH also announced the first portable MP3 Player with the Multimedia card.

Another popular format currently supported by more than 500 companies, Secure Digital (SD) card, was developed by SanDisk, Toshiba and Matsushita shortly after the introduction of

${ }^{36}$ Oct 4, 1999 www.cnn.com 
Multimedia cards. These two formats are nearly identical with several exceptions. The most important difference is that, as the name suggests, the SD format offers built-in cryptographic security based on the Secure Digital Music Initiative (SDMI) requirements. These cards are growing in popularity because of their tiny size, a higher data-transfer rate (starts at $2 \mathrm{Mbit} / \mathrm{s}$ ) and the patent capability - the ability to lock copyright material, which ease a lot of concerns from the music and movie industries about digital content privacy. The SD card offers the ability to design very small consumer friendly devices and is therefore ideally suited for portable digital audio players, handheld computers, PDAs, smart phones, car navigation systems and electronic books.

Moreover, in 2003 SanDisk unveiled at CeBit the Mini SD, which is half the size of a typical SD card and is designed for mobile phones and other even smaller devices. Mini SD currently handles up to $1 \mathrm{~GB}$ but is expected to reach a capacity of $4 \mathrm{~GB}$ later in 2006 . The Mini SD card has been adopted by the SD Card Association as an ultra-small form factor extension to the SD card standard. Compared to standard SD cards, the Mini SD card saves more than $40 \%$ of the printed circuit board area and more than $60 \%$ of the volume required to support the card in a portable device. A key benefit of the Mini SD card is that it is both electrically and software compatible with the existing SD standard. It uses the same SD interface, including security features for Content Protection Rights Management (CPRM) as the standard SD card. To allow interoperability with standard SD devices, SanDisk also offers an adapter that converts the Mini SD card into the SD card form factor. The adapter allows the Mini SD card to fit into existing SD card slots, and thereby provide compatibility with the rapidly growing number of SD compatible devices in the market.

In 2004, to further exploit the expanding market of ultra-small flash memory cards, the 
counter part of Mini SD in the MMC family, the Reduced-Size Multimedia Card (RS-MMC) was introduced. RS-MMC is about half the size of the MMC. By using an adapter, an RS-MMC can be used in any MMC (or SD) slot. A notable feature of the MMC family is that the Multimedia Card Association (MMCA), the organization that defines the physical, functional and interface specifications of MMCs, promotes an open, royalty-free policy towards the production and development of the MMCs. While the SD cards family, governed by the SD Card Association, follows a different strategy of charging a licensing fee to members and royalty fees to any company that wants to manufacture the format.

As new formats emerged to partition the market, the expansion of the SmartMedia's storage capacity was severely limited by their wafer-thin form factor. The maximum capacity of SmartMedia remained at $128 \mathrm{MB}$, as the size of images captured by digital cameras gets larger and larger, this constraint became a fatal drawback for a memory card. Soon after its peak in 2001, SmartMedia faded out of the market as most digital devices have stood away from its interface since 2001. Market share declined rapidly and its demise seemed inevitable after Olympus and Fuji, the two major manufacturers that adopted SmartMedia in a big way, stopped to use this interface in their digital cameras.

Likewise, Sony's Memory Stick was plagued with the same 128MB capacity constraint. Nevertheless, Sony was able to overcome this limitation by reengineering its products and forming strategic alliance with SanDisk. In September, 2001, Sony and SanDisk signed a cooperation agreement. Under the agreement, SanDisk will supply under market-competitive terms a portion of Sony's NAND flash memory requirements and Sony will supply SanDisk with completed Memory Stick cards that SanDisk will resell under its own brand through its retail channel. In 2003, Sony extended its Memory Stick licensing agreement with SanDisk through a 
cross-licensing deal that allow SanDisk to manufacture and sell Memory Stick cards, including Memory Stick, Memory Stick Pro, Memory Stick Duo, under the SanDisk brand name.

This cooperation turned out to be a successful move. In 2003, Sony and SanDisk introduced two new versions with larger capacities. Memory Stick Duo stores 256MB, and is only one-third the volume and half the weight of the standard Memory Stick card. The target market was the small form factor flash memory market where Mini SD and RS-MMC held dominance. Another variant of Memory Stick, Memory Stick Pro, also jointly developed by Sony and SanDisk, was intended for use in recording and streaming media devices. It has the same external dimensions as a standard Memory Stick ( $50 \mathrm{~mm}$ by $21.5 \mathrm{~mm}$ by $2.8 \mathrm{~mm}$ ) but offers greater capacity than the standard Memory Stick's 128MB. Memory Stick Pro cards are currently available in capacities up to $4 \mathrm{~GB}$ and the card's design allows a theoretical capacity limit of $32 \mathrm{~GB}$, according to Sony. Sony has also introduced the MagicGate Memory Stick, which includes security via the SDMI standard and is geared for cell phones and other devices that demand data encryption. These products enlarge the Memory Stick family by incorporating extra features aiming at different market segments. As a result of these efforts, Sony began to steadily gain market share and was able to charge a higher price premium for its enlarging user base. By the end of 2002, Sony had produced about 1,600,000 cards per month and had taken up 20 percent global market share. Meanwhile, Fortune Magazine added SanDisk to its list of Top 40 Market Performers in 2003 and its shares surged in the stock market.

Other than the above flash memory formats, another major competing format, the $\mathrm{xD}$ Picture card ( $x D$ stands for Extreme Digital), was developed by Fuji Film and Olympus to compete with the similarly sized Secure Digital and Memory Stick cards. The two companies began to introduce digital cameras that use the $\mathrm{xD}$ Picture card in 2002. Cards ranging from 
$16 \mathrm{MB}$ to $128 \mathrm{MB}$ appeared in the second quarter of 2003 , followed by a $256 \mathrm{MB}$ card in December, 2003. The format has the capability to go up to $8 \mathrm{~GB}$, according to the technical specification listed on Olympus website ${ }^{37}$. To alleviate the impact of incompatibility with the existing SmartMedia format, Fuji Film and Olympus offer an external xD-Picture card to SmartMedia adapter that can read xD cards from a SmartMedia port. However, the maximum capacity of the $\mathrm{xD}$ card to be used in these adapters are subject to the $128 \mathrm{MB}$ capacity constraint and other restrictions of the SmartMedia reader. The two companies also provide PC cards and CompactFlash adapters that allow xD Picture cards to be used in notebooks and other devices.

The introduction of the $\mathrm{xD}$ Picture cards and the strategic abandonment of backward compatibility virtually implied the death of SmartMedia, which looks oversized and slow compared to its competitors. Surprisingly, unlike its predecessor, xD Picture card started out as a proprietary standard. Only digital devices manufactured by Fuji and Olympus adopt this interface. Even though both companies are confident that the $\mathrm{xD}$ card will be the leading format among the next generation flash memory cards. The actual market penetration for $\mathrm{xD}$ Picture cards is far from being optimistic, as the market share has remained at single digit since 2002.

\subsubsection{Conversion Technologies in the Flash Memory Market}

An interesting phenomenon that arises in the flash memory card market is that: as the needs for flash cards grew, formats multiplied. This is not consistent with the prediction of the network effects theory, which suggests that when there exists lower demand for variety in the market (which is clearly the case in the flash memory market since consumers don't care about the format of the memory card, rather, they will be much better off having one single format) and high economies of scale, the market tips and there would be one main survivor in a standards war

\footnotetext{
${ }^{37} \underline{\text { http://www.olympusamerica.com/cpg_section/cpg_pressDetails.asp?press } \mathrm{No}=192}$
} 
(Shapiro and Varian, 1999). Several reasons could be hypothesized for the enlarging array of memory card formats. First, it might well be that the market has not evolved long enough for the tipping to take place. However, since tipping occurs in the VCR market within ten years after the standards war began, and the first flash memory product was brought into the market more than thirteen years ago, the length of time needed for a dominant standard to emerge is less likely to be the major reason for the lack of standardization in the flash memory market. Second, it is likely that network effects are not strong enough to warrant a "winner-takes-all" outcome. Third, the network effects could be mitigated by some exogenous factors, such as the existence of interplatform gateway technology (David and Bunn, 1988), namely, flash memory card converters. In this section, we will briefly describe the history of the conversion technology in the flash memory card market and empirically test the second and the third explanations in $§ 4.3$.

As flash memory card manufacturers and consumers are struggling for a more compatible format. Great efforts have also been devoted by hardware manufacturers to provide support for multiple leading memory card formats. One of the reasons driving these efforts is that early digital devices, for example, digital cameras, use serial interface to transfer data. The speed is much slower than today's prevailing USB interface. Sometimes it takes several minutes to upload a digital image. Furthermore, computer operating systems can not automatically recognize the digital devices when they are connected through the serial cable. In most cases, a driver is required to enable communications between the device and PC. These technical constraints had made it very inconvenient to transfer data between digital devices. The problem was further intensified by the incompatibility across different memory card formats. As an alternative to serial cables, memory card readers provide a fast and easy way of communications between digital devices. Card readers are more easily recognized by most PCs as they use the 
more universal USB interface and can be treated as a removable drive. Without installing any driver, consumers can plug a memory card into a reader and transfer the data to PC or other digital devices at a speed 100 times faster than from a serial port. The early memory card readers can only read one format. As technology advanced and formats multiplied, multiple card readers were introduced into the market. These readers have multiple slots and are capable of reading almost all the formats available in the market. The emergence of these memory card readers greatly facilitates communications among various digital devices. It eliminates the hassle of carrying the cable and device driver. Most readers are portable and inexpensive, making them the most favorable accessories of the digital consumer electronics.

SanDisk was among the first to introduce a memory card reader for its products. In 1998, SanDisk introduced the first "ImageMate" memory card reader for its CompactFlash cards. The action was followed by a lot of flash card manufacturers such as Lexar, Viking, SimpleTech, Sony, Olympus, etc. Currently, a multiple card reader only costs about $\$ 20$ to $\$ 35$ in the market.

As floppy disk has approached the end of its life, which media format will emerge as the substitute has been a topic of discussions in both the industry and trade press. At present, USB flash drives, CD-ROMs and DVD-ROMs seem to be filling floppy drive's role. Nevertheless, from both technical and functional standpoints, flash memory cards are more likely to be a successor to the floppy drives in next generation PCs. As is evident from the trend that more and more PC and laptop manufacturers are providing a flash memory card reader as a standard I/O component of their systems and it is actually serving the function of the floppy drive. Sony and Samsung are now building both Memory Stick and SD slots into its laptops, and HP's Photosmart 100 printer accepts a trio of cards: CompactFlash, SmartMedia, and Memory Stick. One of the advantages of flash memory card over USB flash drive and other storage media is that 
it can be used in multiple digital devices. In that regard, it enlarges the scope of data exchange from between PCs (as offered by floppy drives) to across PCs and multiple digital devices. Flash memory cards also outperform the other potential competitors - Zip Drive, I-Omega drive, CDROM or even DVD-ROM with its greater room for capacity improvement, faster read/write speed, lower cost of production and much smaller form factor (portability). In light of these technical and economic advantages, it is more likely that flash memory card will eventually substitute floppy drive and become the universal data transfer media in future PCs.

Given flash memory's wide usage in various digital devices and its potential impacts on the PC and consumer electronic industries, compatibility across formats becomes a major obstacle for flash memory cards to formally take over floppy drive in PCs. Consumers will be much better off having a single unified format for all the electronic devices they possess. Manufacturers can enjoy greater supply side economy of scale and positive network effects from format compatibility. The society will be better off as no excess efforts will be wasted on designing and producing multiple incompatible formats. Eventually, conversion costs can be saved too as there is no need to transfer the data through any intermediary. Once the market for flash memory card is fully standardized, portable multiple memory card reader can be reduced to a single slot fixed drive in PC.

Ideally, standardization can be attained through the power of the "invisible hand". However, even when government regulation is involved, the superior technology (i.e. HDTV in US) has to sacrifice some performance in return for being chosen as the market standard (Farrell et al., 1992). In addition, negotiation and coordination cause long delay which imposes significant loss on both consumers and manufacturers. In any case, high costs of standardization offset the benefits brought by positive network externalities. 
In the absence of a successful mechanism to achieve standardization, the provision of a conversion technology might help avoid the undesirable sub-optimal social outcomes since it allows sufficient time for the market to select the technically superior technology and reduces the risks of be stranded as a result of pursuing a new technology. This follows exactly what Shapiro and Varian (1999) described in their book as the "controlled migration path" through which migration from the old technology to the new technology occurs smoothly without radical impact on compatibility and sacrifices in design and performance. In the context of the flash memory market, with the presence of a conversion technology, the potential network externality might be lessened to the degree that several competitors can coexist in the technology transition period. The minority formats are more likely to survive the standards war than in the absence of the conversion technologies. We further explore the market dynamics in $§ 4.3$.

\subsection{Research Model and Hypotheses}

Since the role of conversion technologies is of primary interest when network effects exist, identifying the presence and magnitude of network effects is an important first step in evaluating the nature of standards competition in the flash memory card market. As discussed in $§ 1.3$, we adopt the same notion of price premium to capture network effects. In the flash memory market, price premium of a flash memory card measures the importance (or value) a consumer places on the size of this flash memory format's installed base, controlling for other flash memory card attributes such as brand, capacity, speed, etc. Note that since price premium only measures the relative impact of a particular product attribute (i.e. network size) on listed price, it does not always move in the same direction as listed price. This distinction is especially important in IT industry (and the flash memory market in particular) where a declining product price is 
commonly observed due to rapid technological development. Although the listed price is declining, a product format could still enjoy a positive price premium from its installed base if consumers believe that compatibility is important.

Our first hypothesis considers the effects of market power and reasons whether dominant producers can charge more for their flash memory cards. In particular, the size of the installed base may play a dual role with respect to the price premium of a flash memory card. On the one hand, when network effects are present, a larger installed base for a product format confers greater utility to consumers. Hence the price premium of a flash memory format could be expected to vary positively with the size of the flash memory format's installed base. For example, in the context of software, consumers of the dominant operating system will find that they can use a larger number of software applications than users of a competing, but minority system. On the other hand, due to economies of scale in production, a flash memory format with a larger sales volume can enjoy a greater cost advantage over those with a smaller sales volume. Hence the price premium of a flash memory format could also be expected to vary negatively with the size of its installed base.

According to the classic network effects theory, if the utility of a product increases with the installed base for the product, there will tend to be one dominant standard in the market, and the firm offering this standard should be able to charge a higher price, reflecting the higher value that consumers perceive. However, in contrast to this typical scenario, in the flash memory card market there is little evidence of standards convergence despite consumers' desire for product compatibility. Thus, an alternative possibility is that the magnitude of positive network effects is not strong enough to warrant a dominant firm market outcome. The dual role of the installed base allows us to empirically examine this alternate explanation. Given the magnitude of 
network effects, we expect that if there exists a strong demand for compatibility, the price premium due to market power will dominate the price reduction effect due to production economies of sale, such that:

Hypothesis 1a: in the presence of strong network effects, the price premium of a flash memory card is positively associated with the size of the installed base of the same format.

Conversely, if there is no demand for compatibility in the flash memory market, or such demand is insufficiently strong, the price of a product will depend largely on its product attributes and production cost. That is, the increment in the price attributable to network effects will be smaller. Hence in this alternative case we would expect that:

Hypothesis 1b: in the absence of strong network effects, the price premium of a flash memory card is negatively associated with the size of the installed base of the same format.

Hypotheses $1 \mathrm{a}$ and $1 \mathrm{~b}$ serve as two competing hypotheses about the magnitude of network effects in the flash memory market, which is an important prerequisite for the analysis of the impact of conversion technologies in the flash memory market.

Our second hypothesis considers how the introduction of digital converters affects the price premium of flash memory cards and argues that digital converters increase the usefulness and thereby the value of flash memory cards, in general (i.e., at an average level of the installed base). When digital converters are available, consumers of flash memory cards with incompatible formats can still exchange content with each other and thereby obtain the benefits of compatibility. Thus, digital converters can increase the consumption utility across flash memory card products of different standards. This implies that greater adoption of digital converters will increase the utility, and thus the price premium, of flash memory cards, even if the cards are not compatible. Therefore: 
Hypothesis 2: the price premium of a flash memory card is positively associated with the adoption of digital converters.

Our third hypothesis considers the interaction between producers' market power and the introduction of digital converters and posits that the presence of converters increases product substitutability and thereby reduces the value of flash memory cards, especially for the dominant producers (i.e., those with an installed base that is larger than average). When making a technology choice, the wide presence of digital converters reduces the consumer's risk of being stranded on a new, but less popular standard, as the chances for survival of a new technology are larger when network effects are less significant. In addition, digital converters allow products with different formats to be compatible. As a result, when digital converters are widely present, consumers are not as motivated to purchase a dominant standard as there is less benefit from it; this lowers the producer's market power and consequently, its price premium due to network effects. Following this logic in the context of flash memory cards, a greater adoption of digital converters will especially affect the price premium of the dominant standard. Producers of flash memory card standards with a larger installed base are expected to lose more market power than those with a smaller installed base, as they have more value to lose from being a dominant standard when converters are present. Thus, we expect that:

Hypothesis 3: the adoption of digital converters reduces the impact of the installed base on flash memory card price premia such that the price reduction effect is stronger for products with a larger installed base than for products with a smaller installed base.

Finally, in Hypothesis 4, we consider the effects of digital converters on market concentration for flash memory card producers. Classic network effects theory predicts that product markets will tip toward a single dominant standard when there are strong network 
effects. Consequently, market concentration will typically increase once the installed base of the leading standard has reached a critical mass. However, as argued here, it is possible that the presence of conversion technology will affect the nature of competition as conversion technology can offset some of the impact of network effects. If this is true, it is less likely that a dominant producer will emerge in a market with an increasing presence of converters. The flash memory card market could then be expected to be less likely to tip toward one dominant producer as many different formats can be converted to become compatible. Therefore:

Hypothesis 4: Market concentration of flash memory card producers decreases as the adoption of digital converters increases.

Figure 8 summarizes these four hypotheses and illustrates the conceptual framework for our empirical analysis along with the predicted directions of the hypothesized interaction between the adoption of digital converters and product's installed base. Figure 8 also illustrates two important market outcomes of network effects: price premium and market concentration. Control variables are shown in dashed boxes.

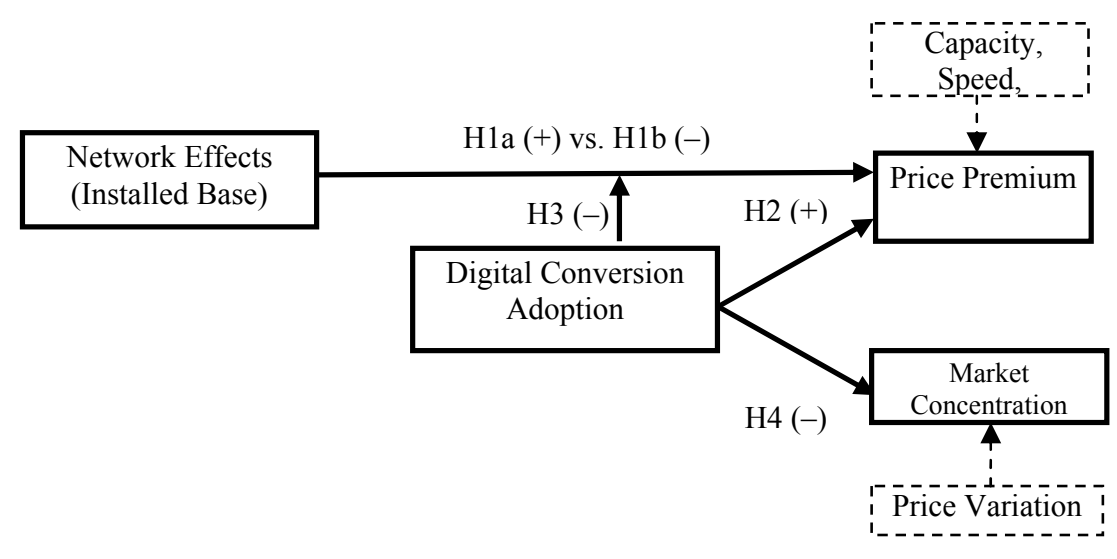

Figure 8. Research Model and Hypotheses 


\subsection{Data and Measures}

To test our hypotheses we assembled a large panel dataset including data on the products and producers in the flash memory card market. The flash memory card market offers a particularly appropriate test case for our hypotheses, as the co-existence of multiple formats, despite the presence of network effects, and the possibility to convert data without quality loss suggest that this is a market with the potential for dynamics significantly different than those previously studied. And, in fact, the market has been quite volatile since flash memory products were first launched in 1994; with many different formats emerging and competing for dominance.

We selected a sample period from 2003 to 2006 for our analysis since this is a critical period in the development of the flash memory card market during which most of the current formats are present. Our primary data were generously provided by the $\mathrm{NPD}^{38}$ research group. These data include detailed information on monthly retail prices and unit sales data of the major flash memory cards and digital converters sold each month by major U.S. retailers from January 2003 to August 2006. To supplement the NPD dataset we also implemented a software agent which automatically retrieved flash memory card prices, sales rank and product attributes from Amazon.com on a daily basis. Finally, we gathered the flash memory cards' product specification data from each flash card format's official trade association.

The final dataset consists of 15,091 observations that cover all six major flash card formats and 45 major brands, with capacities ranging from $4 \mathrm{MB}$ to $8 \mathrm{~GB}$. As a result we have a total of 706 product panels ${ }^{39}$ across 44 months. Each product panel represents a format $i$, brand $j$, capacity $k$ flash memory card sold during month $t$. The product level panels allow us to control

\footnotetext{
${ }^{38} \mathrm{NPD}$ (www.npd.com) is a leading global research company. The firm provides critical consumer and retail market information based on data collected from point-of-sale (POS) terminals in major retailers across a range of outlets.

${ }^{39}$ Note that this is not a balanced panel due to the fact that some brands may only produce a type of flash memory cards at certain capacities, and some flash memory cards are discontinued after a certain period of time.
} 
for variation due to formats, capacities and brands, whereas the time series data allow us to control for variation due to any potential "seasonal fluctuations" (e.g., holiday sales surge) and time trends (e.g., declining costs). The distribution of observations, broken down by format and year, is shown in Table 11 below.

Table 11. Distribution of Flash Memory Card Observations by Card Type/Year

\begin{tabular}{|l|l|l|l|l|l|l|}
\hline Card Type & $\mathbf{2 0 0 3}$ & $\mathbf{2 0 0 4}$ & $\mathbf{2 0 0 5}$ & $\mathbf{2 0 0 6}^{*}$ & Total & $(\%)$ \\
\hline Compact Flash Card & 1205 & 1309 & 1412 & 921 & 4847 & $(32.12 \%)$ \\
\hline Memory Stick & 334 & 453 & 492 & 343 & 1622 & $(10.75 \%)$ \\
\hline Multimedia Card & 317 & 360 & 453 & 267 & 1397 & $(9.26 \%)$ \\
\hline Secure Digital Card & 742 & 1063 & 1386 & 1251 & 4442 & $(29.43 \%)$ \\
\hline Smart Media Card & 583 & 461 & 387 & 200 & 1631 & $(10.81 \%)$ \\
\hline xD Picture Card & 190 & 264 & 385 & 313 & 1152 & $(7.63 \%)$ \\
\hline Grand Total & 3371 & 3910 & 4515 & 3295 & 15091 & \\
\hline
\end{tabular}

${ }^{*}$ Note that 2006 observations include up to August, 2006

Table 12 below provides definitions of the variables used in our analysis.

Table 12. Definitions of Variables

\begin{tabular}{|c|c|}
\hline Variable Name & Definition \\
\hline CardPrice $_{i, j, k, t}$ & $\begin{array}{l}\text { deflated (in } 2003 \text { Q1 dollar) average retail price of a format } \boldsymbol{i} \text {, brand } \boldsymbol{j} \text { and capacity } \boldsymbol{k} \text { flash } \\
\text { memory card sold during month } \boldsymbol{t} \text {. }\end{array}$ \\
\hline InstalledBase $_{i, t}$ & percentage of cumulative sales volume (in units) of format $\boldsymbol{i}$ flash cards as of month $\boldsymbol{t}$ \\
\hline ConverterAdoption $_{t}$ & $\begin{array}{l}\text { number of digital converters }{ }^{\dagger} \text { sold as a percentage of the total number of flash memory } \\
\text { cards sold in month } \boldsymbol{t}\end{array}$ \\
\hline Capacity & capacity (in MB) of a flash memory card \\
\hline Speed & average read/write speed of a flash memory card \\
\hline D_CF & dummy variable, 1 if the flash memory card is compatible with the Compact Flash format \\
\hline D_MS & dummy variable, 1 if the flash memory card is compatible with the Memory Stick format \\
\hline D_MMC & dummy variable, 1 if the flash memory card is compatible with the Multimedia Card format \\
\hline D_SD & dummy variable, 1 if the flash memory card is compatible with the Secure Digital format \\
\hline D_SM & dummy variable, 1 if the flash memory card is compatible with the SmartMedia format \\
\hline D_xD & dummy variable, 1 if the flash memory card is compatible with the $\mathrm{xD}$ Picture format \\
\hline D_Brand $\boldsymbol{j}$ & a "make effect" dummy variable, 1 if the flash memory card is manufactured by Firm $j$ " \\
\hline D_Quarter $\boldsymbol{q}$ & a seasonal effect dummy, 1 if the observation belongs to quarter $\boldsymbol{q}(\boldsymbol{q}=1,2,3$ or 4$)$ \\
\hline D_Year $y$ & a year dummy, 1 if the observation belongs to year $y(y=2003,2004,2005$ or 2006) \\
\hline
\end{tabular}

The key variables for our analysis are price and the installed base of a flash memory card model, as well as the adoption level of converters. We compute flash memory card price, CardPrice $_{i, j, k, t}$, as the deflated (in 2003 Q1 dollars) average retail price of a format $i$, brand $j$, 
capacity $k$ flash memory cards sold during month $t$ (Brynjolfsson and Kemerer, 1996). The current installed base, InstalledBase $i$, , is the percentage of the cumulative units of format $i$ compatible flash memory cards sold in month $t$. The level of digital converter adoption, ConverterAdoption $_{t}$, is the number of digital converters sold as a percentage of the total flash memory cards sold during month $t$. We include two product attribute variables, capacity and speed, as control variables to account for possible variations due to memory card size and product specifications. We capture other format specific product features with six format dummy variables. Finally, we create three other dummy variables to control for brand, seasonal and year effects.

Table 13. Descriptive Statistics

\begin{tabular}{lcc}
\hline Variable & Mean & Std. Dev. \\
\hline CardPrice $_{i, j, k, t}$ & 61.08 & 85.29 \\
InstalledBase $_{i, t}$ & 0.23 & 0.13 \\
ConverterAdoption $_{t}$ & 0.65 & 0.23 \\
Capacity & 420.74 & 804.97 \\
Speed & 20.68 & 15.04 \\
\hline
\end{tabular}

We present descriptive statistics in Table 13 and the correlations of the key variables in Table 14. The inter-correlations between the variables in our model are generally low. As expected, two control variables, capacity and speed, are both positively correlated with flash memory card price, with cards having larger capacities and faster speeds commanding higher prices, ceteris paribus. The other two key variables, flash card installed base and converter adoption are modestly correlated with price, with installed base having a positive correlation and converter adoption a negative correlation.

Table 14. Correlations of Key Variables

\begin{tabular}{lccccc}
\hline & CardPrice $_{i, j, k, t}$ & InstalledBase $_{i, t}$ & ConverterAdoption $_{t}$ & Capacity $^{\text {Speed }}$ \\
\hline CardPrice $_{i, j, k, t}$ & 1.000 & & & & \\
InstalledBase $_{i, t}$ & $0.056^{* *}$ & 1.000 & & & \\
ConverterAdoption $_{t}$ & $-0.096^{* *}$ & 0.010 & 1.000 & & \\
Capacity & $0.637^{* *}$ & $0.117^{* *}$ & $0.237^{* *}$ & 1.000 & \\
Speed & $0.192^{* *}$ & $0.237^{* *}$ & 0.011 & $0.231^{* *}$ & 1.000 \\
\hline$*: \mathrm{p}<5 \% ; * *: \mathrm{p}<1 \%$. & & & & &
\end{tabular}




\subsection{Empirical Models, Estimation and Results}

\subsubsection{Network effects, digital converters and price premia}

We construct several econometric models to test our hypotheses. Given that the effect of converters is nonlinear, it cannot be captured by the independent predictor of product price in the classic linear hedonic model framework. Therefore, we test Hypotheses 1 through 3 by modifying the classic hedonic regression model to include an interaction term between installed base and the adoption of digital converters ${ }^{40}$.

[Model 1]

CardPrice $_{i, j, k, t}=\alpha_{0}+\alpha_{1}$ InstalledBase $_{i, t-1}+\alpha_{2}$ ConverterAdoption $_{t-1}+$ $\alpha_{3}$ InstalledBase $_{i, t-1} *$ ConverterAdoption $_{t-1}+\alpha_{4}$ Capacity $\alpha_{5}$ Format $_{i}+\alpha_{6}$ Brand $_{j}+\alpha_{7}$ Year $+\alpha_{8}$ Quarter $+\varepsilon_{i, t}$

When the variable ConverterAdoption and its associated interaction term are both absent, Model 1 reduces to a classic hedonic price regression where the coefficient $\alpha_{1}$ represents the impact of network size on price premium and is expected to be positive and significant when there are strong network effects. However, when these two variables are included in the model, the marginal effect of the installed base on price premium is not solely captured by coefficient $\alpha_{1}$. Instead, the impact of the interacting variable also needs to be taken into account. More specifically, the marginal effect on price premium should be computed as the partial derivative of the dependent variable with respect to the variable of interest. Thus, Hypothesis 1a (or Hypothesis 1b), which predicts that, ceteris paribus, a larger installed base will increase (or decrease) the price premium of a flash memory card, can be represented as:

$$
\mathrm{H} 1 \mathrm{a}: \frac{\partial \text { CardPrice }_{i, j, k, t}}{\text { InstalledBase }_{i, t-1}}=\alpha_{1}+\alpha_{3} \text { ConverterAdoption }_{t-1}>0(\text { or }<0 \text { for } \mathrm{H} 1 \mathrm{~b}) \text {, }
$$

\footnotetext{
${ }^{40}$ We use quarterly dummy variables instead of monthly dummy variables because quarterly dummies explain the variation in price better than monthly dummy do (higher adjusted $\mathrm{R}^{2}$ ). However, the results are consistent across both specifications.
} 
when evaluated at the mean of ConverterAdoption $t_{t-1}$. Similarly, Hypothesis 2 , which predicts that the adoption of digital converters will lead to a flash card price premium, can be represented as:

$$
\mathrm{H} 2: \frac{\partial \text { CardPrice }_{i, j, k, t}}{\partial \text { ConverterAdoption }_{t-1}}=\alpha_{2}+\alpha_{3} \text { InstalledBase }_{i, t-1}>0,
$$

when evaluated at the mean of InstalledBase $e_{i, t-1}$.

Finally, Hypothesis 3, which focuses on the interaction between the installed base and converters, can be tested by examining the significance level of coefficient $\alpha_{3}$, and by conducting an F-test on the restricted model (the one without the interaction term) and the unrestricted model (the one with the interaction term).

We first estimate a restricted model (without the interaction term) and then include the interaction term in an unrestricted model to examine if the coefficient estimates and model fit statistics are sensitive to this specification change. Other variables in the restricted model include capacity and speed, as well as format, brand, and seasonal and year dummies. The brand dummies cover the top ten flash card brands in our dataset. The omitted dummy variables for the other categories are, the Smartmedia format, spring quarter, and the year 2003. Therefore, the constant term estimated in the model may be interpreted as the predicted price of a non-major brand Smartmedia card sold in the spring of 2003.

The Ordinary Least Square (OLS) regression results of both the restricted model and the unrestricted model are provided in Table 15. In the restricted model the coefficient for InstalledBase $_{i, t-1}$ is positive, and the coefficient for ConverterAdoption ${ }_{t-1}$ is negative, and only the latter is significant at the $1 \%$ level. When the interaction term is included into the restricted model the signs of coefficients for both InstalledBase $e_{i,-1}$ and ConverterAdoption ${ }_{t-1}$ remain unchanged, but both become significant at the $1 \%$ level. The interaction term is negative and significant at the $1 \%$ level as well. Before we proceed to interpret the coefficients and test the 
hypotheses, we also conduct several econometric analyses to ensure that our results are robust to various specification errors and violations of OLS estimation assumptions.

Table 15. Regression Results - Model $\mathbf{1}^{\text {\# }}$

\begin{tabular}{|c|c|c|c|c|}
\hline $\begin{array}{l}\text { Dependent Variable: } \\
\text { CardPrice }_{i, j, k, t}\end{array}$ & $\begin{array}{c}\text { OLS Regression } \\
\text { Restricted Model } \\
\text { (No interaction) }\end{array}$ & $\begin{array}{c}\text { OLS Regression } \\
\text { Unrestricted } \\
\text { (Interaction) Model }^{41}\end{array}$ & $\begin{array}{l}\text { GLS Estimation } \\
\text { Interaction Model }\end{array}$ & $\begin{array}{l}\text { 2SLS Estimation } \\
\text { Interaction Model }\end{array}$ \\
\hline Constant & $\begin{array}{l}34.691 \\
(3.34)^{* *}\end{array}$ & $\begin{array}{l}45.310 \\
(3.42)^{* *}\end{array}$ & $\begin{array}{l}43.005 \\
(3.47)^{* *}\end{array}$ & $\begin{array}{l}21.53 \\
(2.518)^{* *}\end{array}$ \\
\hline InstalledBase $_{i, t-1}$ & $\begin{array}{l}17.676 \\
(9.61)^{*}\end{array}$ & $\begin{array}{l}83.543 \\
(10.84)^{* *}\end{array}$ & $\begin{array}{l}43.573 \\
(3.97)^{* *}\end{array}$ & $\begin{array}{l}49.814 \\
(10.34)^{* *}\end{array}$ \\
\hline ConverterAdoption $_{t-1}$ & $\begin{array}{l}-35.450 \\
(11.45)^{* *}\end{array}$ & $\begin{array}{l}-41.677 \\
(11.40)^{* *}\end{array}$ & $\begin{array}{l}-20.323 \\
(1.96)^{* *}\end{array}$ & $\begin{array}{l}-75.24 \\
(11.49)^{* *}\end{array}$ \\
\hline $\begin{array}{l}\text { InstalledBase* } \\
\text { ConverterAdoption }{ }_{t-1}\end{array}$ & & $\begin{array}{l}-514.728 \\
(39.99)^{* *}\end{array}$ & $\begin{array}{l}-190.87 \\
(14.48)^{* *}\end{array}$ & $\begin{array}{l}-802.28 \\
(56.53)^{* *}\end{array}$ \\
\hline Adjusted $\mathrm{R}^{2}$ & 0.532 & 0.553 & $\begin{array}{l}\text { Log likelihood } \\
=-54658.9\end{array}$ & 0.538 \\
\hline Fit Statistic & $\begin{array}{c}\mathrm{F}(23,15067)= \\
747.9^{* *}\end{array}$ & $\begin{array}{c}\mathrm{F}(24,15066)= \\
761.47^{* *}\end{array}$ & $\begin{array}{l}\text { Wald } \chi^{2}(24)= \\
12208.97 *\end{array}$ & $\begin{array}{c}\mathrm{F}(23,14827)= \\
749.21^{* *}\end{array}$ \\
\hline
\end{tabular}

$\mathrm{N}=15,091, \mathrm{~N}_{i}=6, \mathrm{~N}_{\mathrm{j}}=45, \mathrm{~N}_{\mathrm{k}}=12, \mathrm{~N}_{\mathrm{t}}=44$ (706 panels across 44 months).

* Standard errors in parentheses. *: $\mathrm{p}<5 \%$; **: $\mathrm{p}<1 \%$.

The multiplicative nature of our model implies that the marginal effects of the linear variables can be confounded with the influence of the interaction term. To make our interpretation of the linear terms more straightforward we follow the current practice in the literature (Jaccard et al., 1990, Aiken and West, 1991, pp 35-36) and center the original interacting variables before computing the interaction term from them, which is done by subtracting the mean from every observation for both interacting variables. After centering, the means of the centered variables are zero and the correlations between the interaction term and the original variables are much smaller. ${ }^{42} \mathrm{~A}$ multicollinearity check also reveals that after centering, the condition number of the interaction model and the variance inflation factors (VIF)

\footnotetext{
${ }^{41}$ As some of the literature on network effects considers a non-linear specification, we also tested a model with an additional variable, a squared term of the installed base, to examine whether the impact of converters is sensitive to the specification of network effects. The results indicate that network effects increase at a faster rate as the size of the installed base increases (the coefficient estimate for the squared term is positive and significant at the $1 \%$ level), but the effects of converters on flash card prices are still qualitatively consistent with those obtained from the linear specification. Therefore, for ease of interpretation we report the results obtained from the linear specification of the network effects model.

${ }^{42}$ For ease of comparison, both InstalledBase $e_{i, t-1}$ and ConverterAdoption ${ }_{t-1}$ are centered in the OLS regressions.
} 
values of the interaction term and the original variables are both below the recommended threshold values of 20 and 10, respectively (Greene 2003, pp. 57-58). Therefore, we conclude that our interaction model does not exhibit multicollinearity.

A Breusch-Pagan / Cook-Weisberg test for heteroskedasticity yields a value of $\chi^{2}(1)=$ $7027.54(\mathrm{p}<0.001)$, suggesting the presence of heteroskedasticity. This is consistent with a plot of the residuals versus fitted (predicted) values, which exhibits a wider scatter with greater Xaxis values.

The Wooldridge test for autocorrelation in the panel data shows that first-order autocorrelation (AR1) cannot be ruled out for our data set. This is not surprising given the longitudinal nature of our data. The presence of heteroskedasticity and AR1 autocorrelation would argue against the use of OLS (Greene, 2003). As both heteroskedasticity and autocorrelation are present in our dataset we address both problems together by applying Generalized Least Squares (GLS) estimation procedures ${ }^{43}$ with corrections to adjust for both heteroskedasticity and panel specific first-order autocorrelation. As shown in Table 15 column 3 our results are robust to these corrections. The interaction effect remains significant and the directions of the estimated coefficients for both the interacting variables and the interaction term remain the same in the GLS regression, although the price increase effects brought by converters to minority formats are smaller compared to those obtained from the OLS regressions.

As the GLS estimator is more robust to heteroskedasticity and autocorrelation we examine both marginal effects and interaction effects using the results from the GLS estimation. To evaluate Hypotheses 1 and 2 in Table 16, we compute the marginal effects of the variables

\footnotetext{
${ }^{43}$ We also run a Hausman test to examine if there are fixed or random effects in our data. The Hausman test rejects the null hypothesis that individual effects are uncorrelated with the other regressors and suggests that fixed effects exist in our data. However, a fixed effect specification results in excessive collinearity (many variables are dropped in a fixed effect model). Therefore, we adopt the GLS estimator.
} 
InstalledBase and ConverterAdoption at the means of the interacting variables. ${ }^{44}$ Following Greene (2003, pp.124), the standard errors of these marginal effects can be computed from:

$\operatorname{Var}\left(\frac{\partial E\left[\text { Cardprice }_{i, j, k, t} \mid \text { InstalledBase }_{i, t} \text { ConverterAdoption }_{t}\right]}{\text { InstalledBase }_{i, t}}\right)=\operatorname{Var}\left[\hat{\alpha}_{1}\right]+\left(\text { InstalledBase }_{i, t}\right)^{2} \operatorname{Var}\left[\hat{\alpha}_{3}\right]+2$ InstalledBase $_{i, t} \operatorname{Cov}\left[\hat{\alpha}_{1}, \hat{\alpha}_{3}\right]$

and similarly for $\operatorname{Var}\left(\frac{\partial E\left[\text { Cardprice }_{i, j, k, t} \mid \text { InstalledBase }_{i, t} \text { ConverterAdoption }_{t}\right]}{\partial \text { ConverterAdoption }_{t}}\right)$. Note that the standard errors of the marginal effects at different values can be obtained by substituting the respective variables with these different values in the above equations. These standard errors are provided in parentheses.

Table 16. Marginal Effects

\begin{tabular}{c|c|c|c|c|c}
\hline & -2 Std. Dev. & -1 Std. Dev. & Mean & +1 Std. Dev. & +2 Std. Dev. \\
\hline Marginal effect of & 93.48 & 68.52 & 43.57 & 18.62 & -6.33 \\
InstalledBase $_{i, t-1}$ & $(3.35)^{* *}$ & $(3.75)^{* *}$ & $(3.97)^{* *}$ & $(4.06)^{* *}$ & $(4.24)^{*}$ \\
\hline Marginal effect of $^{*}$ & 28.30 & 3.99 & -20.32 & -44.64 & -68.95 \\
ConverterAdoption $_{t-1}$ & $(1.59)^{* *}$ & $(1.72)^{* *}$ & $(1.96)^{* *}$ & $(2.31)^{* *}$ & $(2.49)^{* *}$ \\
\hline
\end{tabular}

The "Mean" column of the first row in Table 16 shows that the marginal effect of the flash memory card installed base is positive at the mean value of the converter adoption level. This indicates that network effects do exist in the flash memory card market such that the price of a flash memory card is positively associated with the size of the installed base for the same format. This provides support for Hypothesis 1a and rejects Hypothesis 1b. The "Mean" column of the second row shows that the marginal effect of digital converter adoption is negative when evaluated at the mean value of the installed base; thus, the price of a flash memory card is negatively associated with the level of converter adoption. Thus, Hypothesis 2 is not supported.

With regard to Hypothesis 3, as shown in Table 16, the flash card price premium changes in the expected direction. The first row suggests that, at average levels of digital converter adoption, digital converters reduce the price premium of leading formats (i.e., those with a larger

\footnotetext{
${ }^{44}$ We also compute the marginal effects at different values of the interacting variables to show how the marginal effects change as the value of the interacting variables varies.
} 
installed base - the +1 and +2 standard deviation columns) more than minority formats (i.e., those with a smaller installed base - the -1 and -2 standard deviation columns). The second row shows that, at average levels of the installed base for a flash memory card format, the marginal effect of digital converter adoption is larger when the level of converter adoption is higher (the +1 and +2 standard deviation columns) than when the level of converter adoption is lower (the -1 and -2 standard deviation columns). Moreover, coefficient $\alpha_{3}$ is highly significant $(p<0.001)$ in the interaction model. An F-test between the restricted model and the unrestricted model confirms that the inclusion of the interaction term significantly contributes to the explanation of the variance in the hedonic regression. Therefore, Hypothesis 3 is supported.

One possible concern about these results is that one of the independent variables, InstalledBase, is the cumulative unit sales volume of a flash memory card format. This variable could be closely correlated with the current period unit sales volume of a flash memory card format, which, in turn, could be correlated with our dependent variable, the current period flash memory card price. To address this potential endogeneity in our model we use the lagged (t-1) cumulative market share as our measure for the installed base and perform a two-stage least square (2SLS) estimation to test for endogeneity. We use the cumulative market share with two months lag as our instrumental variable. Following Baum, Schaffer and Stillman (2003) we tested for endogeneity in our augmented form using a generalized methods of moments (GMM) estimation with specifications for autocorrelation and heteroskedasticity. ${ }^{45}$ The results from the GMM estimation are consistent with those obtained from the OLS and GLS estimations. Neither a Wu-Hausman F test $(\mathrm{p}$-value $=0.48)$ nor a Durbin-Wu-Hausman chi-square test ( $\mathrm{p}$-value $=0.47)$ could reject the null hypothesis that the lagged cumulative market share is exogenous. This provides confidence in our results against potential endogeneity concerns.

\footnotetext{
${ }^{45}$ The same approach is also adopted in Mittal and Nault (2006) which has a similar situation.
} 


\subsubsection{The effect of converters on market concentration}

When converters are not available in markets with strong network effects, a large installed base can give firms a significant advantage in standards competition and may lead to a "winnertake-all” outcome. However, Hypothesis 4 predicts that when converters are available this competitive advantage will be weakened and market concentration will decrease as the adoption of digital converters increases. To test Hypothesis 4 we use the following model to examine the relationship between the adoption of digital converters and the shift in market shares of the competing flash memory card formats:

[Model 2]

MarketConc entration $_{t}=\beta_{0}+\beta_{1}$ ConverterAdoption $_{t-1}+\beta_{2} \operatorname{Var}(\text { CardPrice } / M B)_{k, t}+\varepsilon_{k, t}$

In Model 2, the dependent variable, market concentration, is measured by the HerfindahlHirschman Index (HHI). HHI is widely used as a measure of the size of firms in relationship to the industry and as an indicator of the amount of competition in a market (Calkins, 1983). A larger value of the HHI indicates higher market concentration and hence less intense standards competition. Note that in our model HHI is computed as the sum of squares of the market shares of the competing formats rather than brands as we are primarily interested in competition among technology formats rather than firms. To perform this analysis we break the data down by month and by capacity, which results in 428 data panels. Next, the value of HHI in each panel is regressed against the lagged adoption level of digital converters of the corresponding panel, controlling for the variance of flash memory card retail prices in each panel. ${ }^{46}$ In order to correct for price differences across different memory capacities, retail price is calculated as the average price per megabyte in each panel.

\footnotetext{
${ }^{46}$ This controls for variation in market concentration due to price variation that is associated with other exogenous factors.
} 
The new dataset consists of panels spanning 12 capacity categories and 44 consecutive months. Applying the OLS estimator to the pooled dataset is likely to also confront heteroskedasticity and autocorrelation issues. Indeed, a Breusch-Pagan / Cook-Weisberg test and a Wooldridge test on the residuals of the OLS regression confirm that both heteroskedasticity and panel specific first-order autocorrelation (AR1) are present in our data. Therefore, we adopt the GLS adjustments to correct for heteroskedasticity and autocorrelation.

Table 17 presents the GLS regression results for Model 2. The coefficient estimate of the variable ConverterAdoption $\mathrm{t}_{t-1}$ is negative and significant at a $5 \%$ level in both specifications, suggesting that across different flash memory card capacity categories, market concentration decreases as the adoption of digital converters increase. Hence Hypothesis 4, that market concentration of flash memory card producers decreases as the adoption of digital converters increases, is supported.

Table 17. Regression Results - Model $2^{\dagger \neq}$

\begin{tabular}{lc}
\hline Dependent Variable: HHI & Coefficients \\
\hline Constant & .531 \\
& $(.0532)^{* *}$ \\
\hline ConverterAdoption & -.180 \\
& $(.081)^{*}$ \\
\hline Var(Card_Price/MB $\left.{ }_{t}\right)$ & $8.72 \mathrm{e}-07$ \\
& $(7.54 \mathrm{e}-07)$ \\
\hline Condition Number & 10.29 \\
Log likelihood & 431.2 \\
\hline${ }^{\dagger} \mathrm{N}=428(12$ different capacities across 44 month). \\
${ }^{*}$ Standard errors in parentheses. $*: \mathrm{p}<5 \% ; * * \mathrm{p}<1 \%$.
\end{tabular}

\subsection{Discussions}

The main empirical question in this study is why, despite the apparent benefits of product compatibility in the flash memory card market, there has been little convergence to a dominant standard. Our findings provide important insights that help to answer this question. 
First, we find that the presence of digital converters has a strong effect on standards competition by offsetting some of the impact of network effects. As shown in Table 16, in markets characterized by network effects, the presence of converters weakens the relationship between installed base and price premia. Though the overall marginal effect of converters on prices is negative at the mean value of the flash card installed base, it is positive only for flash memory card formats with an installed base below the average. For a flash card format with a smaller installed base (i.e., 2 standard deviations below the mean), a 1\% increase in the adoption level of digital converters raises the flash card premium by an estimated $\$ 0.283$. But, this price premium disappears when a format's installed base is close to the industry average. This finding is consistent with our predictions and can be explained intuitively. A converter serves as tool for data exchange between the otherwise incompatible flash card formats. Such a converter is relatively more valuable for consumers who own a minority format as it allows them to communicate with consumers of a much larger network. Hence the utility gain, and consequently the willingness to pay a higher price, is larger for consumers of the minority formats than for those of the dominant format.

In addition to the differential impact of converters on consumers who belong to different networks several other factors may account for the lack of support for Hypothesis 2. For example, flash memory card vendors can also profit from the sales of digital converters. If a vendor is engaged in the sale of both converters and flash cards, such a vendor can theoretically transfer some of the price premium from the flash memory cards to the sales of digital converters and still profit overall. A similar argument applies for vendors who do not produce their own converters, but license a third party vendor to do so. In this case, the licensing fee could more than compensate for the loss due to flash card price reduction. 
However, it is also important to note that, while network effects are weakened with the adoption of digital converters, the effects are not fully eliminated. This implies that a larger installed base is still a competitive advantage over other competing formats. This advantage is more significant as a format's installed base grows. All else being equal, a $1 \%$ increase in the installed base of a flash card format gives rise to $\$ 0.43$ price premium $(0.705 \%$ price increase) of a compatible flash memory card. ${ }^{47}$ It is also important to note that the strength of network effects, as represented by the price premium, is very sensitive to the adoption of digital converters. When the level of digital converters adoption is relatively low, i.e. at one standard deviation below the mean, the price premium increases by more than $50 \%$, to $\$ 0.69$. However, when the adoption of digital converters is high, i.e., at one standard deviation above the mean, such a price premium almost disappears.

Figures 9 and 10 illustrate the interaction between network effects (installed base) and the adoption of digital converters.

In Figure 9, the x-axis denotes the adoption level of digital converters and the y-axis represents the price premium of a type of flash card. The dashed, dotted, and solid lines represent the price premium of a flash card format with a large ( +2 standard deviations), average, and small ( -2 standard deviations) market share respectively. Figure 9 shows that the price premium of a flash card format with a larger installed base decreases as the adoption of digital converters increases, whereas the price premium of a flash card format with a smaller installed base increases as the adoption of digital converters increases, suggesting that there is a negative interaction effect between the installed base of the flash card format and the sales of digital converters. In other words, the adoption of digital converters has an opposite impact on majority and minority flash memory card formats.

\footnotetext{
${ }^{47}$ Interestingly, this is a price premium of a similar order of magnitude $(0.753 \%$ price increase $)$ as that found in the microcomputer spreadsheet software market (Brynjolfsson and Kemerer, 1996).
} 


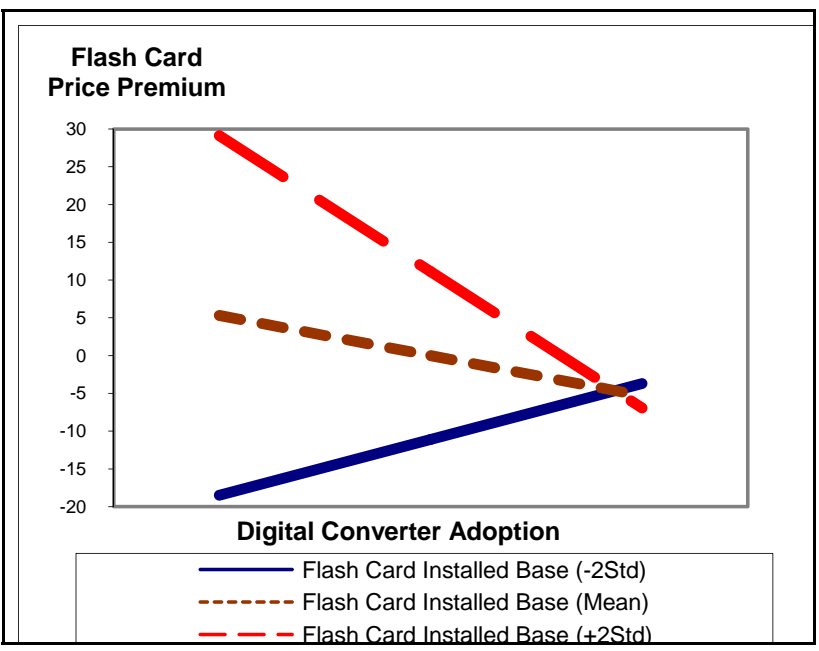

Figure 9. Price Premium of A Flash Memory Format at + or - 2 Standard Deviations of the Mean Converter Adoption Level

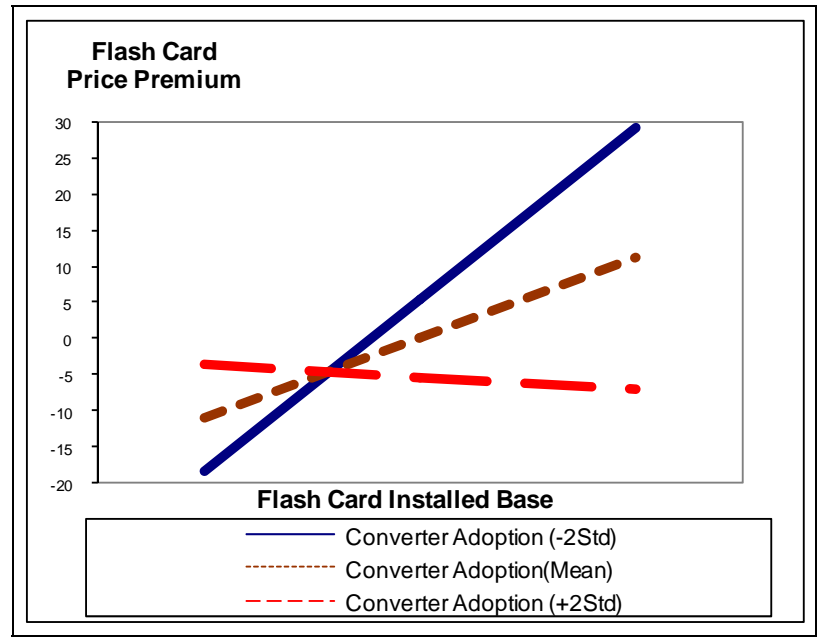

Figure 10. Price Premium of A Flash Memory Format at + or - 2 Standard Deviations of the Mean Flash Card Installed Base

A similar interaction is depicted in Figure 10 where the $\mathrm{x}$-axis denotes the installed base of a flash memory card format and the y-axis represents the price premium of that type of flash memory card. The dashed, dotted, and solid lines represent the price premium of a flash card format when the adoption of digital converters is high ( +2 standard deviations), average, and low (-2 standard deviations) respectively. One can see that network effects are present (upward slope of price premium curve) only when the adoption level of digital converters is below a certain level. When there is extensive adoption of digital converters (i.e. above +2 standard deviations), 
network effects have only a minimal impact on the market (downward slope of the price premium curve).

In addition to moderating the impact of installed base on product prices, our findings reveal that digital converters have the potential to change the nature of competition in the flash memory card market. The results from Model 2 indicate that market competition escalates as converters are widely adopted. One interpretation of the negative price premium for the dominant formats is that with fierce competition the dominant firms might use a price war as a tool to deter potential entrants and to drive the secondary formats out of the market, as the short-term incentive to seize market share may dominate the long-term profit maximization goal.

The results from Model 2 indicate that, as converter penetration increases, the market share gap among various competing formats is reduced. Consequently, buyers' expectations are more likely to hinge on other product attributes and competition will arise in other dimensions, such as quality and performance. Leading formats can no longer rely on a large installed base to deter new entrants and suppress competition as such a competitive advantage is like to be eroded over time as converters become widely available. In contrast to the self-reinforcing loop in classic network effects theory, with the presence of digital converters, the larger the leading format's installed base, the more such a benefit can be appropriated among consumers of the minority formats, creating an opposite feedback loop that pushes the market away from high concentration. Under such a competitive environment, a standards competition characterized with extensive adoption of converters is likely to undergo a more unpredictable growth path.

We discuss the implications of our results in the next chapter. 


\subsection{CONTRIBUTIONS AND MANAGEMENT INSIGHTS}

The conventional wisdom in the popular and business press is that many technology markets will exhibit a "tipping point" where strong network effects will lead the market to a winner-take-all outcome. However, many of the examples used to support this outcome are drawn from existing physical and analog product environments where conversion from one standard to another is costly both in terms of time and quality. Our contention is that the unique characteristics of digital environments may alter some of the conventional wisdom about network effects. This prediction has been confirmed with the results derived from our analytic and empirical studies.

In particular, our analytic results show that the existence of a converter can mediate the network effects of a pre-existing installed base. A "winners-take-some" outcome that sustains competition after the entrant enters the market is more likely to arise with lower conversion costs and higher conversion quality, characteristics of many digital products in IT markets. When we endogenize the decision to provide a converter and incorporate explicit negotiations between firms concerning the extent of conversion, we find that the subgame perfect equilibrium involves firms' agreeing on providing converters at a sufficiently low price to all consumers. At this equilibrium, not only the entrant but also the incumbent is better off since the provision of converters alleviates price competition and leads to both higher product revenues and higher proceeds from the sale of converters. Moreover, under some circumstances the provision of converters is welfare enhancing. 
Consistent with the analytic findings, our empirical study illustrates some of these issues in the context of the flash memory market where, in spite of apparent network effects, there are multiple competing standards and little evidence of market consolidation. Specifically, we apply a modified hedonic regression to an extensive dataset cataloging prices and sales of flash memory cards and flash memory converters. Our results show that low cost digital conversion technologies reduce the tendency towards market dominance by a single standard and allow multiple standards to survive and thrive in the market. The availability of digital converters reduces the price premium of the leading flash card formats more than that of the minority formats. In addition, market concentration decreases as converters become more widely available.

The findings from this research have theoretical implications for the growing literature on network effects in IT markets. The combination of the analytical and empirical framework provides a complementary set of research methods to investigate the research question. Our study is one of the first attempts to add empirical analysis to complement the analytic literature on conversion technologies in markets with standards competition. Although the presence and magnitude of network effects have been empirically demonstrated in the literature, our use of market data contributes to the existing body of knowledge on network effects by providing new insights into how conversion technologies affect competition in digital markets. Moreover, our analytic model also extends the existing analytic literature on conversion technologies in an important way. By developing a sequential competition framework with a negotiation mechanism to endogenize the provision of conversion technology, we explore several questions that have not been examined before and obtain some findings that differ from those established in the literature. We believe that we model the phenomenon in a way that more accurately 
reflects the environment facing firms competing in actual marketplaces.

Our findings on the effects of conversion technologies also have managerial implications for consumers, vendors and policy makers in IT markets. From the consumer's perspective, in the absence of standardization, the presence of conversion technologies allow users of a minority product to communicate with users of a dominant product, thus extending the lifecycle of their products and maximizing the return on their investments. In markets where different products enter sequentially, consumers can expect less risk of being stranded on a new technology if a conversion technology is available. Consequently, consumers are more likely to consider adopting new products, which, in turn, encourages more market participation. Accordingly, product variety will increase as new entrants can be more aggressive in pursuing new and more innovative technologies. Our theoretical framework also allows consumers to better predict the likelihood of achieving compatibility through converters and make a more informed adoption decision based on the strength of the network effects, the market shares of the existing products, and the quality and costs of converters.

From the vendor's perspective, as converters become more popular, consumer perceptions of network effects decrease, since compatibility can be achieved at a lower cost. Consequently, the choice of a product may rely more on other attributes, such as brand and quality attributes, than on market share. If this shift in consumer preferences occurs, vendors' marketing and pricing strategies should adjust accordingly. For example, the findings from the flash memory market illustrate that eextensive adoption of digital converters reduces the magnitude of network effects, as seen by a reduced price premium of the leading flash format. As a result, new standards are more likely to attract customers than in the absence of digital converters. Competition intensifies as the market power of the leading format is weakened, as reflected by a decreasing market concentration ratio with increasing converter adoption. These findings explain 
the seemingly counter-intuitive trend of the lack of standards convergence currently seen in the flash memory card market and are consistent with the observed market behavior that converters have become increasingly important in the market and have been disproportionately adopted by entrants and minority formats. For example, since their introduction in the market in early the 2000s, variants of the Secure Digital (SD), MicroSD and MiniSD formats have all come with free converters to the SD format, allowing them to take full advantage of the SD cards' large installed base. This action was quickly followed by Sony, the major retailer of Memory Stick cards, who announced a worldwide initiative to promote its Memory stick card reader to be installed on a variety of laptops and desktops. Today, more and more PC manufacturers are including flash memory card readers as a standard component on their PCs, suggesting increasing consensus among different market participants about the prospect and importance of digital conversion.

The above findings also shed light on some contemporary markets that are undergoing stiff competition among incompatible technology standards. Two current examples, the next generation DVD market and the market for satellite radio are often portrayed in the press as shaping up as 'the next Beta vs. VHS' competition, implying that a single winner must emerge (Wall Street Journal, March 15, 2004, Wall Street Journal, March 30, 2005). However, unlike the analog Beta vs. VHS competition, these newer digital technologies lend themselves to inexpensive and perfect conversion. For example, in satellite radio two providers were granted licenses, Sirius and $\mathrm{XM}$, and these two competitors have spent considerable sums trying to establish themselves as the market leader. However, since the content is digital, it is easy from a technical perspective, to imagine adding a converter to a car already equipped with one receiver to allow it to receive and convert the alternative signal. And, in fact, as these two providers have 
recently sought FCC permission to merge, it seems clear that a cooperative converter solution is a practical possibility (Wall Street Journal, February 20, 2007). In the market for next generation DVDs, two proprietary formats, Blu-Ray and HD-DVD, are undergoing similar competition. Without a clear winner on technical criteria, it is obvious that a "standards war" will be costly and ultimately not desirable from a consumer perspective. Alternatively, an equilibrium with digital conversion between the formats would prevent early adopters of either format from being 'stranded,' and would reduce the delay in technology progress caused by consumers and producers of complementary goods (e.g., movie studios) from taking a 'wait and see attitude.'

With regard to technology innovation and adoption, in many IT industries when the market cannot settle on an industry-wide technology standard, both consumers and content providers (or application developers) postpone their investment until the market is clear about which standard to adopt. However, this delay in adoption results in even more uncertainty about the future of the technology. However, if a digital converter were available to convert data from one incompatible form to another form that can be mutually accepted, consumers would be more willing to embrace the new technology as the risk of being stranded on either technology is minimized. And, once any excess inertia among stragglers is overcome, technology adoption can be expected to accelerate and lead itself into a traditional evolutionary path.

Finally, from a policy standpoint, our findings lend important theoretical support for policy makers to promote converters in maximizing social welfare. Ideally, industry-wide compatibility can be attained through market forces or a voluntary industry committee. However, history has shown that it is often very difficult for the industry to unanimously agree upon a standard. ${ }^{48}$ As a

\footnotetext{
${ }^{48}$ The recent bitter ending of the Blu-ray and HD DVD standards war also illustrates the importance of a feasible mechanism to achieve compatibility in IT markets. Having gone through such stiff competition, standardization occurs at the costs of Toshiba's significant loss in product development and promotion, as well as prolonged delay of consumers' adoption of both technologies.
} 
result, social/governmental planners have always been confronted with a dilemma between standardization, with its attendant social benefits, and possible antitrust concerns when enforcing standardization give rise to natural monopolies. ${ }^{49}$ In either case, regulatory measures might produce a net negative impact on technology progress, social welfare or both. In light of these tradeoffs, the presence of conversion technology may provide a less costly form of achieving compatibility without incurring significant standardization costs. For markets characterized with high consumer heterogeneity, the provision of a converter reduces the need to compromise between product variety and standardization.

In summary, our findings illustrate that success is not always characterized with outcompeting the other players in the market. In particular the digital nature of the products in many information goods markets greatly facilitates the coordination process for the provision of conversion technologies. In the digital economy, a "win-win" situation can be achieved through the use of converters among multiple otherwise incompatible standards. Given that there is still reasonable disagreement over the tradeoffs between market competitiveness and the social benefit of industry wide compatibility, our analysis contributes to the debate on standardization in IT markets by enriching the alternative choice set of such consideration.

\footnotetext{
${ }^{49}$ Although jointly agreed industry-wide standards can be one solution to this dilemma, history has shown that it is often very difficult for the industry to unanimously agree upon a standard. For a recent example, see the battle over the next generation DVD standard (Wall Street Journal, March 15, 2004).
} 


\subsection{EXTENSIONS AND FUTURE RESEARCH}

The dynamic nature of the flash memory card market and the likely evolution of standards competition in other, similar digital product markets also raise several interesting questions for future research. In this dissertation, we show that provision of conversion technology can be greatly facilitated with the proposed Nash Bargaining solution and the profit allocation scheme. In reality, both firms may also license a third party vendor to undertake the production and sale of converters. In this case, firms' licensing strategy and the third-party vendor's pricing strategy may yield a different outcome than what we derived from this dissertation. Modeling the competition in this context would definitely yields interesting new insights to both researchers and practitioners. Moreover, as is common in the flash memory and other digital goods market, there are often multiple firms competing for dominance in the market. The results derived from a duopoly competition model may be further complicated with more than two competitors entering the market in an infinite time frame. Therefore, a dynamic analysis to extend the duopoly model developed in this study would merit attention from future studies. Finally, as demonstrated in Chapter 2, both social welfare and private surplus are likely to be affected by the introduction of conversion technologies. Due to the limitation of our dataset, we are not able to pursue an empirical analysis on the social welfare change as a result of the introduction of converters. Further studies to quantify these impacts will provide important guidance for policy makers

concerned about the nature and consequences of new technology adoption and innovation in markets characterized with network effects and the possibility of digital conversion. 


\section{BIBLIOGRAPHY}

Aiken, L. S., West, S. G. 1991 Multiple Regression: Testing and Interpreting Interactions, Sage Publications.

Asvanund, A., Clay, K., Krishnan, R., Smith, M. D. 2004. An Empirical Analysis of Network Externalities in Peer-to-Peer Music-Sharing Networks. Information Systems Research, 15(2) 155-174.

Baum, C. F., Schaffer, M. E., Stillman, S. 2003. Instrumental Variables and GMM: Estimation and Testing. Boston College, Department of Economics, Working Paper No.545.

Bresnahan, T. F. 2001. Network Effects and Microsoft. Department of Economics, Stanford University Working Paper.

Brynjolfsson, E., Kemerer, C. F. 1996. Network Externalities in Microcomputer Software: An Econometric Analysis of the Spreadsheet Market. Management Science, 42(12) 16271647.

Calkins, S. 1983. The New Merger Guidelines and the Herfindahl-Hirschman Index California Law Review, 71(2) 28.

Chen, P. Y., Forman, C. 2006. Can Vendors Influence Switching Costs and Compatibility in an Environment with Open Standards? MIS Quarterly, 30541-562.

Chen, P. Y., Hitt, L. M. 2002. Measuring Switching Costs and the Determinants of Customer Retention in Internet-Enabled Businesses: A Study of the Online Brokerage Industry. Information Systems Research, 13(3) 255-274.

Choi, J. P. 1996. Do Converters Facilitate the Transition to a New Incompatible Technology? A Dynamic Analysis of Converters. International Journal of Industrial Organization, 14(6) $825-835$. 
--- 1997. The Provision of (two-way) Converters in the Transition Process to a New Incompatible Technology. Journal of Industrial Economics, 45(2) 139-153.

Christensen, C. M., Suárez, F. F., Utterback, J. M. 1998. Strategies for Survival in Fast-Changing Industries. Management Science, 44(12) S207-S221.

Coase, R. H. 1972. Durability and Monopoly. Journal of Law \& Economics, 15(1) 143-149.

Conner, K. R. 1995. Obtaining Strategic Advantage from Being Imitated: When Can Encouraging "Clones" Pay? Management Science, 41(2) 209-225.

Cusumano, M. A., Mylonadis, Y., Rosenbloom, R. S. 1992. Strategic Maneuvering and MassMarket Dynamics - the Triumph of VHS over Beta. Business History Review, 66(1) 5194.

David, P. A., Bunn, J. A. 1988. The economics of gateway technologies and network evolution: Lessons from electricity supply history. Information Economics and Policy, 3(2) 165-202.

Dranove, D., Gandal, N. 2003. THE DVD vs. DIVX Standard War: Empirical Evidence of Network Effects AND Preannouncement Effects. Journal of Economics \& Management Strategy, 12(3) 363-386.

Economides, N. 1989. Desirability of Compatibility in the Absence of Network Externalities. American Economic Review, 79(5) 1165-1181.

--- 1996. The Economics of Networks. International Journal Of Industrial Organization, 14(6) 673-699.

Economides, N., Himmelberg, C. 1995. Critical Mass and Network Size with Application to the US Fax Market. Discussion Paper \# EC-95-11, Stern School of Business, New York University.

Farrell, J., Saloner, G. 1985. Standardization, compatibility, and innovation. RAND Journal of Economics, 16(1) 70-83. 
--- 1986. Installed Base and Compatibility: Innovation, Product Preannouncements, and Predation. American Economic Review, 76(5) 940-955.

--- 1992. Converters, Compatibility, and the Control of Interfaces. Journal of Industrial Economics, 40(1) 9-35.

Farrell, J., Shapiro, C., Nelson, R. R., Noll, R. G. 1992. Standard Setting in High-Definition Television. Brookings Papers on Economic Activity. Microeconomics, 19921-93.

Gallaugher, J. M., Wang, Y.-M. 2002. Understanding network effects in software markets: Evidence from Web server pricing. MIS Quarterly, 26(4) 303-327.

Gandal, N. 1994. Hedonic Price Indexes for Spreadsheets and an Empirical Test for Network Externalities. RAND Journal of Economics, 25(1) 160-170.

--- 1995. Competing Compatibility Standards and Network Externalities in the PC Software Market. Review of Economics and Statistics, 77(4) 599-608.

Gilder, G. 2000 Telecosm: How Infinite Bandwidth Will Revolutionize Our World, The Free Press, New York, NY.

Greene, W. H. 2003 Econometric Analysis, Prentice Hall, Upper Saddle River, New Jersey.

Greenstein, S. M. 1993. Did Installed Base Give an Incumbent any (Measurable) Advantages in Federal Computer Procurement? RAND Journal of Economics, 24(1) 19-39.

Hartman, R. S. 1989. An Empirical Model of Product Design and Pricing Strategy. International Journal of Industrial Organization, 7419-436.

Jaccard, J., Wan, C. K., Turrisi, R. 1990. The Detection and Interpretation of Interaction Effects Between Continuous Variables in Multiple Regression. Multivariate Behavioral Research, 25(4) 467.

Katz, M. L., Shapiro, C. 1985. Network Externalities, Competition, and Compatibility. American Economic Review, 75(3) 424. 
--- 1986a. Technology Adoption in the Presence of Network Externalities. The Journal of Political Economy, 94(4) 822-841.

Kauffman, R. J., McAndrews, J., Yu-Ming, W. 2000. Opening the 'Black Box' of Network Externalities in Network Adoption. Information Systems Research, 11(1) 61.

Lee, J., Lee, J., Lee, H. 2003. Exploration and exploitation in the presence of network externalities. Management Science, 49(4) 553-570.

Liebowitz, S. J., Margolis, S. E. 1994. Network Externality: An Uncommon Tragedy. Journal of Economic Perspectives, 8(2) 133-150.

--- 1999 Winners, Losers, and Microsoft: Competition and Antitrust in High Technology, The Independent Institute, Oakland, CA.

Wall Street Journal 2007. Europe Steps Up Probe of New DVD Formats, July 3

Matutes, C., Regibeau, P. 1988. "Mix and Match": Product Compatibility without Network Externalities. RAND Journal of Economics, 19(2) 221-234.

Mittal, N., Nault, B. R. 2006. Investments in Information Technology: Indirect Effects and Information Technology Intensity. Haskayne School of Business, University of Calgary, Working Paper.

Nash, J. F. 1950. The Bargaining Problem. Econometrica, 18(2) 8.

Park, S. 2004. Quantitative Analysis of Network Externalities in Competing Technologies: The VCR Case. Review of Economics \& Statistics, 86(4) 937-945.

Shapiro, C., Varian, H. R. 1999 Information Rules: A Strategic Guide to the Network Economy Harvard Business School Press, Boston, MA

Stokey, N. L. 1979. Intertemporal Price Discrimination. Quarterly Journal of Economics, 93(3) 355-371. 
Suárez, F. F., Utterback, J. M. 1995. Dominant designs and the survival of firms. Strategic Management Journal, 16(6) p415-430, 16p.

Wall Street Journal 2004. Technology Titans Battle Over Format of DVD Successor, March 15

Wall Street Journal 2005. Two Upstarts Vie for Dominance in Satellite Radio, March 30

Wall Street Journal 2006. Boot Camp Turns Your Mac Into a Reliable Windows PC, April 6

Wall Street Journal 2007. Sirius and XM Agree to Merge, Despite Hurdles, February 20

Xie, J., Sirbu, M. 1995. Price Competition and Compatibility in the Presence of Positive Demand Externalities. Management Science, 41(5) 909-926.

Zhu, K., Kraemer, K. L., Gurbaxani, V., Xu, X. 2006. Migration to Open-Standard Interorganizational Systems: Network Effects, Switching Costs and Path Dependency. MIS Quarterly, 30515-539. 


\section{APPENDIX}

Derivation of the Market Segmentation equilibrium in the extended model (Table 3): The

following incentive constraints must be satisfied in order for the interior solution to exist:

IC 1: A consumer who buys product B with a converter in period 2 enjoys greater utility than:

(1a): buying A with a converter in period 2.

$$
\begin{aligned}
& 1-x+\beta M S_{\mathrm{B}}-\mathrm{P}_{\mathrm{B}}+\theta \beta \cdot\left(M S_{\mathrm{A} 1}+M S_{\mathrm{A} 2}\right)-c \geq x+\beta\left(M S_{\mathrm{A} 1}+M S_{\mathrm{A} 2}\right)-P_{A 2}+\theta \beta M S_{B}-c \\
& \Rightarrow x \leq \frac{1+P_{A 2}-P_{B}-\beta(1-\theta)\left(M S_{A 1}+M S_{A 2}-M S_{B}\right)}{2}=s_{1}^{*}
\end{aligned}
$$

(1b): buying B without a converter in period 2 .

$$
\begin{aligned}
& 1-x+\beta M S_{\mathrm{B}}-P_{B}+\theta \beta \cdot\left(M S_{A 1}+M S_{A 2}\right)-c \geq 1-x+\beta M S_{\mathrm{B}}-P_{B} \\
& \Rightarrow c \leq \theta \beta\left(M S_{\mathrm{A} 1}+M S_{\mathrm{A} 2}\right)=c_{1}{ }^{*},
\end{aligned}
$$

(1c): buying A without a converter in period 2.

$$
\begin{aligned}
& 1-x+\beta M S_{B}-P_{B}+\theta \beta \cdot\left(M S_{A 1}+M S_{A 2}\right)-c \geq x+\beta\left(M S_{A 1}+M S_{A 2}\right)-P_{A 2} \\
& \Rightarrow c \leq \theta \beta\left(M S_{A 1}+M S_{A 2}\right)+1+P_{A 2}-P_{B}-\beta\left(M S_{A 1}+M S_{A 2}-M S_{B}\right)-2 x=2\left(s_{1}{ }^{*}-x\right) .
\end{aligned}
$$

IC 2: A consumer who buys product B without a converter in period 2 enjoys larger utility than:

(2a): buying A without a converter in period 2 .

$$
\begin{aligned}
& 1-x+\beta M S_{B}-P_{B} \geq x+\beta\left(M S_{A 1}+M S_{A 2}\right)-P_{A 2} \\
& \Rightarrow x \leq \frac{1+\mathrm{P}_{\mathrm{A} 2}-\mathrm{P}_{\mathrm{B}}-\beta\left(M S_{\mathrm{A} 1}+M S_{\mathrm{A} 2}-M S_{\mathrm{B}}\right)}{2}=s_{2}{ }^{*},
\end{aligned}
$$

(2b): buying B with a converter in period 2 .

$$
\Rightarrow c \geq \theta \beta\left(M S_{\mathrm{A} 1+} M S_{\mathrm{A} 2}\right)=c_{1}{ }^{*},
$$

(2c): buying A with a converter in period 2 . 


$$
\begin{aligned}
& 1-x+\beta M S_{\mathrm{B}}-\mathrm{P}_{\mathrm{B}} \geq x+\beta\left(M S_{\mathrm{A} 1}+M S_{\mathrm{A} 2}\right)-\mathrm{P}_{\mathrm{A} 2}+\theta \beta M S_{\mathrm{B}}-c \\
& \Rightarrow c \geq \theta \beta\left(M S_{\mathrm{A} 1}+M S_{\mathrm{A} 2}\right)+\left(2 x-\left(1+\mathrm{P}_{\mathrm{A} 2}-\mathrm{P}_{\mathrm{B}}-\beta(1-\theta)\left(M S_{\mathrm{A} 1}+M S_{\mathrm{A} 2}-M S_{\mathrm{B}}\right)\right)=\theta \beta M S_{\mathrm{A}}+2\left(x-S_{1}^{*}\right) .\right.
\end{aligned}
$$

IC 3: A consumer who buys product A with a converter in period 2 enjoys greater utility than:

(3a): buying B with a converter in period 2.

$\Rightarrow x \geq \frac{1+\mathrm{P}_{\mathrm{A} 2}-\mathrm{P}_{\mathrm{B}}-\beta(1-\theta)\left(M S_{\mathrm{A} 1}+M S_{\mathrm{A} 2}-M S_{\mathrm{B}}\right)}{2}=s_{1}{ }^{*}$,

(3b): buying A without a converter in period 2.

$$
\begin{aligned}
& x+\beta\left(M S_{\mathrm{A} 1+} M S_{\mathrm{A} 2}\right)-\mathrm{P}_{\mathrm{A} 2}+\theta \beta M S_{\mathrm{B}}-c \geq x+\beta\left(M S_{\mathrm{A} 1+} M S_{\mathrm{A} 2}\right)-\mathrm{P}_{\mathrm{A} 2} \\
& \Rightarrow c \leq \theta \beta M S_{\mathrm{B}}=c_{2}{ }^{*}
\end{aligned}
$$

(3c): buying B without a converter in period 2.

$\Rightarrow c \leq \theta \beta M S_{\mathrm{B}}+\left(2 x-\left(1+\mathrm{P}_{\mathrm{A} 2}-\mathrm{P}_{\mathrm{B}}-\beta\left(M S_{\mathrm{A} 1}+M S_{\mathrm{A} 2}-M S_{\mathrm{B}}\right)\right)=\theta \beta M S_{\mathrm{B}}+2\left(x-S_{2}{ }^{*}\right)\right.$,

(3d): buying A with a converter in period 1.

$$
\begin{aligned}
& x+\beta\left(M S_{\mathrm{A} 1+} M S_{\mathrm{A} 2}\right)-\mathrm{P}_{\mathrm{A} 2}+\theta \beta M S_{\mathrm{B}}-c \geq 2 x+\beta\left(2 M S_{\mathrm{A} 1+} M S_{\mathrm{A} 2}\right)+\theta \beta M S_{\mathrm{B}}-c-\mathrm{P}_{\mathrm{A} 1} \\
& \Rightarrow x \leq \mathrm{P}_{\mathrm{A} 1}-\mathrm{P}_{\mathrm{A} 2}-\beta M S_{\mathrm{A} 1}=i^{*}
\end{aligned}
$$

(3e): buying A without a converter in period 1.

$$
\begin{aligned}
& x+\beta\left(M S_{\mathrm{A} 1+} M S_{\mathrm{A} 2}\right)-\mathrm{P}_{\mathrm{A} 2}+\theta \beta M S_{\mathrm{B}}-c \geq 2 x+\beta\left(2 M S_{\left.\mathrm{A} 1+M S_{\mathrm{A} 2}\right)-\mathrm{P}_{\mathrm{A} 1}}\right. \\
& \Rightarrow c \leq \theta \beta M S_{B}+\left(P_{A 1}-P_{A 2}-\beta M S_{A 1}-x\right)=\theta \beta M S_{\mathrm{B}}+\left(i^{*}-x\right) .
\end{aligned}
$$

IC 4: A consumer who buys product A without a converter in period 2 enjoys larger utility than: (4a): buying B without a converter in period 2.

$$
\Rightarrow x \geq \frac{1+\mathrm{P}_{\mathrm{A} 2}-\mathrm{P}_{\mathrm{B}}-\beta\left(M S_{\mathrm{A} 1}+M S_{\mathrm{A} 2}-M S_{\mathrm{B}}\right)}{2}=s_{2}{ }^{*},
$$

(4b): buying A with a converter in period 2.

$$
\Rightarrow c \geq \theta \beta M S_{\mathrm{B}}=c_{2}^{*},
$$

(4c): buying B with a converter in period 2. 


$$
\begin{aligned}
& x+\beta\left(M S_{\mathrm{A} 1}+M S_{\mathrm{A} 2}\right)-\mathrm{P}_{\mathrm{A} 2} \geq 1-x+\beta M S_{\mathrm{B}}-\mathrm{P}_{\mathrm{B}}+\theta \beta \cdot\left(M S_{\mathrm{A} 1}+M S_{\mathrm{A} 2}\right)-c \\
& \Rightarrow c \geq \theta \beta\left(M \mathrm{~S}_{\mathrm{A} 1}+M S_{\mathrm{A} 2}\right)+1+\mathrm{P}_{\mathrm{A} 2}-\mathrm{P}_{\mathrm{B}}-\beta\left(M S_{\mathrm{A} 1}+M S_{\mathrm{A} 2}-M S_{\mathrm{B}}\right)-2 x=\theta \beta M S_{\mathrm{B}}+2\left(s_{2}{ }^{*}-x\right),
\end{aligned}
$$

(4d): buying A without a converter in period 1.

$$
\begin{aligned}
& x+\beta\left(M S_{\mathrm{A} 1}+M S_{\mathrm{A} 2}\right)-\mathrm{P}_{\mathrm{A} 2} \geq 2 x+\beta\left(2 M S_{\left.\mathrm{A} 1+M S_{\mathrm{A} 2}\right)-\mathrm{P}_{\mathrm{A} 1}}\right. \\
& \Rightarrow x \leq \mathrm{P}_{\mathrm{A} 1}-\mathrm{P}_{\mathrm{A} 2}-\beta M S_{\mathrm{A} 1}=i^{*}
\end{aligned}
$$

(4d): buying A with a converter in period 1.

$$
\begin{aligned}
& x+\beta\left(M S_{\mathrm{A} 1}+M S_{\mathrm{A} 2}\right)-\mathrm{P}_{\mathrm{A} 2} \geq 2 x+\beta\left(2 M S_{\mathrm{A} 1+} M S_{\mathrm{A} 2}\right)+\theta \beta M S_{\mathrm{B}}-c-\mathrm{P}_{\mathrm{A} 1} \\
& \Rightarrow c \geq \theta \beta M S_{\mathrm{B}}+\left(x-\left(\mathrm{P}_{\mathrm{A} 1}-\mathrm{P}_{\mathrm{A} 2}-\beta M S_{\mathrm{A} 1}\right)\right)=\theta \beta M S_{\mathrm{B}}+\left(x-i^{*}\right) .
\end{aligned}
$$

IC 5: A consumer prefers to buy product A with a converter in period 1 when:

$$
\begin{aligned}
& x \geq P_{A 1}-P_{A 2}-\beta M S_{\mathrm{A} 1}=i^{*}, \\
& c \leq \theta \beta M S_{\mathrm{B}}=c_{2}^{*}, \\
& c \leq \theta \beta M S_{\mathrm{B}}+\left(x-i^{*}\right) .
\end{aligned}
$$

IC 6: A consumer prefers to buy product A without a converter in period 1 when:

$$
\begin{aligned}
& x \geq P_{A 1}-P_{A 2}-\beta M S_{\mathrm{A} 1}=i^{*}, \\
& c \geq \theta \beta M S_{\mathrm{B}}=c_{2}{ }^{*}, \\
& c \geq \theta \beta M S_{\mathrm{B}}+\left(i^{*}-x\right) .
\end{aligned}
$$

Substituting $s_{1}{ }^{*}$ and $s_{2}{ }^{*}$ and $i^{*}$ into the incentive constraints yields the following results:

In order for case 1 (buy product B with a converter in period 2) to exist, it requires:

$0 \leq x \leq s_{1}{ }^{*}$. If $0 \leq x \leq s_{2}{ }^{*}$, then $c \leq \theta \beta\left(M S_{A 1}+M S_{A 2}\right)$ and if $s_{2}{ }^{*} \leq x \leq s_{1}{ }^{*}$, then $c \leq \theta \beta\left(M S_{A 1}+M S_{A 2}\right)+2\left(s_{2}{ }^{*}-x\right)$.

In order for case 2 (buy product B without a converter in period 2) to exist, it requires:

$0 \leq x \leq s_{2}{ }^{*}$ and $c \geq \theta \beta\left(M S_{A 1}+M S_{A 2}\right)\left(\right.$ since $\theta \beta\left(M S_{A 1}+M S_{A 2}\right)+2\left(x-s_{1}{ }^{*}\right)<\theta \beta\left(M S_{A 1}+M S_{A 2}\right)$ when $\left.0 \leq x \leq s_{2}{ }^{*}\right)$.

In order for case 3 (buy product A with a converter in period 2) to exist, it requires:

$s_{1}{ }^{*} \leq x \leq i^{*}$ and $c \leq \theta \beta M S_{B}\left(\right.$ since $\theta \beta M S_{B}+2\left(x-s_{1}{ }^{*}\right) \geq \theta \beta M S_{B}$ and $\theta \beta M S_{B}+\left(i^{*}-x\right) \geq \theta \beta M S_{B}$ when $\left.s_{1}{ }^{*} \leq x \leq i^{*}\right)$. 
In order for case 4 (buy product A without a converter in period 2) to exist, it requires:

$s_{2}{ }^{*} \leq x \leq i^{*}$. If $s_{2}{ }^{*} \leq x \leq s_{1}{ }^{*}$ then $c \geq \theta \beta M S_{B}+2\left(s_{1}{ }^{*}-x\right)$ and if $s_{1}{ }^{*} \leq x \leq i^{*}$, then $c \geq \theta \beta M S_{B}$.

In order for case 5 (buy product A with a converter in period 1 $)$ to exist, it requires:

$x \geq i^{*}$ and $c \leq \theta \beta M S_{B}\left(\right.$ since $\theta \beta M S_{B}+\left(x-i^{*}\right) \geq \theta \beta M S_{B}$ when $\left.x \geq i^{*}\right)$.

In order for case 6 (buy product A with a converter in period 1 $)$ to exist, it requires:

$x \geq i^{*}$ and $c \geq \theta \beta M S_{B}\left(\right.$ since $\theta \beta M S_{\mathrm{B}}+\left(i^{*}-x\right) \leq \theta \beta M S_{B}$ when $\left.x \geq i^{*}\right)$.

The above inequalities characterize the boundaries of the six regimes of the Segmentation equilibrium, from which we can derive firms' market shares $M S_{A 1}, M S_{A 2}$, and $M S_{B}$ as functions of $P_{A 1}, P_{A 2}, P_{B}, \theta, \beta$ and $\bar{C}$ :

$$
\begin{gathered}
M S_{B}=S_{2}^{*}+\frac{\left(c_{1}^{*}+c_{2}^{*}\right)}{2 \bar{C}}\left(S_{1}^{*}-S_{2}^{*}\right)=\frac{1+P_{A 2}-P_{B}-\beta\left(M S_{A 1}+M S_{A 2}-M S_{B}\right)}{2}+\frac{\theta \beta\left(M S_{A 1}+M S_{A 2}+M S_{B}\right) \cdot \theta \beta\left(M S_{A 1}+M S_{A 2}-M S_{B}\right)}{4 \bar{C}} \\
=\frac{1+P_{A 2}-P_{B}-\beta\left(M S_{A 1}+M S_{A 2}-M S_{B}\right)}{2}+\frac{\theta^{2} \beta^{2}\left(M S_{A 1}+M S_{A 2}-M S_{B}\right)}{4 \bar{C}} \\
M S_{A 1}=\left(1-i^{*}\right)=1-P_{A 1}+P_{A 2}+\beta M S_{A 1} \\
M S_{A 2}=1-M S_{A 1}-M S_{B} .
\end{gathered}
$$

Solving (A23), (A24) and (A25) jointly yields:

$$
M S_{B}=\frac{1}{2}+\frac{\bar{C}\left(P_{A 2}-P_{B}\right)}{2 \bar{C}-2 \bar{C} \beta+\theta^{2} \beta^{2}} .
$$

Working backward, in stage 2, firm A and firm B maximize their profits given $M S_{A 1}$.

$$
\begin{aligned}
& \underset{P_{A 2}}{\operatorname{Max} \prod_{A 2}}=P_{A 2} \bullet M S_{A 2}=P_{A 2} \bullet\left(\frac{1}{2}-\frac{\bar{C}\left(\mathrm{P}_{\mathrm{A} 2}-\mathrm{P}_{\mathrm{B}}\right)}{2 \bar{C}-2 \bar{C} \beta+\theta^{2} \beta^{2}}-M S_{A 1}\right) . \\
& \operatorname{Max}_{P_{B}} \Pi_{B}=P_{B} \cdot M S_{B}=P_{B} \bullet\left(\frac{1}{2}+\frac{\bar{C}\left(\mathrm{P}_{\mathrm{A} 2}-\mathrm{P}_{\mathrm{B}}\right)}{2 \bar{C}-2 \bar{C} \beta+\theta^{2} \beta^{2}}\right) \cdot
\end{aligned}
$$

Maximizing with respect to $P_{A 2}, P_{B}$ and solving the FOCs yields:

$$
P_{A 2}=\left(\frac{1}{2}-\frac{2 M S_{A 1}}{3}\right)\left(2-2 \beta+\frac{\theta^{2} \beta^{2}}{\overline{\mathrm{C}}}\right)=\left(2-2 \beta+\frac{\theta^{2} \beta^{2}}{\overline{\mathrm{C}}}\right) \cdot M S_{A 2}
$$




$$
P_{B}=\left(\frac{1}{2}-\frac{M S_{A 1}}{3}\right)\left(2-2 \beta+\frac{\theta^{2} \beta^{2}}{\overline{\mathrm{C}}}\right)=\left(2-2 \beta+\frac{\theta^{2} \beta^{2}}{\overline{\mathrm{C}}}\right) \cdot M S_{B} .
$$

where $M S_{A 2}=\left(\frac{1}{2}-\frac{2 M S_{A 1}}{3}\right), M S_{B}=\left(\frac{1}{2}-\frac{M S_{A 1}}{3}\right)$ and $M S_{A}=\left(\frac{1}{2}+\frac{M S_{A 1}}{3}\right)$. From (A24), we can obtain $P_{A 1}$ as a function of $M S_{\mathrm{A} 1}$, namely:

$$
P_{A 1}=1+P_{A 2}-(1-\beta) M S_{A 1}
$$

Substituting (A25), (A27) and (A29) into the objective function of firm A in stage 1 yields the joint profits of firm A over both stages as a function of $M S_{A 1}$ :

$$
\underset{M S A 1}{\operatorname{Max}\left(\prod_{A 1}+\prod_{A 2}\right)}=\left[1+P_{A 2}^{*}-(1-\beta) M S_{A 1}\right] \cdot M S_{A 1}+P_{A 2}^{*} \cdot M S_{A 2}=M S_{A 1}+P_{A 2}\left(M S_{A 1}+M S_{A 2}\right)-(1-\beta)\left(M S_{A 1}\right)^{2},
$$

where both $P_{\mathrm{A} 2}$ and $M S_{\mathrm{A} 2}$ can be expressed by $M S_{A 1}$. Maximizing with respect to $M S_{A 1}$ (which is equivalent to maximizing with respect to $P_{A 1}$ ) and solving the first order condition yields:

$$
M S_{A 1}^{*}=\frac{3\left(4 \bar{C}+2 \bar{C} \beta-\theta^{2} \beta^{2}\right)}{4\left(13 \bar{C}-13 \bar{C} \beta+2 \theta^{2} \beta^{2}\right)}
$$

Hence we can express the values of the parameters $P_{j k}{ }^{*}, M S_{j k}{ }^{*}, \Pi_{A}{ }^{*}$ and $\Pi_{B}{ }^{*}$ as functions of $M S_{\mathrm{A} 1}{ }^{*}$ as summarized in Table 3.

Proof of Proposition 4: In the extended model, both a Segmentation and a Dominance equilibrium are possible when $\beta>\frac{1}{2-\theta}$ and inequality (11) holds. However, profit comparison reveals that:

$$
\Pi_{A}^{\text {Segmentation }}=\frac{3\left(40 \bar{C}^{2}-64 \bar{C}^{2} \beta+36 \bar{C}^{2} \beta^{2}+20 \bar{C} \theta^{2} \beta^{2}-24 \bar{C} \theta^{2} \beta^{3}+3 \theta^{4} \beta^{4}\right)}{16 \bar{C}\left(13 \bar{C}-13 \bar{C} \beta+2 \theta^{2} \beta^{2}\right)}>\Pi_{A}^{\text {Dominance }}=(2-\theta) \beta-1
$$

Therefore, a unique Nash Equilibrium always exists in the extended model.

\section{Comparative Static of the Market Segmentation Equilibrium with respect to $\theta$ and $\bar{C}$ :}

$$
\frac{\partial M S_{A 1}}{\partial \theta}=-\frac{3 \theta \beta^{2}\left(4 \bar{C}+2 \bar{C} \beta-\theta^{2} \beta^{2}\right)}{\left(13 \bar{C}-13 \bar{C} \beta+2 \theta^{2} \beta^{2}\right)^{2}}-\frac{3 \theta \beta^{2}}{2\left(13 \bar{C}-13 \bar{C} \beta+2 \theta^{2} \beta^{2}\right)}=\frac{9 \bar{C} \theta \beta^{2}(3 \beta-7)}{2\left(13 \bar{C}-13 \bar{C} \beta+2 \theta^{2} \beta^{2}\right)^{2}}<0
$$




$$
\frac{\partial M S_{A 1}}{\partial \bar{C}}=\frac{3(4-2 \beta)}{4\left(13 \bar{C}-13 \bar{C} \beta+2 \theta^{2} \beta^{2}\right)}-\frac{3(13-13 \beta)\left(4 \bar{C}+2 \bar{C} \beta-\theta^{2} \beta^{2}\right)}{4\left(13 \bar{C}-13 \bar{C} \beta+2 \theta^{2} \beta^{2}\right)^{2}}=\frac{9 \theta^{2} \beta^{2}(3 \beta+7)}{4\left(13 \bar{C}-13 \bar{C} \beta+2 \theta^{2} \beta^{2}\right)^{2}}>0
$$

Since $M S_{A 2}=\left(\frac{1}{2}-\frac{2 M S_{A 1}}{3}\right), M S_{B}=\left(\frac{1}{2}-\frac{M S_{A 1}}{3}\right)$ and $M S_{A}=\left(\frac{1}{2}+\frac{M S_{A 1}}{3}\right)$, we can derive:

$$
\begin{aligned}
& \frac{\partial M S_{A 2}}{\partial \theta}=\frac{\partial M S_{A 2}}{\partial M S_{A 1}} \frac{\partial M S_{A 1}}{\partial \theta}=\left(-\frac{2}{3}\right) \frac{\partial M S_{A 1}}{\partial \theta}>0 . \\
& \frac{\partial M S_{A}}{\partial \theta}=\frac{\partial M S_{A}}{\partial M S_{A 1}} \frac{\partial M S_{A 1}}{\partial \theta}=\left(\frac{1}{3}\right) \frac{\partial M S_{A 1}}{\partial \theta}<0 . \\
& \frac{\partial M S_{B}}{\partial \theta}=\frac{\partial M S_{B}}{\partial M S_{A 1}} \frac{\partial M S_{A 1}}{\partial \theta}=\left(-\frac{1}{3}\right) \frac{\partial M S_{A 1}}{\partial \theta}>0 .
\end{aligned}
$$

From (A27), (A28), and (A29), we can derive:

$$
\begin{aligned}
& \frac{\partial P_{A 1}}{\partial \theta}=\frac{\partial P_{A 2}}{\partial \theta}-(1-\beta) \frac{\partial M S_{A 1}}{\partial \theta}>0 \\
& \frac{d P_{A 2}}{d \theta}=\frac{\partial P_{A 2}}{\partial M S_{A 2}} \frac{\partial M S_{A 2}}{\partial \theta}+\frac{\partial P_{A 2}}{\partial \theta}=\left(2-2 \beta+\frac{2 \theta \beta^{2}}{\bar{C}}\right) \frac{\partial M S_{A 2}}{\partial \theta}+\left(\frac{2 \theta \beta^{2}}{\bar{C}}\right) M S_{A 2}>0 . \\
& \frac{d P_{B}}{d \theta}=\frac{\partial P_{B}}{\partial M S_{B}} \frac{\partial M S_{B}}{\partial \theta}+\frac{\partial P_{B}}{\partial \theta}=\left(2-2 \beta+\frac{2 \theta \beta^{2}}{\bar{C}}\right) \frac{\partial M S_{B}}{\partial \theta}+\left(\frac{2 \theta \beta^{2}}{\bar{C}}\right) M S_{B}>0 . \\
& \frac{\partial \Pi_{B}}{\partial \theta}=\frac{\partial P_{B}}{\partial \theta} M S_{B}+\frac{\partial M S_{B}}{\partial \theta} P_{B}>0 .
\end{aligned}
$$

The signs of the derivatives with respect to $\bar{C}$ can be obtained in a similar manner.

Using the envelop theorem, from firm A's stage 1 payoff function (A30) we can also derive:

$$
\begin{gathered}
\frac{\partial \Pi_{A}}{\partial \theta}=\frac{\partial P_{A 2}}{\partial \theta} \cdot\left(M S_{A 1}^{*}+M S_{A 2}^{*}\right)>0 . \\
\frac{\partial \Pi_{A}}{\partial \bar{C}}=\frac{\partial P_{A 2}}{\partial \bar{C}} \cdot\left(M S_{A 1}^{*}+M S_{A 2}^{*}\right)<0 .
\end{gathered}
$$

These results are summarized in Table 4 and discussed in $\$ 2.4$. 
Proof of Proposition 7a: When $0<\beta \leq 3 / 5$ and constraint (15) holds, Segmentation is the only feasible type of equilibrium regardless of the presence of converters. From Table 2, we have: $\Pi_{\mathrm{A}}=\frac{3\left(10-16 \beta+9 \beta^{2}\right)}{52(1-\beta)}$. In Table 4, substituting $M S_{A 1}^{*}=\frac{3\left(\bar{C} \bar{C}+2 \bar{C} \beta-\theta^{2} \beta^{2}\right)}{4\left(13 \bar{C}-13 \bar{C} \beta+2 \theta^{2} \beta^{2}\right)}$ into firm A's profit yields:

$$
\Pi_{A}^{c}=\frac{3\left(40 \bar{C}^{2}-64 \bar{C}^{2} \beta+36 \bar{C}^{2} \beta^{2}+20 \bar{C} \theta^{2} \beta^{2}-24 \bar{C} \theta^{2} \beta^{3}+3 \theta^{4} \beta^{4}\right)}{16 \bar{C}\left(13 \bar{C}-13 \bar{C} \beta+2 \theta^{2} \beta^{2}\right)}
$$

Hence we have, $\Pi_{A}^{c}-\Pi_{A}=\frac{9\left[\bar{C} \theta^{2} \beta^{2}\left(60-148 \beta+80 \beta^{2}\right)+13 \theta^{4} \beta^{4}(1-\beta)\right]}{208 \bar{C}(1-\beta)\left(13 \bar{C}-13 \bar{C} \beta+2 \theta^{2} \beta^{2}\right)}$. Since when $0<\beta \leq 3 / 5$,

$\left(60-148 \beta+80 \beta^{2}\right)>0 \Rightarrow \Pi_{A}^{c}>\Pi_{A}$. Similarly, we can show that for the entrant, $\Pi_{B}^{c}>\Pi_{B}$ when

$0<\beta \leq 3 / 5$ and constraint (11) holds.

Proof of Proposition 7b: When $0<\beta \leq 3 / 5$ and constraint (11) holds, it can be shown that:

$$
\begin{aligned}
& P_{A 1}^{c}-P_{A 1}=\frac{3 \bar{C} \theta^{2} \beta^{2}(127-151 \beta)+78 \beta^{4} \theta^{4}}{52 \bar{C}\left(13 \bar{C}-13 \bar{C} \beta+2 \theta^{2} \beta^{2}\right)}>0, \\
& P_{A 2}^{c}-P_{A 2}=\frac{3 \bar{C}^{2}\left(156-416 \beta+260 \beta^{2}\right)+\bar{C} \beta^{2} \theta^{2}(77-111 \beta)+13 \beta^{4} \theta^{4}}{26 \bar{C}\left(13 \bar{C}-13 \bar{C} \beta+2 \theta^{2} \beta^{2}\right)}>0 \text { and } \\
& P_{B}^{c}-P_{B}=\frac{\bar{C} \theta^{2} \beta^{2}(328-382 \beta)+65 \beta^{4} \theta^{4}}{52 \bar{C}\left(13 \bar{C}-13 \bar{C} \beta+2 \theta^{2} \beta^{2}\right)}>0 .
\end{aligned}
$$

Proof of Proposition 7c: In the baseline model, $\Delta M S=M S_{A}-M S_{B}=\frac{2+\beta}{13(1-\beta)}$. In the extended model,

$$
\Delta M S^{c}=M S_{A}{ }^{c}-M S_{B}{ }^{c}=\frac{4 \bar{C}+2 \bar{C} \beta-\theta^{2} \beta^{2}}{2\left(13 \bar{C}-13 \bar{C} \beta+2 \theta^{2} \beta^{2}\right)} \text {. Hence, } \Delta M S-\Delta M S^{c}=\frac{3\left(7 \theta^{2} \beta^{2}-3 \theta^{2} \beta^{3}\right)}{26(1-\beta)\left(13 \bar{C}-13 \bar{C} \beta+2 \theta^{2} \beta^{2}\right)}>0 .
$$

\section{Proof of Proposition 8}

$$
\begin{aligned}
\Delta \Pi & =\Pi_{A}^{\text {Segmentation }}{ }_{-\Pi_{A} \text { Dominance }}=\frac{3\left(40 \bar{C}^{2}-64 \bar{C}^{2} \beta+36 \bar{C}^{2} \beta^{2}+20 \bar{C} \theta^{2} \beta^{2}-24 \bar{C} \theta^{2} \beta^{3}+3 \theta^{4} \beta^{4}\right)}{16 \bar{C}\left(13 \bar{C}-13 \bar{C} \beta+2 \theta^{2} \beta^{2}\right)}-(2 \beta-1) \\
& =\frac{328 \bar{C}^{2}-816 \bar{C}^{2} \beta+524 \bar{C}^{2} \beta^{2}+92 \bar{C} \theta^{2} \beta^{2}-136 \bar{C} \theta^{2} \beta^{3}+9 \theta^{4} \beta^{4}}{16 \bar{C}\left(13 \bar{C}-13 \bar{C} \beta+2 \theta^{2} \beta^{2}\right)} .
\end{aligned}
$$


The denominator $16 \bar{C}\left(13 \bar{C}-13 \bar{C} \beta+2 \theta^{2} \beta^{2}\right)>0$ since $0<\beta<1$. Therefore, the sign of $\Delta \Pi$ can be determined by the sign of the numerator of (A44). It can be easily shown that $\Delta \Pi>0$ when $3 / 5<\beta \leq 7 / 8$ and constraint (11) holds. When $7 / 8<\beta \leq 1$, the sign of $\Delta \Pi$ is ambiguous.

\section{Proof of Lemma 2}

Differentiating $J^{P}\left(i^{*}, C^{P}\right)=\frac{5 i^{* 2}(2-\beta)^{2}-2 i^{*}(2-\beta)\left(1-C^{P}\right)+2\left(1-C^{P}\right)^{2}}{9(2-\beta)}+\frac{C^{P}\left[i^{*}(2-\beta)+\left(1-C^{P}\right)\right]}{3(2-\beta)}$ from Table 5 with respect to $C^{P}$ yields $\frac{10 i^{*}-5 i^{*} \beta-2 C^{P}-1}{9(2-\beta)}=0$. Thus we obtain the interior solution $C_{\mathrm{int}}^{P}=\frac{5 i^{*}(2-\beta)-1}{2}$ as shown in (26). Note that in order for the Partial Conversion equilibrium to hold, the equilibrium price of the converter must be no more than the maximum willingness to pay on the part of consumers $\left(C_{\max }^{P}=\beta M S_{A}^{P}\right)$, that is, $C^{P} \leq C_{\max }^{P}=\beta M S_{A}^{P}$. Solving this inequality yields:

$$
i^{*}<\frac{1+\beta-\beta^{2}}{(2-\beta)(5-3 \beta)} \text {. }
$$

Therefore, when (A45) holds, the optimal converter price is given by (16). Moreover, from Table $5, i^{*}$ must satisfy $i^{*}>1 / 4$, and all prices derived in Table 5 must be positive, hence the remaining market size $i^{*}$ must satisfy $1>i^{*}>\operatorname{Max}\left\{\frac{1-C^{P}}{2(2-2 \beta)}, \frac{1}{4}\right\}$. Substituting (16) into this inequality yields $1>i^{*}>\operatorname{Max}\left\{\frac{1}{3(2-\beta)}, \frac{1}{4}\right\}$. Combining this inequality with (A45) yields the results reported in the first part of Lemma 2 .

When (A45) does not hold $\left(C_{\mathrm{int}}^{P}>C_{\max }^{P}\right)$, the constraint is binding and the optimal price of the converter is given by: $C^{P^{*}}=C_{\max }^{P}=\beta M S_{A}^{P}=\frac{\beta\left[(5-3 \beta)-i^{*}(2-\beta)\right]}{2(3-2 \beta)}$ as shown in (27). Substituting (27) into 
the inequality $1>i^{*}>\operatorname{Max}\left\{\frac{1-C^{P}}{2(2-2 \beta)}, \frac{1}{4}\right\}$ yields $1>i^{*}>\operatorname{Max}\left\{\frac{1-\beta}{4-3 \beta}, \frac{1}{4}\right\}$. Combining this inequality with $i^{*}>\frac{1+\beta-\beta^{2}}{(2-\beta)(5-3 \beta)}$ yields the results reported in the second half of Lemma 2 .

\section{Proof of Observation 1:}

(i) From (19) and Tables 5 and 6, we have, $P_{B}^{N}=\frac{2 i^{*}+1-2 i^{*} \beta-\beta}{3}, P_{B}^{p}=\frac{2 i^{*}+1-2 \beta-C^{P}}{3}$, and $P_{B}^{F}=\frac{2 i^{*}+1}{3}$. Let $x=P_{B}^{P}-P_{B}^{N}=\frac{2 i^{*} \beta-\beta-C^{P}}{3}$. When $C^{P^{*}}=C_{\max }^{P}, x=\frac{\beta(1-\beta)+i^{*} \beta(8-5 \beta)}{6(3-2 \beta)}>0$ always holds when $0<\beta<1$. When $C^{p *}=C_{I N T}^{p}, x=\frac{1-10 i^{*}+2 \beta+7 i^{*} \beta}{6}$. In order for $x>0$ to hold, it requires that $0<i^{*}<\frac{2 \beta+1}{10-7 \beta}$.

From (A45) we have $i^{*}<\frac{1+\beta-\beta^{2}}{(2-\beta)(5-3 \beta)}<\frac{2 \beta+1}{10-7 \beta}$, therefore, $x>0$ also holds when $C^{P^{*}}=C_{I N T}^{P}$.

Moreover, since $P_{B}^{F}-P_{B}^{P}=\frac{i^{*} \beta+C^{P}}{3}>0$, we have $P_{B}^{F}>P_{B}^{P}>P_{B}^{N}$.

(ii) Let $\Pi_{A B}$ denote firms' joint product revenue in stage 2, From (24) and Tables 5 and 6, we have: $\Pi_{A B}^{N}=\frac{(1-\beta)\left(10 i^{* 2}-2 i^{*}+1\right)}{9}, \Pi_{A B}^{P}=\frac{5 i^{* 2}(2-\beta)^{2}-2 i^{*}(2-\beta)\left(1-C^{P}\right)+2\left(1-C^{P}\right)^{2}}{9(2-\beta)}$ and $\Pi_{A B}^{F}=\frac{1-2 i^{*}+10 i^{* 2}}{9}$

Let $z=\Pi_{A B}^{F}-\Pi_{A B}^{P}=\frac{C^{P}\left(4-2 C^{P}-4 i^{*}+2 i^{*} \beta\right)-\beta\left(1+5 i^{*}-10 i^{* 2}\right)}{9(2-\beta)}$, and $y=\Pi_{A B}^{P}-\Pi_{A B}^{N}=\frac{C^{P}\left(-4+2 C^{P}+4 i^{*}-2 i^{*} \beta\right)+\beta\left(3-4 i^{*}+10 i^{* 2}\right)-\beta^{2}\left(1-2 i^{*}+5 i^{* 2}\right)}{9(2-\beta)}$

When $C^{p *}=C_{\max }^{p}, y=\frac{\beta\left(21-42 i^{*}+102 i^{* 2}\right)-\beta^{2}\left(28+56 i^{*}+136 i^{* 2}\right)+9 \beta^{3}\left(1-2 i^{*}+5 i^{* 2}\right)}{18(3-2 \beta)^{2}}>0$, and 
$z=\frac{\beta\left(-3+6 i^{*}+78 i^{* 2}\right)+\beta^{2}\left(4-8 i^{*}-104 i^{* 2}\right)+\beta^{3}\left(1-2 i^{*}-35 i^{* 2}\right)}{18(3-2 \beta)^{2}}>0$. When $C^{P^{*}}=C_{I N T}^{P}$, we can also

obtain that when $i^{*}>\operatorname{Max}\left\{\frac{1}{4}, \operatorname{Min}\left\{\frac{1}{3(2-\beta)}, \frac{1+\beta-\beta^{2}}{(2-\beta)(5-3 \beta)}\right\}\right\}$

$y=\frac{-5+64 i^{*}-140 i^{* 2}-\beta\left(2+32 i^{*}-160 i^{* 2}\right)-45 i^{* 2} \beta^{2}}{18(2-\beta)}>0$, and

$z=\frac{5-64 i^{*}+140 i^{* 2}+6 \beta\left(1+4 i^{*}-20 i^{* 2}\right)-2 \beta^{2}+4 i^{*} \beta^{2}+25 i^{* 2} \beta^{2}}{18(2-\beta)}>0$. Hence $\Pi_{A B}^{F}>\Pi_{A B}^{P}>\Pi_{A B}^{N}$.

\section{Proof of Observation 2:}

Let $\Pi_{C}$ denote the proceeds from the sale of the converters. From Tables 5 and 6, we have:

$\Pi_{C}^{F}=\beta\left(\frac{2 i^{*}+1}{6}\right)$ and $\Pi_{C}^{P}=\frac{C^{P}\left[i^{*}(2-\beta)+\left(1-C^{P}\right)\right]}{3(2-\beta)}$. Substituting (26) and (27) into $\Pi_{C}^{P}$ yields

$\Pi_{C}^{P}=\frac{\left(1-10 i^{*}+5 i^{*} \beta\right)\left(-3+10 i^{*}-5 i^{*} \beta\right)}{12(2-\beta)}\left(\right.$ when $\left.C^{P^{*}}=C_{I N T}^{P}\right)$ and $\Pi_{C}^{P}=\frac{\left.\left(1+2 i^{*}-\beta-i^{*} \beta\right)\left(5 \beta-2 i^{*} \beta-3 \beta^{2}+i^{*} \beta^{2}\right)\right]}{4(3-2 \beta)^{2}}$

(when $C^{P^{*}}=C_{\max }^{P}$ ). It can be shown that $\Pi_{C}^{F}>\Pi_{C}^{P}$ for any feasible ranges of $C^{P^{*}}$.

\section{Proof of Proposition 12:}

We designate the profits that accrue in each case by $\Pi_{A}^{F}, \Pi_{A}^{P}, \Pi_{A}^{N}$ and $\Pi_{A}^{D}$ (corresponding to Full,

Partial, and No Conversion, and to Dominance, respectively), and compare the overall profits of the incumbent under these four regimes. We find that when $0<\beta<0.717, \Pi_{A}^{F}>\Pi_{A}^{P}>\Pi_{A}^{N}>\Pi_{A}^{D}$,

when $0.717<\beta<0.982, \Pi_{A}^{F}>\Pi_{A}^{D}>\Pi_{A}^{P}$, and when $0.982<\beta<1, \Pi_{A}^{D}>\Pi_{A}^{F}>\Pi_{A}^{P}$, where the ranking is

valid when the corresponding commitment regimes are feasible. This outcome leads to the result reported in Proposition 12.

\section{Proof of Proposition 13:}

As shown in (33), Social welfare consists of the sum of three components: product reservation price $r$, the average network benefits, and product differentiation $(P D)$ benefits. Since 
$r$ and $P D$ are the same across different types of equlibria. Social welfare is maximized when the average network effects benefits are maximized. As is obvious from (33), Full Conversion yields the largest average network effect benefits. Hence social welfare is maximized with Full Conversion, which is given by:

$$
T S^{F}=r+\left[\beta+\beta\left(1-i^{*}\right)^{2}\right]+s^{*}\left(1-\frac{s^{*}}{2}\right)+\frac{i^{* 2}-s^{* 2}}{2}+\left(1-i^{* 2}\right), \text { s.t. } 0<s^{*} \leq i^{*}<1 .
$$

Solving the first order condition with respect to $i^{*}$ yields $i^{*}=\frac{2 \beta}{2 \beta-1}$. When $\beta<1 / 2, i^{*}<0$, implying that the lower bound constraint is binding and $i^{*}$ assumes the smallest possible value, namely, $i^{*}=S^{*}$. When $\beta>1 / 2, i^{*}>1$, implying again a corner solution. Substituting $i^{*}=s^{*}$ into the objective function and differentiating with respect to $i^{*}$ yields the solution reported in Proposition 13. It is positive only if $\beta<1 / 2$. 